

\section{VISNYK}

OF THE NATIONAL BANK OF UKRAINE

\section{No. 245 2018}

Published since March 1995

quarterly research journal

https://doi.org/10.26531/vnbu2018.245

\section{Editorial Board}

\author{
Dmytro Sologub \\ (Chairman of the Editorial Board) \\ Deputy Governor, \\ National Bank of Ukraine
}

\section{Tom Coupe}

Associate Professor,

University of Canterbury, PhD

\section{Oleg Korenok}

Associate Professor,

Virginia Commonwealth University, PhD

\section{Oleksiy Kryvtsov}

Senior Research Director in the International Economic

Analysis Department, Bank of Canada, PhD

\section{Oleksandr Petryk}

Professor, Banking University, Kyiv,

Doctor of Economics, Member of NBU Council

\section{Inna Spivak}

Head of International Economy Analysis Unit, Monetary Policy and Economic Analysis Department, National Bank of Ukraine, Doctor of Economics

\section{Andriy Tsapin}

Deputy Head of Research Unit,

Monetary Policy and Economic Analysis

Department, National Bank of Ukraine, PhD

\author{
Sergiy Nikolaychuk \\ (Deputy Chairman of the Editorial Board) \\ Director of Monetary Policy \\ and Economic Analysis Department, \\ National Bank of Ukraine, PhD
}

\section{Yuriy Gorodnichenko \\ Professor, University of California, \\ Berkeley, PhD \\ Viktor Koziuk \\ Professor, Ternopil National Economic \\ University, Doctor of Economics, \\ Member of NBU Council}

\section{Tymofiy Mylovanov}

Professor, University of Pittsburgh,

Honorary President of Kyiv School of Economics, Deputy Chairman of NBU Council, PhD

\section{Marko Skreb}

Advisor on the Activities of Central Banks

\section{Oleksandr Talavera \\ Professor, Swansea University, PhD}

\section{Vitaliy Vavryshchuk}

Director of Financial Stability Department, National Bank of Ukraine

\section{Vadym Volosovych \\ Associate Professor, \\ Erasmus University \\ Rotterdam, PhD}

Founder and publisher: National Bank of Ukraine

Editorial Board ensures compliance with ethical standards of publishing

For reprinting materials published herein the reference to the journal

"Visnyk of the National Bank of Ukraine" is compulsory

The Editorial Board can publish materials being under discussion, not sharing the author's opinion

The author bears responsibility for the accuracy of the materials

(C) National Bank of Ukraine 1995-2018

All rights reserved

Address: 9 Instytutska Street, Kyiv, 01601, Ukraine

E-mail: journal@bank.gov.ua
Design and layout: Zlatograf LTD.

Address: Ukraine, Kyiv, 01001,

Prorizna Street, 12, office 10.

Phone: +380 (44) 360-94-60. 


\section{PREFACE BY THE CHAIRMAN OF THE EDITORIAL BOARD}

\section{Dear readers,}

The current issue of the Visnyk of the National Bank of Ukraine aims to bring more attention to the topical problems of land reform and asymmetric information in the banking system, which, if resolved, could make the financial markets in Ukraine more effective. We also continue to explore the economic impact of fiscal policy and how it reacts to business cycles.

In the first article of the issue, Land Reform in the Credit Cycle Framework: The Case of Ukraine, Mykhailo Matvieiev uses a conventional framework for Dynamic Stochastic General Equilibrium models with collateral constraints to model the effect of agricultural land reforms. The collateralization of agricultural land is shown to lead to a significant additional amplification of loan-to-value shocks compared to the case in which land cannot be used to secure loans. As the author concludes, lifting the moratorium allows land to be traded and to be used as an additional way to secure loans. If there are binding borrowing constraints, additional collateral leads to constraint easing, which increases the borrowing power of impatient economic agents.

The second article, Communicative Efficiency in Ukraine's Banking System: Evidence from Independent Auditor Reports, by Oleksandr Sukhomlyn, applies a quantitative content analysis to independent auditor reports of Ukrainian banks to test whether report communicative value affects bank performance in the subsequent period. The author demonstrates that a more negative tone of an auditor report is associated with an increase in bank ROA and ROE in the following year. One key conclusion is that Ukrainian banks pay particular attention to the information in auditor reports when considering changes in policy related to key financial indicators.

The article by Artem Vdovychenko, entitled Estimating the Fiscal Impulse in Ukraine, applies different econometric techniques to evaluate fiscal policy stance. The author finds that the fiscal policy response to the 2014 crisis was significantly tighter than the response to the crisis of 2008-2009. In addition, the study identifies the particular budget items that are most sensitive to fluctuations in the business cycle. Specifically, corporate income tax shows the strongest response to economic cycles among all budget revenue categories, while VAT provides the greatest contribution to the cyclical component of Ukraine's budget balance.

The research findings presented in this issue of the journal emphasize the importance of reform and communications, which can benefit the economy and its main stakeholders, including the regulator, auditors, banks and their clients. There is no doubt that effective communications play an essential role in economic policy and that such communications can be regarded as a key channel for policy transmission for the central banks. With this in view, the Editorial Board of the Visnyk of the National Bank of Ukraine encourages researchers to participate in the annual international research conference "Central Bank Communications: From Mystery to Transparency", which will be hosted by the National Bank of Ukraine on 23-24 May 2019. We also invite you to submit original fundamental and applied studies for publication in the Visnyk of the National Bank of Ukraine.

Best regards,

Dmytro Sologub 


\title{
LAND REFORM IN THE CREDIT CYCLE FRAMEWORK: THE CASE OF UKRAINE
}

\section{MYKHAILO MATVIEIEV ${ }^{*}$}

${ }^{a}$ Kyiv School of Economics

Email: mmatvieiev@kse.org.ua

\begin{abstract}
In this work I show that land reform can affect business cycle dynamics through the financial accelerator. For this purpose, I employed a conventional framework for Dynamic Stochastic General Equilibrium models with collateral constraints to model the effect of agricultural land reforms. The model was estimated on the basis of Ukrainian data and tested with an impulse response function analysis. I found that the collateralization of agricultural land leads to a quantitatively significant additional loan-to-value shock amplification compared to the case when land cannot be used to secure loans.
\end{abstract}

JEL Codes E31, E32, E44, Q15, R21

Keywords credit cycles, land reform, collateral constraints, financial accelerator

\section{INTRODUCTION}

It has been almost two decades since land reform was launched in Ukraine, and the issue has prompted what seems like interminable debate on the issue. By 2001, as a result of the ongoing reform, a substantial part of the country's farmland had been distributed among the employees of the agricultural sector. However, in 2002 a moratorium on the sale of agricultural land was imposed by parliament, which suspended the functioning of the land market for more than 15 years. Along with the trade in agricultural land, the moratorium temporarily prohibits the use of agricultural land as collateral.

A new stage of the land reform debate was launched with the prolongation of the moratorium in 2017. The rights to land ownership cannot now be transferred until 2019. While the consequences of lifting the moratorium have been analyzed at the macro and micro levels, as well as from an institutional point of view, this paper investigates how macroeconomic shocks will affect business cycle dynamics under the proposed changes. Considering that the financial sector is one of the key drivers of output fluctuations during the business cycle, land collateralization could potentially facilitate access to the financial markets, and thereby influence the propagation of shocks.

To track the effect of the land reform on shock transmission and amplification in an economy with collateral constraints, I selected DSGE modelling. On the one hand, Dynamic Stochastic General Equilibrium models are microfounded, and appear to be less subject to the Lucas critique. On the other hand, the development of macroeconomic theory has drawn substantial attention to the financial accelera- tor, which is reflected in DSGE models. As imperfection on the financial markets may cause a quantitatively significant amplification of shocks, financial frictions were incorporated into the general equilibrium setup by Bernanke (1999) in the form of the external finance premium, and by Kiyotaki and Moore (1997), through collateral constraints. The latter approach was further developed by lacoviello (2005), who studied collateral constraints within the New-Keynesian framework, and extended for debt deflation. Gerali et al. (2010) introduced monopolistic competition in banking sector, while lacoviello and Neri (2010) added supply side on the housing market to capture credit cycle dynamics more accurately. Thus, structural macroeconomic models now have sufficient tools to investigate possible changes in amplification caused by collateral constraints. However, the question of the very presence of the financial accelerator in emerging economy naturally arises.

To substantiate the impact of financial imperfections on the business cycle, I partially replicated the VAR evidence of lacoviello (2005), (Figure 1 "VAR Evidence, United States", p. 741) for Ukraine data. ${ }^{1}$

Figure 1 represents the comovement of consumption and house prices in Ukraine. This relation can be explained by the collateral effect. The mechanism is rather straightforward: in an economy with borrowing constraints, a positive shock on asset price leads to the relaxation of constraints, allowing higher consumption spending. Houses usually serve as a means of collateral, which reveals a positive correlation between their prices and consumption. Thus, VAR evidence suggests that the collateral effect may play some role in the process of shock propagation and amplification in

"A part of this paper was drafted within the framework of Research Internship Program of the National Bank of Ukraine, where the author participated. The author is grateful to (in alphabetic order) Oleksandr Faryna, Oleg Nivievskyi, and Maksym Obrizan for their useful comments and suggestions.

${ }^{1}$ I used 2006Q1-2016Q4 time series on private consumption spending (seasonally adjusted, \$; data source: State Statistics Service of Ukraine, own calculations), interest rate (interest rates on interbank deposits 1-3 months; data source: National Bank of Ukraine), consumer price index (data source: State Statistics Service of Ukraine) and real estate price (\$ per $\mathrm{m}^{2}$, Kyiv, residential real estate, secondary market). 


\section{Figure 1. IRF to the House Price Shock}

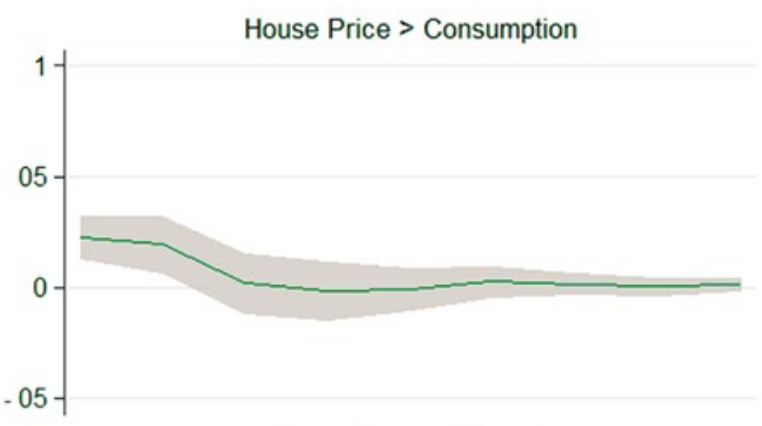

House Price $>$ Interest

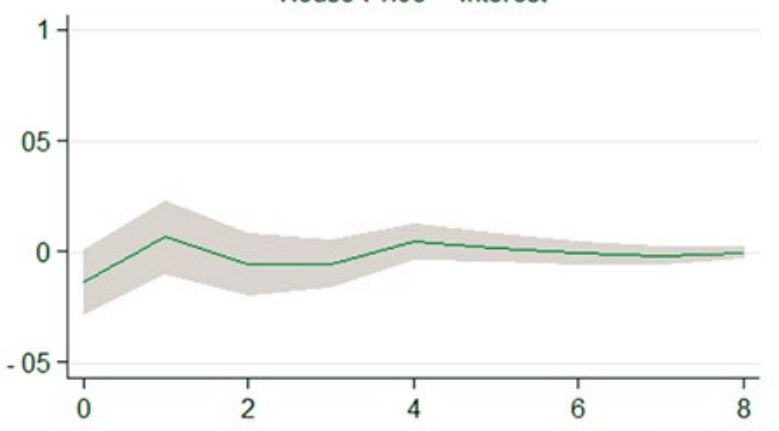

QUARTERS

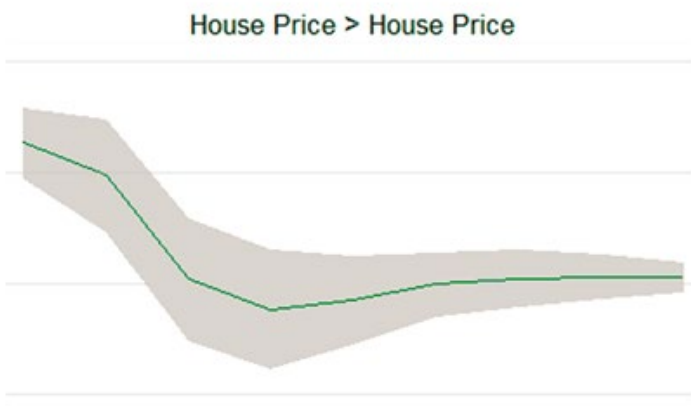

House Price > Inflation

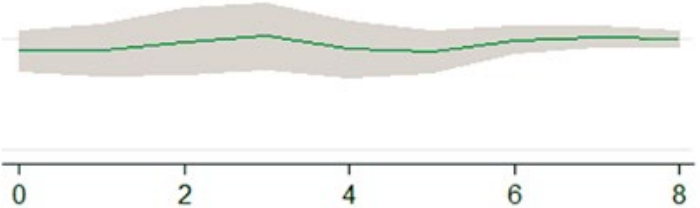

Orthogonalized irf
Ukraine. Consequently, the cancelation of the moratorium, which entails an increase in the amount of collateral, will affect the dynamics of the business cycle.

To simulate the changes caused by transformations on the land market, I extended the DSGE model with collatera constraints by introducing farmland as potentially an additional way to secure a loan. I developed two models: "initial" and "modified", which represent the economy before and after the land reform, and tested their properties with an impulse response function (IRF) analysis.

The models are constructed identically in all aspects except land. The model setup to a large extent follows and inherits the majority of the features of the framework elaborated by lacoviello (2005) and further developed by Gerali et al. (2010), lacoviello and Neri (2010). It is the Dynamic Stochastic General Equilibrium Model with monopolistic competition at the retail level, and collateral constraints taken from Kiyotaki and Moore (1997). Borrowings of economic agents must be secured by the value of houses in possession in the "initial" model, and by the value of houses or land in the "modified" one. Using land as a collateral eases the borrowing constraint, thereby altering business cycle dynamics via the financial accelerator.

In other respect, the frameworks differ in terms of the possibility to buy and sell land. The model that simulates the economy after the end of the agricultural reform enables land to be sold, while the initial model does not. In this fashion, the current paper attempts to take into account changes in the transmission mechanism in the economy of Ukraine that will take place in the near future.

The model of the actual economy was calibrated and estimated with the Maximum Likelihood procedure based on
Ukrainian data. In order examine if allowing agricultural land to serve as a mean of collateral affects shock propagation, the dynamics of the factual and counterfactual economies were juxtaposed and compared by means of an IRF analysis.

The remainder of this work is organized as follows: Chapter 2 presents a brief overview of the legal status of agricultural land in Ukraine. Chapter 3 proceeds with a review of the literature. I incorporated agricultural land in the general equilibrium setup in chapter 4 . The paper concludes with parametrization in chapter 5 , results in chapter 6 , and conclusions in chapter 7.

\section{AGRICULTURAL LAND IN UKRAINE}

The fall of the Soviet Union accompanied by the gaining of independence brought Ukraine onto the path of liberal transformations. One example of such transformations is land reform, which was launched in March 1991. The Law on Forms of Land Ownership (1992) abolished more than 75 years of state monopoly on the right to own land, and the Land Code (1992) stipulated how land was to be transferred from state to private or collective ownership. The transfer of land to collective ownership was a transitional stage on the way to full privatization, allowing the transformation to proceed gradually.

The next stage of the reform was related to the Decree on the Order of Land Division (1995), which stipulated the procedure for the transition from collective to private ownership of land. As a result, by the end of the last century, collective farms were reorganized and about 28 million hectares of agricultural land were transferred into private ownership. This land was distributed as "pays" (shares) at no cost among the workers who participated in collective farms. 
At the beginning of the 2000's, the population that received agricultural land during the process of privatization had no means of production sufficient for individual farming, which potentially created the threat that land would accumulate in the hands of big enterprises. To avoid the unfavorable consequences of market formation, a moratorium on the sale of land shares was introduced by Ukraine's parliament, the Verkhovna Rada, as a temporary measure (for four years) in 2001. The law prohibits any transfer of ownership of "pays", other than through inheritance, including land sales and land donation. The moratorium has been prolonged nine times, and currently expires on 1 January 2019. The moratorium does not permit any legal ways for farmland expropriation, so land cannot be used as collateral. At the moment, the loan-to-value ratio for agricultural land in Ukraine is zero.

Farmland constitutes 42.7 million hectares or $70.8 \%$ of the territory of Ukraine (StateGeoCadastre). 41 million hectares out of this 42.7 million hectares (that is $96 \%$ ) are under the moratorium and cannot be traded. The large chunk of this land is in private ownership (30.8 million hectares), while farmland that hasn't been privatized constitutes 10.7 million hectares (in accordance with the monthly land review of StateGeoCadastre). Large agricultural enterprises hold about 6 million hectares of farmland combined (Nizalov, 2017), while the rest of the privatized land is distributed across the population.

Without taking into account shadow schemes for transferring property rights, the only way non-farmers can use land that is under the moratorium is to lease it out. According to the State Service of Ukraine for Geodesy, Cartography and Cadastre, as of January 1, 2018, 4.9 million land lease agreements were in place, covering 19 million hectares of land (both state and collective). The average rental price is about $\$ 50$ per hectare for private farmland, and about $\$ 107$ for state land (according to StateGeoCadastre data).

Lifting the moratorium will allow to farmland to be purchased and make it possible to use land as collateral. According to the most conservative estimates, the liberalization of the land market will increase the price of agricultural land at least by 3.5 times and rental prices accordingly; land collateralization will facilitate the access to financing, and increase lending by $\$ 25$ billion overall (Nizalov, 2017).

\section{LITERATURE REVIEW}

Irving Fisher is generally considered to have had the closest early approximation to the modern view on the financial sector. His contemplation of the roots of the Great Depression resulted in debt deflation theory, which maintains that recessions emanate from deflation, which, in turn, leads to an increase in the real value of debt. The starting point of Fisher's reasoning (1933) is an assumption of the existence of a state of over-indebtedness. On this basis, he successively deduced the sequence of developments that inevitably lead an economy into a recession after the bursting of a debt bubble. Debt liquidation, followed by a decrease in the money velocity proceeds to a price level decline, compounded by a fall in the value of businesses, resulting in falling output, unemployment, and other attributes of recession. These inferences, derived within the confines of general equilibrium theory, constitute Fisher's standpoint on the causes of the Great Depression and make him relevant to the contemporary view on the financial sector.
In a similar manner, John Maynard Keynes attached importance to the financial markets. Five years before his General Theory was published, the economic crisis in Germany became the object of Keynes' (1931) close attention, and he found the origins of its propagation to have been in the banking sector. Recession is inevitably accompanied by a fall in prices of all types of assets, including real estate. Banks, playing the role of intermediators between lenders and borrowers, may face problems meeting their obligations as a consequence of an asset price decline, which is a threat for the whole financial system. Keynes' position on the role of the fall of asset values in amplifying a downturn amplification to a great extent anticipates the views of more recent economists regarding the financial sector.

The development of the idea of the financial accelerator over the following 60 years was observed only in partial equilibrium models. A new stage of the evolution of the concept of financial frictions is usually associated with works of Bernanke. Bernanke and Gertler's (1990) OLG neoclassical model is often viewed as first attempt to construct a general equilibrium model with the financial sector. The model is used to study output fluctuations caused by changes in the credit worthiness of firms and households. The integration of financial frictions in the form of the external finance premium into the general equilibrium setup is an attempt to make the theoretical framework relevant and coherent with the observable results of monetary regulations. This necessity was induced by numerous empirical papers that were seeking an explanation for the "black box" effect of monetary policy. An example of such a work is Bernanke and Gertler (1995), who tried to rationalize the output response to monetary shock through bank lending and balance sheet channels.

Bernanke, Gertler and Gilhrist (1996), in trying to explain the amplification mechanism, or "how small shocks generate large fluctuations", established the concept of "the financial accelerator" and discussed its implications. The idea of the external finance premium, a natural consequence of asymmetric information, was reflected in a DSGE model by Bernanke, Gertler and Gilhrist (1999), and having made this setup ubiquitous this engendered a whole generation of DGSE models with financial frictions.

The external finance premium could be described as "price" financial friction, as it arises from a higher lending rate compared to the case of perfect information. However, there is a particular subset of DSGE models that implement "quantitative" types of financial frictions, incarnated in the borrowing constraint. In such models, the size of a loan available to an economic agent is restricted by the value of assets it possesses.

Kiyotaki and Moore (1997) built a deterministic general equilibrium model with the collateral constraint, and described the propagation mechanism. Durable goods, defined as land, are determined to have a fixed supply and serve at the same time as a factor of production and as a means to secure a loan. Some negative shock causes the net worth of firms to fall, which, in turn, decreases the demand for land and drives its price down. The land price drop amplifies the fall of the net worth of firms and, in this manner, the effect of the negative shock propagates. The work of Kiyotaki and Moore originated a line of DSGE models in which this transmission mechanism is inherent. 
Kocherlakota (2000) continued the stream of research initiated by Kyiotaki. As the previous researchers suggest, he emphasizes that the size, persistence and asymmetry of the observed output responses cannot be embedded in the RBC framework. Summarizing the previous developments, Kocherlakota models the economy with limited contract enforceability, which entails borrowing constraints, and shows that such frictions give rise to a quantitatively significant amplification of shocks.

While the latter researchers made an attempt to study the effect of the monetary and real shocks in an economy with collateral constraints, through introduction of the price and labor frictions, Cordoba and Ripoll (2004) presented an ingenious alternative. Their model exploits the Kiyotaki-Moore economy, where heterogeneous agents have to hold enough money for transactions one period before the transaction takes place. This cash-in-advance constraint, compounded by the collateral type of borrowing constraint, generates a powerful source of shock propagation. Cordoba and Ripoll's model allows monetary shock through money injection via open market operations, and they found that the framework spawns persistent output fluctuations as result of this shock. The degree and duration of the fluctuations depend on the extent to which credit market imperfections tend to amplify initial the output increase/decline.

lacoviello (2005) continues the tradition of Kiyotaki and Moore in many respects, and introduces several features that make this framework a "workhorse" DSGE model for these types of financial frictions. Heterogeneity among consumers and borrowers, along with nominal debt assumption as incorporated in the New-Keynesian setup allows consumptionasset price comovement (houses considered as collateral) to be captured, and brings the model's dynamic close to the real data. In other aspects, the author follows Kiyotaki and Moore (1997) such as fixed asset supply, no imperfections in the banking sector, etc.

lacoviello and Neri (2010) addressed the question of housing market determinants in a similar fashion. For this purpose, they extended the DSGE with collateral constraint in several directions. On the supply side of the economy a housing sector was introduced (previous models included only the demand side of the housing market). House producers are separated out as particular economic agents. They operate on a competitive market and produce homogeneous product with constant returns to scale production function. All production sectors experience slow technological growth. Nominal rigidities on the labor market are also implemented in order to explain fluctuations in the housing market and how they could be transmitted to other sectors of the economy. They concluded that house price growth outstrips technological progress in housing construction, and that wage rigidities on the housing market (which is competitive) matter. Another important finding is that house preference shocks have an important role in the expansion of the U.S. economy. The paper of lacoviello and Neri made a great contribution to analyzing housing market spillovers, and their framework is extensively used by European central banks and the IMF.

Gerali et al. (2010) further developed the DSGE with borrowing constrains model by introducing monopolistic competition in the banking sector. The model is estimated for the Euro zone, and shows that much of the fluctuation during the 2008 crisis can be explained by shocks in the banking sector. The other implication is that an imperfect banking sector has various effects on the magnitude of fluctuations caused by monetary and technological shocks.

As the productivity shock affects output directly, it proved to be unable to change asset prices significantly and therefore abet the shock amplification. This fact calls into doubt the ability of the credit cycle theory to contribute to explaning macroeconomic dynamics, moreover, it makes business investmentsland price comovement puzzling. Liu, Wang and Zha (2013) posit that preference shocks may substantially affect asset prices, resolving the puzzle. They built a model a-la lacoviello (2005) in which land plays the role of collateral for borrowing economic agents, and is a source of utility for households (the reason for the substitution of housing with land is that housing prices are mostly driven by land prices). They performed several robustness checks and found a firm link between land price and investments.

In papers that focus on borrowing restrictions, there is usually only one asset under consideration. Studying the case of more than one mean of collateral can be regarded as a side stream of research. However, the question of an instant collateral increase, compounded by the issue of mutual collateral price dynamics during the business cycle, is a topic of some scientific curiosity and has some originality.

\section{THE MODELS}

To a large extent I follow lacoviello (2005). The model is constructed in discrete time and assuming infinitely-living economic agents. The economy consists of patient households, impatient households and entrepreneurs. Patient and impatient households differ in the value of discount factor but identical in other respects - they draw utility from consumption and housing, and disutility from work. Patient households lend money to impatient households and entrepreneurs. An important extension is that both types of households get rent from the possession of land, but do not draw utility from it.

Entrepreneurs produce wholesale goods and draw utility from consumption. The inputs are capital, labor (supplied by both types of households), land and houses. Firms sell their goods to retailers on a competitive market and buy labor on a perfect market as well.

In the models, retail firms are run by patient households. They differentiate wholesale goods without costs and vend them to aggregators, who produce final goods. The central bank follows the Taylor rule. Both land and housing supplies are fixed.

\subsection{Initial Model}

There are two principle differences between initial and modified models: (1) the presence of a free land market; (2) the possibility of using land as collateral.

\subsubsection{Patient Households}

Patient households maximize the horizon of expected utilities from final goods consumption, stock of housing, and disutility from work. Following lacoviello, I use the logarithmic form of the utility function, which is a special case of the Constant Relative Risk Aversion (CRRA) utility function. The objective function is: 


$$
\mathrm{U}^{\mathrm{P}}=\mathrm{E}_{0} \sum_{\mathrm{t}=0}^{\infty} \beta^{\mathrm{P}^{\mathrm{t}}}\left(\ln \mathrm{c}_{\mathrm{t}}^{\mathrm{p}}+\mathrm{j}_{\mathrm{t}} \ln \mathrm{h}_{\mathrm{t}}^{\mathrm{p}}-\frac{\mathrm{L}_{\mathrm{t}}^{\mathrm{P}}}{\eta}\right),
$$

where $\mathrm{t}-$ time index, $\beta^{\mathrm{P}}-$ discount factor, $\mathrm{c}^{\mathrm{P}}$ and $\mathrm{h}^{\mathrm{P}}-$ consumption of goods and housing respectively, $\mathrm{L}^{\mathrm{P}}$ - working hours, $\eta$ - labor supply aversion, $\mathrm{E}$ - expectation operator, $\mathrm{j}$ - housing preference parameter that follows the AR(1) process:

$$
j_{t}=j_{t-1}^{\rho_{h}} \exp \left(\varepsilon_{h, t}\right), \varepsilon_{h, t} \sim N\left(0, \sigma_{h}\right)
$$

Expenditures in each period consist of consumption, expenses on the change in the stock of housing, and borrowing repayments. These can be finances from borrowing, labor income, rent from land, profits (as patient households run retail firms that operate on a market with monopolistic competition) and lump-sum net budget transfers. In the flow of funds, all variables are specified in real terms:

$$
\begin{gathered}
c_{t}^{P}+q_{t}^{h}\left(h_{t}^{P}-h_{t-1}^{P}\right)+R_{t-1} \frac{b_{t-1}^{P}}{\pi_{t}} \leq \\
\leq b_{t}^{P}+w_{t}^{P} L_{t}^{P}+r_{t}^{P} Z^{P}+F_{t}+T_{t}^{P},
\end{gathered}
$$

where $\mathrm{q}^{\mathrm{h}}$ - the real price of a house, $\mathrm{w}^{\mathrm{P}}$ - real wage, $\mathrm{r}^{\mathrm{p}}-$ real land rent of patient consumer. $\mathrm{F}$ denotes lump-sum profits from running retail firms, $\mathrm{T}$ - lump-sum government transfers, $\mathrm{R}$ - the nominal interest rate, $\mathrm{b}^{\mathrm{p}}$ - borrowings, and $\pi-$ inflation.

The difference from lacoviello (2005) is the presence of rent payments in the budget constraint. Households hold some agricultural land and can do nothing else (before the lifting of the moratorium on the land sale) but lease it out and get rent payments in return. Note, that $Z^{P}$ (amount of land) is exogenously given and is not a subject of optimization. Thus, patient consumers choose consumption, number of working hours, housing stock and borrowing.

Combined first order conditions can yield quite standard equations for the labor supply, housing demand and Euler equation for this type of DSGE model, which can be found in Appendix A.

\subsubsection{Impatient Households}

Impatient households have a lower value for the discount factor (compared to patient ones), which endogenously defines them as borrowers. Impatient as well as patient households derive utility from consumption $c^{\prime}$, houses $h^{\prime}$ and labor L' (disutility):

$$
\mathrm{U}^{\mathrm{I}}=\mathrm{E}_{0} \sum_{\mathrm{t}=0}^{\infty} \beta^{\mathrm{I}^{\mathrm{t}}}\left(\ln \mathrm{c}_{\mathrm{t}}^{\mathrm{I}}+\mathrm{j}_{\mathrm{t}} \ln \mathrm{h}_{\mathrm{t}}^{\mathrm{I}}-\frac{\mathrm{L}_{\mathrm{t}}^{\mathrm{I}}}{\eta}\right) .
$$

Expenditures on houses, consumer goods and loan repayments can be financed by new borrowings $b^{1}$, wages $\mathrm{w}^{\mathrm{I}}$ from labor and rent $\mathrm{r}^{\mathrm{I}}$ from possessing land $\left(\mathrm{Z}^{\mathrm{I}}\right)$. Budget constraint has the following form (the same as for patient hosueholds):

$$
\begin{aligned}
c_{t}^{I}+ & q_{t}^{h}\left(h_{t}^{I}-h_{t-1}^{I}\right)+R_{t-1} \frac{b_{t-1}^{I}}{\pi_{t}} \leq \\
& \leq b_{t}^{I}+w_{t}^{I} L_{t}^{I}+r_{t}^{I} Z^{I}+T_{t}^{I} .
\end{aligned}
$$

As mentioned, impatient household discount future utility faster than patient ones due to low $\beta$. In an economy inhabited by heterogeneous agents (in terms of $\beta$ ), this heterogeneity will inevitably make borrowers of those that have a lower discount factor. So impatient households' optimization leads to borrowing, making them "impatient" in the full sense of the word.

The borrowing of impatient households cannot exceed the expected future value of their assets:

$$
R_{t} b_{t}^{I} \leq m_{t} \pi_{t+1} q_{t+1}^{h} h_{t}^{I}
$$

where $\mathrm{m}^{1}$ is loan-to-value ratio. I made the LTV ratio stochastic, similar to Gerali et al. (2009), and it follows the AR(1) process:

$$
\mathrm{m}_{\mathrm{t}}=\mathrm{m}_{\mathrm{t}-1} \rho_{\mathrm{m}} \exp \left(\varepsilon_{\mathrm{m}, \mathrm{t}}\right), \varepsilon_{\mathrm{m}, \mathrm{t}} \sim \mathrm{N}\left(0, \sigma_{\mathrm{m}}\right) .
$$

To make the model clearer, is also useful to draw a distinction between the housing stock and the land stock in the setup. Households get utility from housing, can buy and sell houses on the housing market (but not rent) and use it as collateral. Land, on the contrary, is not in the utility function, can be leased (and bring rent payments), but cannot be traded or collateralized. However, the latter two assumptions will be relaxed in the succeeding sections.

Optimizing of (5) with respect to (6) and (7) we can obtain labor supply and house demand for impatient households (Appendix B).

\subsubsection{Entrepreneurs}

In this setup, firms are separate economic agents and draw utility from consumption only. They have a lower discount factor than patient households, and this defines their behavior as borrowers.

$$
\mathrm{U}^{\mathrm{E}}=\mathrm{E}_{0} \sum_{\mathrm{t}=0}^{\infty} \beta^{\mathrm{E}^{\mathrm{t}}} \ln \mathrm{c}_{\mathrm{t}}^{\mathrm{E}} .
$$

In order to finance their consumption, entrepreneurs produce wholesale goods. Compared to lacoviello (2005), I introduced agricultural land as an additional factor of production:

$$
\mathrm{Y}_{\mathrm{t}}=\mathrm{A}_{\mathrm{t}} \mathrm{K}_{\mathrm{t}-1}^{\mu} \mathrm{h}_{\mathrm{E}, \mathrm{t}-1}^{\mathrm{v}}\left(\mathrm{Z}_{\mathrm{E}}^{\varphi} \mathrm{Z}_{\mathrm{P}}^{\mathrm{d}} \mathrm{Z}_{\mathrm{I}}^{1-\varphi-\mathrm{d}}\right)^{\mathrm{u}}\left(\mathrm{L}_{\mathrm{P}, \mathrm{t}}^{\alpha} \mathrm{L}_{\mathrm{I}, \mathrm{t}}^{1-\alpha}\right)^{1-\mu-\mathrm{u}-\mathrm{v}}
$$

The production function is constructed in the spirit of lacoviello in a way that leads to analytical solutions. Output is produced with capital $\mathrm{K}$, houses $\mathrm{h}^{\mathrm{E}}$, land of all types of economic agents $\mathrm{Z}^{\mathrm{p}}, \mathrm{Z}^{\mathrm{I}}, \mathrm{Z}^{\mathrm{E}}$ and labor of patient $\mathrm{L}^{\mathrm{P}}$ and impatient $\mathrm{L}^{\mathrm{I}}$ households. $\mu$ stands for capital share in output, $v$ for house share in output, and $u$ for land share in output. Wages and rents are distributed according to the shares of economic agents $(\varphi, d, \alpha)$. The total factor productivity follows an $\operatorname{AR}(1)$ process:

$$
A_{t}=A_{t-1}^{\rho_{A}} \exp \left(\varepsilon_{A, t}\right), \varepsilon_{A, t} \sim N\left(0, \sigma_{A}\right)
$$

Entrepreneurs maximize their utility with respect to an entrepreneur's flow of funds. The incorporation of land requires two additional (compared to lacoviello (2005)) terms (rent payments to patient households, and rent payments to impatient households): 


$$
\begin{gathered}
c_{t}^{\mathrm{E}}+q_{t}^{\mathrm{h}}\left(h_{t}^{\mathrm{E}}-h_{t-1}^{\mathrm{E}}\right)+R_{t-1} \frac{b_{t-1}^{\mathrm{E}}}{\pi_{t}}+w_{t}^{\mathrm{I}} L_{t}^{\mathrm{I}}+w_{t}^{\mathrm{P}} L_{t}^{\mathrm{P}}+ \\
+\mathrm{r}_{\mathrm{t}}^{\mathrm{I}} \mathrm{Z}^{\mathrm{I}}+\mathrm{r}_{\mathrm{t}}^{\mathrm{P}} \mathrm{Z}^{\mathrm{P}}+\mathrm{I}_{\mathrm{t}}+\xi_{\mathrm{t}}^{\mathrm{K}} \leq \frac{\mathrm{Y}_{\mathrm{t}}}{\mathrm{X}_{\mathrm{t}}}+\mathrm{b}_{\mathrm{t}}^{\mathrm{E}}
\end{gathered}
$$

Firms spend their income from production and borrowing on consumption, housing, borrowing repayments, land, and labor factor payments to patient and impatient households. Labor and land markets are modeled as competitive, so the factor owners get their marginal product. In every period, $\delta$ share of capital depreciates, and capital stock can be replenished by investments I:

$$
\mathrm{I}_{\mathrm{t}}=\mathrm{K}_{\mathrm{t}}-(1-\delta) \mathrm{K}_{\mathrm{t}-1}
$$

Capital adjustment $\xi^{\mathrm{K}}$ costs have a quadratic form, such that in a steady-state they are equal to zero:

$$
\xi_{\mathrm{t}}^{\mathrm{K}}=\frac{\psi}{2 \delta}\left(\frac{\mathrm{I}_{\mathrm{t}}}{\mathrm{K}_{\mathrm{t}-1}}-\delta\right)^{2} \mathrm{~K}_{\mathrm{t}-1} .
$$

In addition, entrepreneurs are limited in borrowings in the same manner as impatient households:

$$
\mathrm{R}_{\mathrm{t}} \mathrm{b}_{\mathrm{t}}^{\mathrm{E}} \leq \mathrm{m}_{\mathrm{t}} \pi_{\mathrm{t}+1} \mathrm{q}_{\mathrm{t}+1}^{\mathrm{h}} \mathrm{h}_{\mathrm{t}}^{\mathrm{E}}
$$

where $\mathrm{m}$ is a stochastic LTV ratio that follows an $\mathrm{AR}(1)$ process:

$$
\mathrm{m}_{\mathrm{t}}=\mathrm{m}_{\mathrm{t}-1} \rho_{\mathrm{m}} \exp \left(\varepsilon_{\mathrm{m}, \mathrm{t}}\right), \varepsilon_{\mathrm{m}, \mathrm{t}} \sim \mathrm{N}\left(0, \sigma_{\mathrm{m}}\right) .
$$

Maximization of (8) with respect to (9), (11), (12), (13) and (14) describe the demand side of the labor markets, an optimal investment schedule, and firms' demand for houses (Appendix C).

\subsubsection{Other Agents}

Retailers and the central bank constitute the rest of the model, and exactly match the corresponding section in lacoviello (2005). There is a continuum of retailers $i$ of mass 1 that buy intermediate homogeneous goods $\mathrm{Y}$ for price $\mathrm{P}^{\mathrm{W}}$, differentiate them without cost, and sell them in an imperfect market with markup X at price P. Aggregate price index $\mathrm{P}_{\mathrm{t}}=\left(\int_{0}^{1} \mathrm{P}_{\mathrm{t}}(\mathrm{i})^{1-\varepsilon} \mathrm{di}\right)_{\varepsilon}^{\frac{1}{1-\mathrm{e}}}$ corresponds to aggregate output $\mathrm{Y}_{\mathrm{t}}=\left(\int_{0}^{1} \mathrm{Y}_{\mathrm{t}}(\mathrm{i})^{\frac{\varepsilon-1}{\varepsilon}} \mathrm{di}\right)^{\frac{\varepsilon}{\varepsilon-1}}$, and it can be shown that each retailer faces $\mathrm{Y}_{\mathrm{t}}(\mathrm{i})=\left(\mathrm{P}_{\mathrm{t}}(\mathrm{i}) / \mathrm{P}_{\mathrm{t}}\right)^{\frac{\varepsilon}{\varepsilon-1}} \mathrm{Y}_{\mathrm{t}}$.

Given standard Calvo pricing, with the probability of price resetting equal to $1-\theta$, each firm maximizes discounted expected profits with respect to optimal price P*:

$$
\sum_{k=0}^{\infty} \theta^{\mathrm{k}} \mathrm{E}_{0}\left(\beta^{\mathrm{P}} \frac{\mathrm{c}_{\mathrm{t}}^{\mathrm{E}}}{\mathrm{c}_{\mathrm{t}+\mathrm{k}}^{\mathrm{E}}}\left(\frac{P_{t}^{*}(i)-P_{t}^{w}}{\mathrm{P}_{\mathrm{t}}}\right) Y_{t+k}(i)\right)
$$

Optimization of (16) coupled with the evolution of price level $P_{t}=\left(\theta P_{\mathrm{e}-1}^{\varepsilon}+(1-\theta) P_{t}^{* 1-\varepsilon}\right)^{\frac{1}{1-\varepsilon}}$ yields the standard New-Keynesian forward-looking Philips Curve.

The central bank follows the Taylor rule:

$$
R_{t}=\left(R_{t-1}\right)^{r_{R}}\left(\pi_{t-1}^{1+r} \pi\left(\frac{Y_{t-1}}{Y}\right)^{r_{Y}} \overline{r r}\right)^{1-r_{R}} e_{R, t}
$$

where $e_{R, t}$ is a monetary policy shock, that follows the $A R(1)$ process:

$$
\mathrm{e}_{\mathrm{R}, \mathrm{t}}=\mathrm{e}_{\mathrm{R}, \mathrm{t}-1} \rho_{\mathrm{e}} \exp \left(\varepsilon_{\mathrm{R}, \mathrm{t}}\right)
$$

\subsubsection{Equilibrium}

The general equilibrium is characterized by equilibria on the goods, labor, financial and housing markets. The model assumes binding collateral constraints, so impatient households and entrepreneurs borrow up to their limit. The definition of all flows between economic agents also requires two out of three budget constraints (by the virtue of Walras law).

The model describes a private (no government spending) closed (no export/import) economy, so final output can be either consumed by entrepreneurs, patient households and impatient households, or adjusted in the form of investments by entrepreneurs. Equilibrium on the goods market is described by equation (19).

$$
Y_{t}=c_{t}^{P}+c_{t}^{I}+c_{t}^{E}+I_{t}
$$

The market-clearing condition in the labor market in fact combines the market-clearing condition in the labor market for patient households and in the labor market for impatient households.

$$
\mathrm{L}_{\mathrm{t}}^{\text {Demand }}=\mathrm{L}_{\mathrm{t}}^{\text {Supply }}
$$

The sum of borrowing is equal to zero, i.e. the sum of borrowing is equal to the sum of savings (negative borrowings) in the economy.

$$
b_{t}^{P}+b_{t}^{I}+b_{t}^{E}=0
$$

Supply on the housing market is fixed and does not depreciate.

$$
h_{t}^{P}+h_{t}^{I}+h_{t}^{E}=\bar{H}
$$

\subsection{Modified Model}

Let us move to a modified model that simulates the changes in the economy associated with lifting the moratorium on land sales. In this model, I allow land to be traded and to use as collateral. This affects all economic agents and this section briefly describes the changes.

\subsubsection{Patient Households}

Patient households consume goods and housing services, work, lend money and choose theamount of land to own, since the land trade is no longer prohibited. Agricultural land delivers no utility, so the utility function stays unchanged:

$$
\begin{gathered}
\mathrm{U}^{\mathrm{P}}=\mathrm{E}_{0} \sum_{\mathrm{t}=0}^{\infty} \beta^{\mathrm{P}^{\mathrm{t}}}\left(\ln \mathrm{c}_{\mathrm{t}}^{\mathrm{p}}+\mathrm{j}_{\mathrm{t}} \ln \mathrm{h}_{\mathrm{t}}^{\mathrm{p}}-\frac{\mathrm{L}_{\mathrm{t}}^{\mathrm{P} \eta}}{\eta}\right), \\
\mathrm{j}_{\mathrm{t}}=\mathrm{j}_{\mathrm{t}-1}^{\rho_{\mathrm{h}}} \exp \left(\varepsilon_{\mathrm{h}, \mathrm{t}}\right), \varepsilon_{\mathrm{h}, \mathrm{t}} \sim \mathrm{N}\left(0, \sigma_{\mathrm{h}}\right) .
\end{gathered}
$$

The budget constraint has been modified - the third term reflects that households can buy and sell land. And the time subscript of $\mathrm{Z}$ (in the income part of the budget constraint) indicates that rents are obtained from the land, the amount of which can be optimized. 


$$
\begin{gathered}
\mathrm{c}_{\mathrm{t}}^{\mathrm{P}}+\mathrm{q}_{\mathrm{t}}^{\mathrm{h}}\left(\mathrm{h}_{\mathrm{t}}^{\mathrm{P}}-\mathrm{h}_{\mathrm{t}-1}^{\mathrm{P}}\right)+\mathrm{q}_{\mathrm{t}}^{\mathrm{Z}}\left(\mathrm{Z}_{\mathrm{t}}^{\mathrm{P}}-\mathrm{Z}_{\mathrm{t}-1}^{\mathrm{P}}\right)+\mathrm{R}_{\mathrm{t}-1} \frac{\mathrm{b}_{\mathrm{t}-1}^{\mathrm{P}}}{\pi_{\mathrm{t}}} \leq \\
\leq \mathrm{b}_{\mathrm{t}}^{\mathrm{P}}+\mathrm{w}_{\mathrm{t}}^{\mathrm{P}} \mathrm{L}_{\mathrm{t}}^{\mathrm{P}}+\mathrm{r}_{\mathrm{t}}^{\mathrm{P}} \mathrm{Z}_{\mathrm{t}-1}^{\mathrm{P}}++\mathrm{F}_{\mathrm{t}}+\mathrm{T}_{\mathrm{t}}^{\mathrm{P}},
\end{gathered}
$$

where $\mathrm{q}_{\mathrm{z}}^{\mathrm{t}}$ is land price and $\left(\mathrm{Z}_{\mathrm{t}}^{\mathrm{P}}-\mathrm{Z}_{\mathrm{t}-1}^{\mathrm{P}}\right)$ is additional land acquired in period $t$

Maximization yields five first-order conditions that can be combined into four equations. They are labor supply, the housing-consumption ratio (housing demand), the Euler equation, and land supply (Appendix D). The first three exactly replicate the results of the initial model. The fourth stands for the land-consumption ratio, and arises due to the additional choice variable (land).

\subsubsection{Impatient Household}

Utility function of impatient household duplicates (4):

$$
\mathrm{U}^{\mathrm{I}}=\mathrm{E}_{0} \sum_{\mathrm{t}=0}^{\infty} \beta^{\mathrm{I}^{\mathrm{t}}}\left(\ln \mathrm{c}_{\mathrm{t}}^{\mathrm{I}}+\mathrm{j}_{\mathrm{t}} \ln \mathrm{h}_{\mathrm{t}}^{\mathrm{I}}-\frac{\mathrm{L}_{\mathrm{t}}^{\mathrm{I}} \eta^{\eta}}{\eta}\right),
$$

subject to a constraint which takes into account land trade (the same as for patient households):

$$
\begin{aligned}
& c_{t}^{\mathrm{I}}+\mathrm{q}_{\mathrm{t}}^{\mathrm{h}}\left(\mathrm{h}_{\mathrm{t}}^{\mathrm{I}}-\mathrm{h}_{\mathrm{t}-1}^{\mathrm{I}}\right)+\mathrm{q}_{\mathrm{t}}^{\mathrm{Z}}\left(\mathrm{Z}_{\mathrm{t}}^{\mathrm{I}}-\mathrm{Z}_{\mathrm{t}-1}^{\mathrm{I}}\right)+ \\
& +\mathrm{R}_{\mathrm{t}-1} \frac{\mathrm{b}_{\mathrm{t}-1}^{\mathrm{I}}}{\pi_{\mathrm{t}}} \leq \mathrm{b}_{\mathrm{t}}^{\mathrm{I}}+\mathrm{w}_{\mathrm{t}}^{\mathrm{I}} \mathrm{L}_{\mathrm{t}}^{\mathrm{I}}++\mathrm{r}_{\mathrm{t}}^{\mathrm{I}} \mathrm{Z}_{\mathrm{t}-1}^{\mathrm{I}}+\mathrm{T}_{\mathrm{t}}^{\mathrm{I}} .
\end{aligned}
$$

Borrowing constraint constitutes the essence of the models, engendering shock amplification. While the initial model replicates the borrowing constraint from lacoviello (2005), in the modified model I allow land to be used as a means of collateral.

$$
\begin{gathered}
\mathrm{R}_{\mathrm{t}} \mathrm{b}_{\mathrm{t}}^{\mathrm{I}} \leq \mathrm{m}_{\mathrm{t}} \pi_{\mathrm{t}+1}\left(\mathrm{q}_{\mathrm{t}+1}^{\mathrm{h}} \mathrm{h}_{\mathrm{t}}^{\mathrm{I}}+\mathrm{q}_{\mathrm{t}+1}^{\mathrm{Z}} \mathrm{z}_{\mathrm{t}}^{\mathrm{I}}\right), \\
\mathrm{m}_{\mathrm{t}}=\mathrm{m}_{\mathrm{t}-1} \rho_{\mathrm{m}} \exp \left(\varepsilon_{\mathrm{m}, \mathrm{t}}\right), \varepsilon_{\mathrm{m}, \mathrm{t}} \sim \mathrm{N}\left(0, \sigma_{\mathrm{m}}\right) .
\end{gathered}
$$

Maximization of the utility function subject to the budget and collateral constraints provides labor supply, the houseconsumption relation, and the land-consumption relation. These equations are reported in Appendix E.

\subsubsection{Entrepreneurs}

Entrepreneurs draw utility from consumption that is equivalent to (8):

$$
\mathrm{U}^{\mathrm{E}}=\mathrm{E}_{0} \sum_{\mathrm{t}=0}^{\infty} \beta^{\mathrm{E}^{\mathrm{t}}} \ln c_{\mathrm{t}}^{\mathrm{E}} .
$$

Production is performed with capital, houses, land and labor. Now the amount of land is a choice variable:

$$
\begin{gathered}
Y_{t}=A_{t} K_{t-1}^{\mu} h_{E, t-1}^{v}\left(Z_{E, t-1}^{\varphi} Z_{P, t-1}^{d} Z_{I, t-1}^{1-\varphi-d}\right)^{u}\left(L_{P, t}^{\alpha} L_{I, t}^{1-\alpha}\right)^{1-\mu-u-v} \\
A_{t}=A_{t-1}^{\rho_{A}} \exp \left(\varepsilon_{A, t}\right), \varepsilon_{A, t} \sim N\left(0, \sigma_{A}\right)
\end{gathered}
$$

The budget constraint is extended for the possibility of land purchases, and takes into account rent payments in favor of patient households and impatient households:

$$
\begin{gathered}
c_{t}^{E}+q_{t}^{h}\left(h_{t}^{E}-h_{t-1}^{E}\right)+q_{t}^{Z}\left(Z_{t}^{E}-Z_{t-1}^{E}\right)+R_{t-1} \frac{b_{t-1}^{E}}{\pi_{t}}+ \\
+w_{t}^{I} L_{t}^{I}+w_{t}^{P} L_{t}^{P}++r_{t}^{I} Z_{t-1}^{I}+r_{t}^{P} Z_{t-1}^{P}+I_{t}+\xi_{t}^{K} \leq \frac{Y_{t}}{x_{t}}+b_{t}^{E} .
\end{gathered}
$$

Capital flow and adjustment costs are left without changes and correspond to (12) and (13). Collateral constraint is modified in the same manner as for impatient households. Entrepreneurs are allowed to secure their loans not only with houses, but also with land.

$$
\begin{gathered}
\mathrm{R}_{\mathrm{t}} \mathrm{b}_{\mathrm{t}}^{\mathrm{E}} \leq \mathrm{m}_{\mathrm{t}} \pi_{\mathrm{t}+1}\left(\mathrm{q}_{\mathrm{t}+1}^{\mathrm{h}} \mathrm{h}_{\mathrm{t}}^{\mathrm{E}}+\mathrm{q}_{\mathrm{t}+1}^{\mathrm{Z}} \mathrm{Z}_{\mathrm{t}}^{\mathrm{E}}\right), \\
\mathrm{m}_{\mathrm{t}}=\mathrm{m}_{\mathrm{t}-1} \rho_{\mathrm{m}} \exp \left(\varepsilon_{\mathrm{m}, \mathrm{t}}\right), \varepsilon_{\mathrm{m}, \mathrm{t}} \sim \mathrm{N}\left(0, \sigma_{\mathrm{m}}\right) .
\end{gathered}
$$

Entrepreneurs' FOCs result in labor demand, demand for land, an optimal investment schedule, land-consumption, and housing consumption relations, reflected in Appendix F.

\subsubsection{Other Agents and Equilibrium}

The rest of the model was kept unchanged. Calvo pricing at the retail level implies a Philips curve analogous to the previous one. The central money authority follows Taylor rule, analogous to (17).

Market clearing conditions are the same as for the initial model, and can be described by equations (19) - (22). The land market implies a fixed land supply, so I introduce an additional condition:

$$
\mathrm{Z}_{\mathrm{t}}^{\mathrm{P}}+\mathrm{Z}_{\mathrm{t}}^{\mathrm{I}}+\mathrm{Z}_{\mathrm{t}}^{\mathrm{E}}=\overline{\mathrm{Z}}
$$

\section{PARAMETERIZATION}

The initial model includes 22 endogenous variables, 23 parameters and four variables with exogenous dynamics. The modified model was extended for four variables (land of three groups of economic agents and land price) comprising 26 endogenous variables and five markets.

I transformed all the variables from absolute values into the form of relative deviations, such that $\tilde{x}_{t}$ denotes the percentage deviation of variable $\mathrm{x}$ from the steady state value $\mathrm{x}$ at time $t$. In this fashion, the initial model was log-linearized around a growthless steady-state with zero inflation, and reduced to the thirteen equations that describe the dynamics of the thirteen endogenous variables, and four equations with exogenous dynamics. The steady-states for the initial model can be found in Appendix G. The log-linearized version of the initial model is reflected in Appendix $\mathrm{H}$. Appendix I and Appendix $\mathrm{J}$ include steady-states and the log-linearized version of the modified model.

In the process of calibration, I was largely guided by the works of Cooley and Prescott (1995), and Gomme and Rupert (2007), who describe several approaches for parameter choice. Under the assumption of perfect competition on the input markets, input owners earn marginal products of corresponding factors of production. The most straightforward way to obtain the sought-for output shares relies on GDP data. Based on the Ukrainian GDP by income statistics for 2016 provided by the State Statistics Service of Ukraine (UKRSTAT), and allowing the ambiguous income (mixed profits) to be distributed between factor owners in the same fractions as the unambiguous income, I set labor share equal 
to 0.7. The marginal product of land is estimated as $\$ 200$ per hectare, and assuming 20 million hectres of farmland in formal production, I picked $\mathrm{u}=0.03$, so capital and housing shares have 0.27 combined. I chose a housing share equal to 0.02 in accordance with lacoviello (2005), leaving 0.25 to capital share. The depreciation rate is determined as the ratio of capital depreciated to overall capital stock. I used the steady-state property that depreciation is equal to the Investment-Capital ratio, and based on the data provided by UKRSTAT I calculated depreciation as 13\% yearly, so choose $\delta=0.031$

According to the NBU study Grui, Lepushynskyi, Nikolaychuk (2018), the equilibrium interest rate for Ukraine is $2.5 \%$, so I picked the discount factor for patient households as the reciprocal of the rate, which for quarterly data, is 0.995. Papers by Lawrance (1991) and Samwick (1997) suggest that the value of the discount factors for the groups of interest should lie between 0.91 and 0.99 , so I picked 0.94 for impatient households. I assign $\eta=2$ to the Frisch labor supply elasticity, which corresponds to spending of $1 / 3$ of time endowment on work. In the $\alpha$ parameter choice I take the results from lacoviello (2010) and assign $64 \%$ of all labor income to patient households. The share of land rental payments received by entrepreneurs constitutes $84 \%$ of all rental payments, so $\varphi$ and $\mathrm{d}$ are 0.84 and 0.07 correspondently.

The procedure of the Taylor rule parameter calibration involves the regression of the interest rate on detrended output, inflation, and the lagged value of the interest rate. In the Ukrainian reality, the results obtained from such procedure could be rather questionable, as a valid estimation of the Taylor rule parameters can be conducted only within the data from the last few years. The results I obtained are in Table 1. The full results of the estimation can be found in in Table K1 (Appendix K). All the calibrated parameters are presented in Table K2 (Appendix K).
In estimations of the parameters of shock persistence, shock standard deviations, adjustment costs, and Calvo rigidity, I follow Ireland (2004), which is the largest NewKeynesian model estimated with Full Information Maximum Likelihood. Once, the model is transformed into the statespace representation, a likelihood function of the observed data can be built according to Bauer, Haltom, and RubioRamírez (2003).

As the model includes four exogenous processes, I use data on four endogenous variables. In the procedure, I use Ukrainian quarterly data 2006Q1-2016Q4 on seasonally adjusted, HP-detrended output and investment per capita, HP-detrended prices for housing, and inflation. All the time series are used in the form of percentage deviations from the long-run steady-state.

The estimation results suggest high persistence of the financial and housing preferences shocks (all between 0.947and 0.980), and persistence of moderate magnitude of the technological shock. The estimates of $\sigma_{a}=0.0262$ and $\sigma_{e}=0.0089$ are significant, and are, as expected, lower than standard deviations of the financial and preference shocks.

I estimated the capital adjustment costs at the level of 0.625 . The estimate for the Calvo stickiness parameter equal to 0.34 implies that firms on average firms reset prices each $1 /(1-0.34)=1.5$ quarters, which is somewhat in contrast with the standard 4 quarters. The results of the ML estimation can be found in Table K3 (Appendix K).

\section{RESULTS}

In this section I describe the results obtained from both models, and then proceed with an impulse response function analysis.

Table 1. The Central Bank Policy Parameters

\begin{tabular}{lcc}
\hline Description & Parameter & Value \\
\hline The Taylor rule parameter of inflation response & $r_{\pi}$ & 0.5377 \\
The Taylor rule inertia parameter & $r_{R}$ & 0.8559 \\
The Taylor rule parameter of output response & $r_{Y}$ & Insignif. \\
\hline
\end{tabular}

The rest was calibrated on the basis of steady-state ratios. I chose the discount factor of entrepreneurs to match the investment-to-output ratio. According to both NBU and UKRSTAT data, investments constitute $14-15 \%$ of GDP, so the value of $\beta^{e}$ should be 0.94 in order to be consistent with the data. To maintain 0.35 (based on the NBU data) as the loansto-output ratio of the entrepreneurs, the loan-to-value ratio was chosen to be equal to 0.31. lacoviello (2005) assumes that the ratio is equal to 0.89 , but he suggests only commercial estate as collateral. The estimates of Christensen (2007) and Gerali et al. (2010) are more germane, and constitute 0.42 and 0.31 correspondently. To keep the loans-to-output ratio of the households equal to 0.07 (based on the NBU data) the weight of housing in the utility function was set at 0.05 .
Since the economy in the present work is modeled as private and closed, the expenditure side of GDP is described as the sum of consumption and investment spending. The Investment-to-Output ratio is immutable across the models (as neither land nor land parameters are included in the equation that define the ratio) and equals 0.137 (based on the data provided by NBU or UKRSTAT it can be calculated as $0.14-0.15)$. The remaining part of the output is devoted to consumption.

Another important result is the increase of the amount of overall borrowing in the country. According to the WORLDBANK data, domestic credit constitutes $47 \%$ of GDP of Ukraine; similar estimates are provided by the NBU, which splits this amount between loans to households (7\% of GDP) and to entrepreneurs (35\%). As land reform allows land col- 
lateralization, impatient households and entrepreneurs can increase their borrowing power. The new steady-state ratios show a dramatic increase in entrepreneurs' borrowings and a moderate increase of household borrowings. The results are summarized in the Table 2 .
In a New-Keynesian DSGE with collateral constraints, a productivity shock may result in a counterintuitive impulse response function. Typically, a positive technological shock leads to inflation waning, through a drop in the marginal costs of production. A decrease in the inflation level fosters

Table 2. The Steady-State Ratios in the "Initial" and "Modified" Models

\begin{tabular}{lcc}
\hline Ratio & Before Land Reform & After Land Reform \\
\hline Investment-to-Output & 0.14 & 0.14 \\
Borrowing-to-Output (Households) & 0.08 & 0.10 \\
Borrowing-to-Output (Entrepreneurs) & 0.35 & 0.81 \\
\hline
\end{tabular}

Next, I examine the properties of the models with an impulse response function analysis. This provides an answer to how the magnitude of the shock amplification will be altered after the changes implied by land reform. The combined responses of output to the technological, monetary, preference, and loan-to value shocks of the initial and modified models are reflected in Figure 2. an enlargement in the real burden of liabilities as a result of debt deflation. Here, financial friction comes into play. The increase in the real value of debt decreases the borrowing ability of entrepreneurs and, as result, reduces consumption, capital and housing. The latter serves as a mean of collateral and weakens demand on the housing market, which reduces the price of houses and the value of collateral. Such

Figure 2. The IRFs of the Output to One Standard Deviation Before (Solid) and After (Dotted) Land Reform
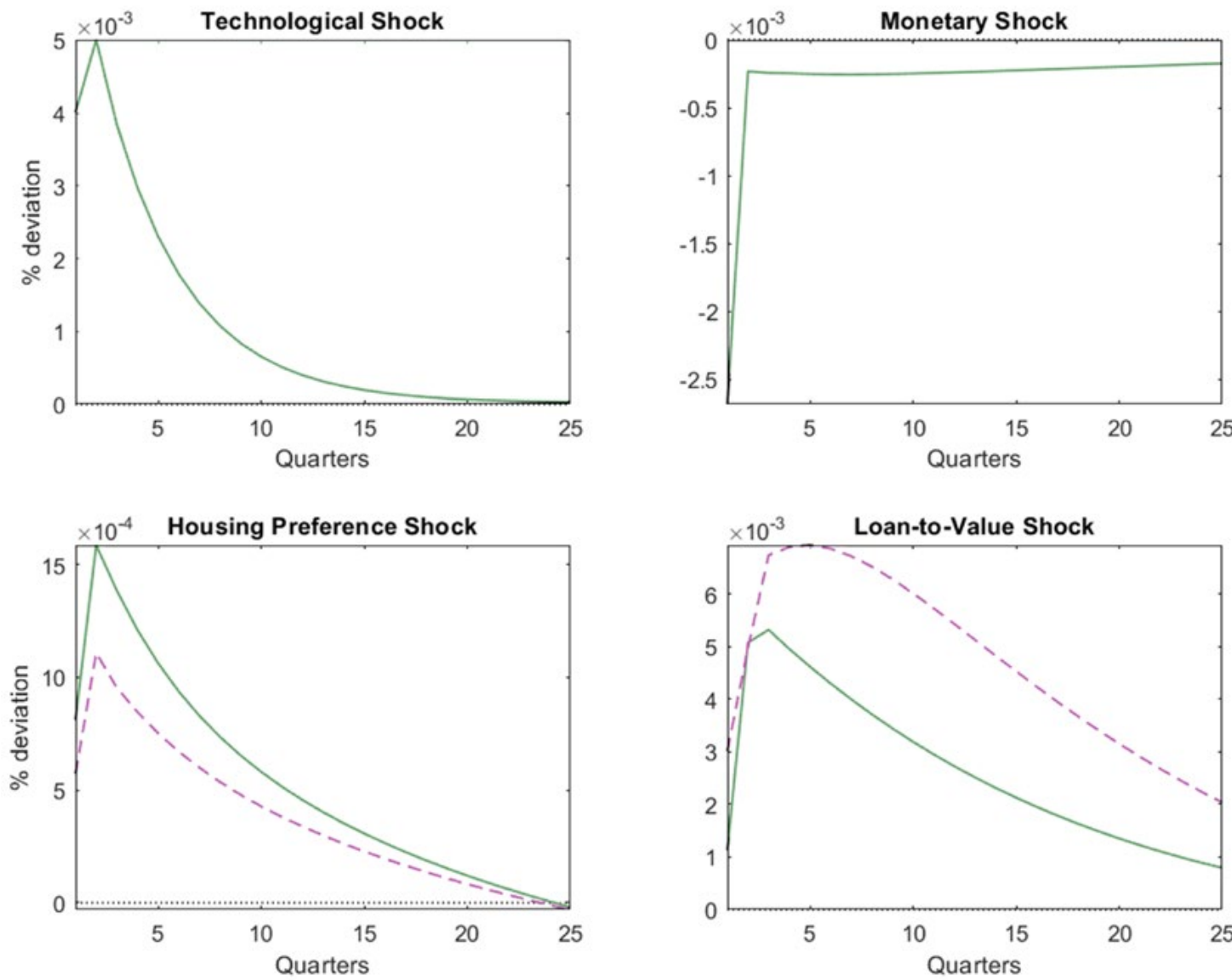

Initial model 
an amplification leads to an initially negative response to a technological shock. However, the estimated model for Ukraine cannot produce deflation of the required amplitude, so productivity drives output up, outweighing the consequences of debt-deflation.

Monetary shock is transmitted to the real sector because of price stickiness. A nominal interest rate increase entails a hike in the real interest rate. The typical consequences of the traditional interest rate channel imply a redistribution of consumption in favor of future periods, and a drop of demand on all markets, including the asset market. A decrease of demand on the housing market induces prices to drop, which, in turn, causes the tightening of the borrowing constraint. Accordingly, the lower value of the collateral available causes a further drop in demand, which in its turn further tightens collateral constraint, and the shock is amplified.

Due to its high persistence, the housing preference shock exerts a significant effect on the macroeconomic dynamics. A positive shock leads to higher demand for houses, which drives their prices up. This means a collateral constraint easing, which in turn allows a higher level of borrowing. Entrepreneurs increase their capital and consumption, whereas households substitute consumption for houses. As only households are subject to the preference shock, it leads to a redistribution of housing wealth from entrepreneurs to households. As entrepreneurs get rid of houses, its collateral constraint starts to tighten, whereas the borrowing constraint of the impatient households has greater inertia: high demand for houses spurs house prices to rise, weakening the limitation on loans, while the redistribution of housing in favor of households makes this effect prolonged.

The monetary and productivity shocks in both the initial and modified models lead to the same dynamics. Land and houses behave alike, with movements in the same direction, and with monetary and technological shocks producing a negligible difference across the models. However, the picture differs significantly in the case of a housing preference shock. The latter shock creates a higher oscillation of the collateral price (in comparison to other considered shocks, see Figure L1 (Appendix L) which is consistent with Liu, Wang and Zha (2013). As housing, as a factor of production, becomes relatively more expensive, optimizing behavior forces entrepreneurs to acquire land and sell houses, while households do the opposite.

The financial shock has the most apprehensible effects, and results in substantial differences across the models. The mechanism is rather straightforward: an increase of the loanto-value ratio fosters collateral constraint easing, which enhances demand on all markets. Higher demand on the housing market leads to higher house prices, which, in its turn, further amplifies the shocks. In the case of an LTV shock, the dynamics of the macroeconomic indicators are directly affected by the amount of collateral. For this reason, the possibility of borrowing against land creates essential differences in the amplification as a result of land reform.

Moving to the historical shock decomposition, I determine to what extent each shock contributes to the overall output deviations from the steady-state, applying the Kalman Smoother algorithm. The algorithm produces smoothed shocks and smoothed initial values. This is the best conjuncture for the shocks, given the observable endogenous variables. Appendix $L$ depicts the smoothed shocks produced by the Kalman Smoother. The cumulative impact of the smoothed shocks on output during 2006-2016 is shown in Figure 3.

\section{Figure 3. Historical Decomposition of the Output of Ukraine}
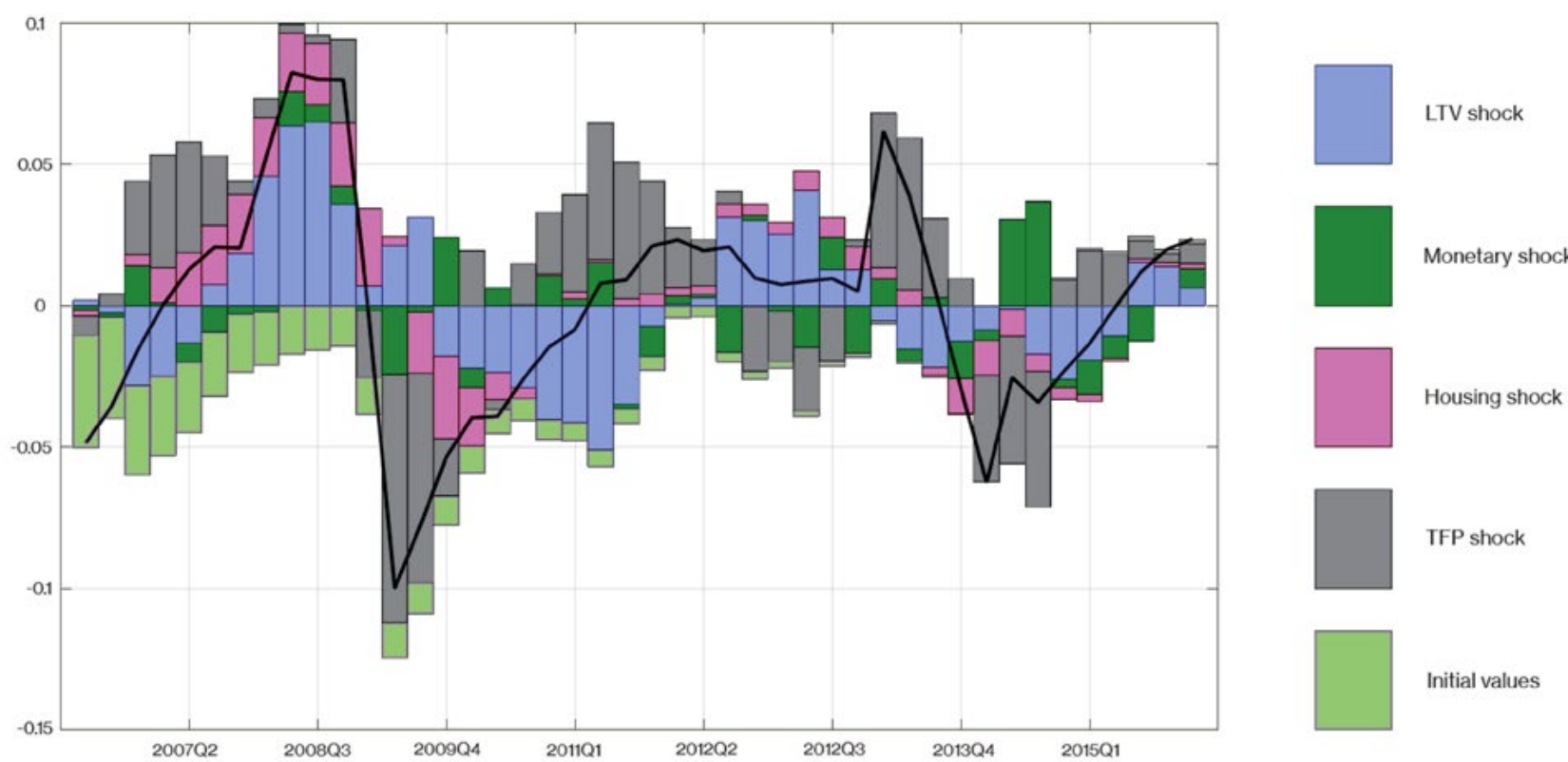

Housing shock

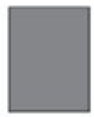

TFP shock

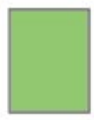

Initial values 
The historical decomposition of the output suggests that in 2009-2011 and 2013Q3-2015Q2 output was below its steady-state level, while between the recessions, GDP was slightly above its natural level with the peak occurring in 2013Q1. The downturn that happened in 2008 and that worsened during 2009 was driven by a negative TFP shock, accompanied by a negative housing preference shock and latter compounded by a loan-to-value shock that broadly incorporated all financial factors. As the economy is modeled as closed, a productivity shock may capture foreign demand shocks and domestic supply shocks. The deviations of output between 2011 and 2015 can be assigned mainly to loanto value and total factor productivity shocks.

Finally, I proceed with a counterfactual experiment. Having obtained the historical decomposition of the output, I extract the historical shocks produced by the Kalman Smoother (Appendix L). So, a natural question arises: "what would have happened with the economy if agricultural land was tradable and collateralizable?" In other words, I took the modified model (which simulates the economy when the moratorium is lifted) and made it subject to the series of shocks produced by the Kalman Smoother to obtain an alternative scenario (Figure 4). trated by the output peak in 2008Q3. From the other side, the house preference shock, which significantly contributed to the GDP drop, mitigates the decline in the alternative scenario. So, under certain conditions, land trade and land collateralization can both contribute to shock amplification, and alleviate its consequences, depending on the nature of the driving force of the output deviation.

\section{CONCLUSIONS}

The final stage of the land reform in Ukraine entails the creation of the land market and the possibility of land collateralization. Treating land as a regular asset improves access to the financial market through the relaxation of borrowing constraints. In the context of the observed housing market spillover effects, that there will be changes in business cycle dynamics due to land collateralization seems to be a legitimate assumption.

To analyze the effect of the land reform on the business cycle, I extended lacoviello (2005). Land is added to the framework as another factor of production, along with capital, labor and housing. With the aim of making a dynamic comparison, two models were constructed. The "Initial Model" is

\section{Figure 4. Counterfactual Experiment. Actual Output (Solid) Versus Alternative (Dotted)}

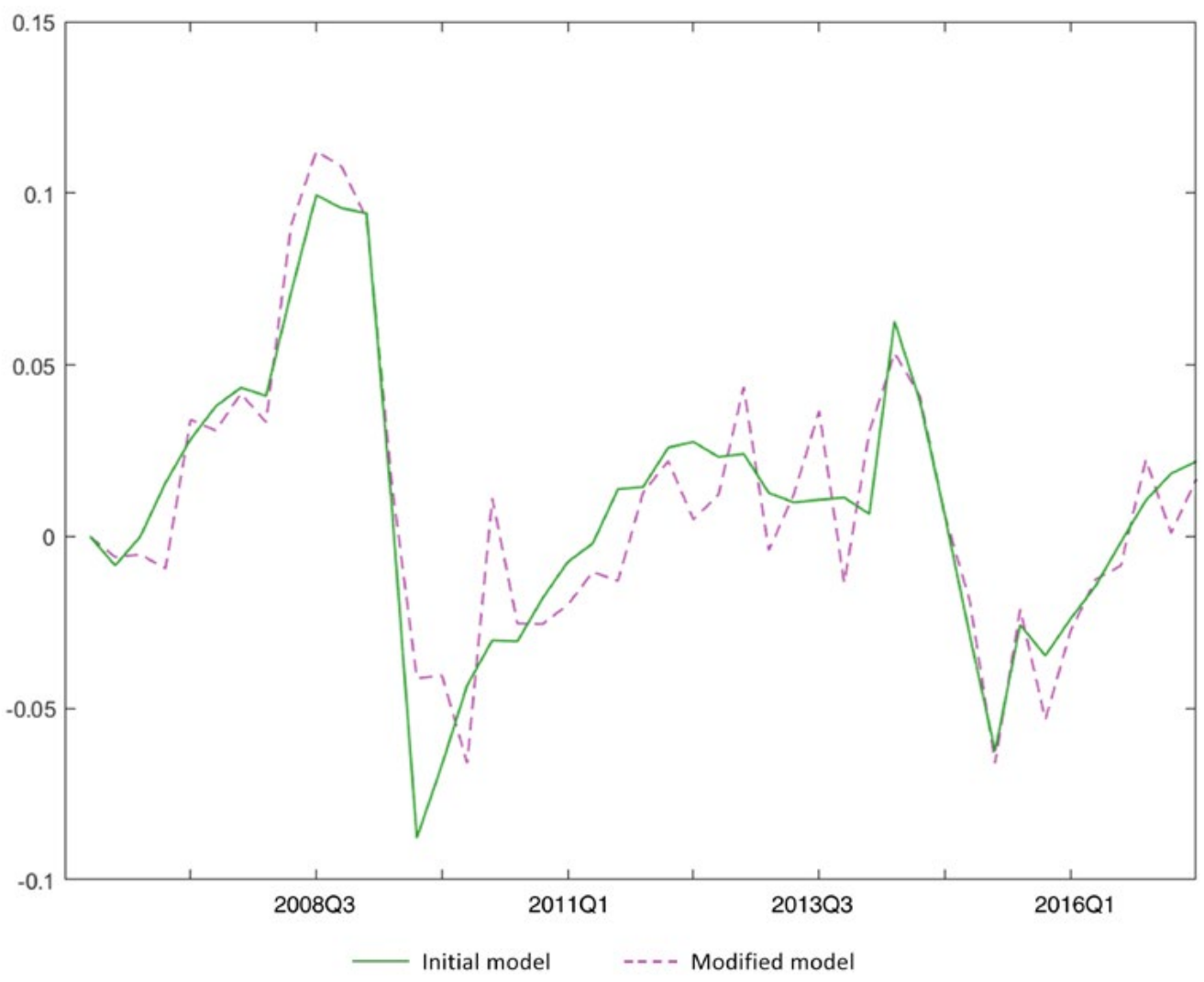

The discrepancy across the scenarios is a logical consequence arising from the fact that the initial and the modified models have different responses to shocks of similar magnitude (see Figure 2). Thus, the model after the lifting of the moratorium tends to amplify both output increases and declines caused by financial shocks, which is clearly illus- constructed such that land is distributed across economic agents and is not the subject to trade or collateralization. The "Modified Model" allows land to be traded and to borrowing against its value. The models were calibrated and estimated with Full Information Maximum Likelihood. The main findings are the following: 
- Lifting the moratorium allows land to be traded and for it to be used as an additional way to secure loans. If there are binding borrowing constraints, additional collateral leads to constraint easing, which increases the borrowing power of impatient economic agents. It has been calculated that the overall Credit-to-GDP ratio would double, from about 0.45 to 0.90 ;

- Historical shock decomposition showed that technological and financial shocks made the biggest contribution to macroeconomic fluctuations; these shocks were also seen to be highly persistent;

- Land collateralization had a significant effect on the amplification magnitude in the case of a loan-to-value shock, as the amount of collateral affects the dynamics directly. Monetary and productivity shocks caused negligible changes in amplification in the counterfactual economy when land reform was implemented;

- The counterfactual experiment suggests that the 2009 decline could have been mitigated, as it was partially caused by the housing preference shocks, whereas the expansion that preceded the recession could have been amplified, since it was the result of financial shocks.

More accurate estimates would require the model to be augmented with elements that reflect the peculiarities of the Ukrainian economy. First, the introduction of the underground sector, which presumably tends to weaken the credit cycle, is reasonable in the case of an emerging economy. Second, the addition of the supply side of the housing market and growth trends similar to those of lacoviello and Neri (2010) could refine model performance significantly. I anticipate that these two extensions would lead to a quantitative improvement. Overall, the main contribution of the present work is a conceptual assessment of the macroeconomic implications of the land market's emergence in Ukraine, with the focus being on credit cycle fluctuations, where tradable land could potentially be used as a means for extending collateralized credit.

\section{REFERENCES}

- Bauer A., Haltom N. and Rubio-Ramirez J.F. (2003). Using the Kalman Filter to Smooth the Shocks of a Dynamic Stochastic General Equilibrium Model. Working Paper, No. 2003-32, Federal Reserve Bank of Atlanta.

- Bernanke B. S., Gertler M. (1995). Inside the Black Box: The Credit Channel of Monetary Policy Transmission. Journal of Economic Perspectives, Vol. 9, No. 4, pp. 27-48. https://doi.org/10.1257/jep.9.4.27

Bernanke B. S., Gertler M., Gilchrist S. (1996). The Financial Accelerator and the flight to Quality. Review of Economics and Statistics, Vol. 78, No. 1, pp. 1-15.

Bernanke B. S., Gertler M., Gilchrist S. (1999). The Financial Accelerator in a Quantitative Business Cycle Framework. Handbook of Macroeconomics, Vol. 1, Part C, pp. 1341-1393.

- Bernanke B., Gertler M. (1990). Financial Fragility and Economic Performance. Quarterly Journal of Economics, Vol. 105, No. 1, pp. 87-114. https://doi.org/10.2307/2937820

- Cooley T. F., Prescott E. C. (1995). Economic Growth and Business Cycles. Frontiers of Business Cycle Research, chapter 1, Princeton University Press, Princeton, New Jersey.

- Cordoba J. C., Ripoll M. (2004). Credit Cycles Redux. International Economic Review, Vol. 45, No. 4, pp. 1011-1046.

- Gerali A., Neri S., Sessa L., Signoretti F. M. (2010). Credit and Banking in a DSGE Model of the Euro Area. Journal of Money, Credit and Banking, Vol. 42, No. s1, pp. 107-141.

- Gomme P., Rupert P. (2007). Theory, Measurement and Calibration of Macroeconomic Models. Journal of Monetary Economics, Vol. 54, No. 2, pp. 460-497.

Grui A., Lepushynskyi V., Nikolaychuk S. (2018). A Neutral Real Interest Rate in the Case of a Small Open Economy: Application to Ukraine. Visnyk of the National Bank of Ukraine, No. 243, pp. 4-20. https://doi.org/10.26531/ vnbu2018.243.004
- lacoviello M. (2005). House Prices, Borrowing Constraints, and Monetary Policy in the Business Cycle. American Economic Review, Vol. 95, No. 3, pp. 739-764. https://doi.org/10.1257/0002828054201477

- lacoviello M. (2015). Financial Business Cycles. Review of Economic Dynamics, Vol.18, No, 1, pp, 140-163. https://doi.org/10.1016/j.red.2014.09.003

- lacoviello M., Neri S. (2010). Housing Market Spillovers: Evidence from an Estimated DSGE Model. American Economic Journal: Macroeconomics, Vol. 2, No. 2, pp. 125-164. https://doi.org/10.1257/mac.2.2.125

- Ireland P. N. (2004). Technology Shocks in the New Keynesian model. Review of Economics and Statistics, Vol. 86, No. 4, pp. 923-936.

- Kiyotaki N., Moore J. (1997). Credit Cycles. Journal of Political Economy, Vol. 105, No. 2, pp. 211-248. https://doi.org/10.1086/262072

- Kocherlakota N. (2000). Creating Business Cycles Trough Credit Constraints. Federal Reserve Bank of Minneapolis Quarterly Review, Vol. 24, No. 3, pp. 2-10.

- Liu Z., Wang P., Zha T. (2013). Land-Price Dynamics and Macroeconomic Fluctuations. Econometrica, Vol. 81, No. 3, pp. 1147-1184. https://doi.org/10.3982/ECTA8994

- Maynard K. J. (1931). The Consequences for the Banks of the Collapse of Money Value. Essays in Persuasion, Collected Writtings of J.M.Keynes, Vol. 9, pp. 150-158. https://doi.org/10.1017/UPO9781139524162

- Nizalov D. (2017). Land reform is not beneficial for those who work under shadow schemes. Vox Ukraine. https://voxukraine.org/uk/ekonomika-139-denis-nizalovzemelna-reforma-nevigidna-tim-hto-pratsyuye-za-tinovimishemami/. 


\section{APPENDIX A. OPTIMIZATION PROBLEM OF PATIENT HOUSEHOLDS} IN THE INITIAL MODEL

$$
\mathcal{L}=\mathrm{E}_{0} \sum_{\mathrm{t}=0}^{\infty} \beta^{\mathrm{P}^{\mathrm{t}}}\left(\ln c_{\mathrm{t}}^{\mathrm{p}}+\mathrm{j}_{\mathrm{t}} \ln \mathrm{h}_{\mathrm{t}}^{\mathrm{p}}-\frac{\mathrm{L}_{\mathrm{t}}^{\mathrm{p} \eta}}{\eta}\right)+\lambda_{\mathrm{t}}^{\mathrm{P}}\left(\mathrm{b}_{\mathrm{t}}^{\mathrm{P}}+\mathrm{w}_{\mathrm{t}}^{\mathrm{P}} \mathrm{L}_{\mathrm{t}}^{\mathrm{P}}+\mathrm{r}_{\mathrm{t}}^{\mathrm{P}} \mathrm{Z}^{\mathrm{P}}+\mathrm{F}_{\mathrm{t}}+\mathrm{T}_{\mathrm{t}}^{\mathrm{P}}-c_{\mathrm{t}}^{\mathrm{P}}-\mathrm{q}_{\mathrm{t}}^{\mathrm{h}}\left(\mathrm{h}_{\mathrm{t}}^{\mathrm{P}}-\mathrm{h}_{\mathrm{t}-1}^{\mathrm{P}}\right)-\mathrm{R}_{\mathrm{t}-1} \frac{\mathrm{b}_{\mathrm{t}-1}^{\mathrm{P}}}{\pi_{\mathrm{t}}}\right) .
$$

Labor supply:

$$
L_{t}^{p \eta-1}=\frac{w_{t}^{P}}{c_{t}^{p}}
$$

Housing demand:

$$
\frac{\mathrm{q}_{\mathrm{t}}^{\mathrm{h}}}{c_{\mathrm{t}}^{\mathrm{p}}}=\frac{\mathrm{j}_{\mathrm{t}}}{\mathrm{h}_{\mathrm{t}}^{\mathrm{p}}}+\beta^{\mathrm{P}} \mathrm{E}_{\mathrm{t}} \frac{\mathrm{q}_{\mathrm{t}+1}^{\mathrm{h}}}{c_{\mathrm{t}+1}^{\mathrm{P}}}
$$

Euler equation:

$$
\frac{1}{c_{t}^{P}}=\beta^{P} E_{t} \frac{R_{t}}{c_{t+1}^{P} \pi_{t+1}} .
$$

\section{APPENDIX B. OPTIMIZATION PROBLEM OF IMPATIENT HOUSEHOLDS IN THE INITIAL MODEL}

$$
\mathcal{L}=E_{0} \sum_{t=0}^{\infty} \beta^{I}\left(\ln c_{t}^{I}+j_{t} \ln h_{t}^{I}-\frac{L_{t}^{I \eta}}{\eta}\right)+\lambda_{t}^{I}\left(b_{t}^{I}+w_{t}^{I} L_{t}^{I}+r_{t}^{I} Z^{I}+T_{t}^{I}-c_{t}^{I}-q_{t}^{h}\left(h_{t}^{I}-h_{t-1}^{I}\right)-R_{t-1} \frac{b_{t-1}^{I}}{\pi_{t}}\right)+\mu_{t}^{I}\left(m_{t} \pi_{t+1} q_{t+1}^{\mathrm{h}} h_{t}^{I}-R_{t} b_{t}^{I}\right)
$$

Labor supply:

$$
\mathrm{L}_{\mathrm{t}}^{\mathrm{I}}{ }^{\eta-1}=\frac{\mathrm{w}_{\mathrm{t}}^{\mathrm{I}}}{\mathrm{c}_{\mathrm{t}}^{\mathrm{I}}}
$$

Housing demand:

$$
\frac{q_{t}^{h}}{c_{t}^{\mathrm{h}}}=\frac{j_{t}}{h_{t}^{I}}+\beta^{I} E_{t} \frac{q_{t+1}^{h}}{c_{t+1}^{I}}+\left(\frac{1}{c_{t}^{1} R_{t}}-\beta^{I} E_{t} \frac{1}{c_{t+1}^{I} \pi_{t+1}}\right) E_{t} m_{t}^{I} \pi_{t+1} q_{t+1}^{h} .
$$

\section{APPENDIX C. OPTIMIZATION PROBLEM OF ENTREPRENEURS IN THE INITIAL MODEL}

$$
\begin{aligned}
\mathcal{L}=\mathrm{E}_{0} & \sum_{\mathrm{t}=0}^{\infty} \beta^{\mathrm{E}^{\mathrm{t}}} \ln c_{\mathrm{t}}^{\mathrm{E}}+\lambda_{\mathrm{t}}^{\mathrm{E}}\left(\frac{\mathrm{Y}_{\mathrm{t}}}{\mathrm{X}_{\mathrm{t}}}+\mathrm{b}_{\mathrm{t}}^{\mathrm{E}}-\mathrm{c}_{\mathrm{t}}^{\mathrm{E}}-\mathrm{q}_{\mathrm{t}}^{\mathrm{h}}\left(\mathrm{h}_{\mathrm{t}}^{\mathrm{E}}-\mathrm{h}_{\mathrm{t}-1}^{\mathrm{E}}\right)-\mathrm{R}_{\mathrm{t}-1} \frac{\mathrm{b}_{\mathrm{t}-1}^{\mathrm{E}}}{\pi_{\mathrm{t}}}-\mathrm{w}_{\mathrm{t}}^{\mathrm{I}} \mathrm{L}_{\mathrm{t}}^{\mathrm{I}}-\mathrm{w}_{\mathrm{t}}^{\mathrm{P}} \mathrm{L}_{\mathrm{t}}^{\mathrm{P}}-\mathrm{r}_{\mathrm{t}}^{\mathrm{I}} \mathrm{Z}^{\mathrm{I}}-\mathrm{r}_{\mathrm{t}}^{\mathrm{P}} \mathrm{Z}^{\mathrm{P}}-\mathrm{I}_{\mathrm{t}}-\frac{\psi}{2 \delta}\left(\frac{\mathrm{I}_{\mathrm{t}}}{\mathrm{K}_{\mathrm{t}-1}}-\delta\right)^{2} \mathrm{~K}_{\mathrm{t}-1}\right) \\
& +\mu_{\mathrm{t}}^{\mathrm{E}}\left(\mathrm{m}_{\mathrm{t}} \pi_{\mathrm{t}+1} \mathrm{q}_{\mathrm{t}+1}^{\mathrm{h}} \mathrm{h}_{\mathrm{t}}^{\mathrm{E}}-\mathrm{R}_{\mathrm{t}} \mathrm{b}_{\mathrm{t}}^{\mathrm{E}}\right)+\mathrm{u}_{\mathrm{t}}^{\mathrm{E}}\left(\mathrm{I}_{\mathrm{t}}-\mathrm{K}_{\mathrm{t}}+(1-\delta) \mathrm{K}_{\mathrm{t}-1}\right)+\mathrm{s}_{\mathrm{t}}^{\mathrm{E}}\left(\mathrm{A}_{\mathrm{t}} \mathrm{K}_{\mathrm{t}-1}^{\mathrm{H}} \mathrm{h}_{\mathrm{E}, \mathrm{t}-1}^{\mathrm{v}}\left(\mathrm{Z}_{\mathrm{E}}^{\varphi} \mathrm{Z}_{\mathrm{P}}^{\mathrm{d}} \mathrm{Z}_{\mathrm{I}}^{1-\varphi-\mathrm{d}}\right)^{\mathrm{u}}\left(\mathrm{L}_{\mathrm{P}, \mathrm{L}}^{\alpha} \mathrm{L}_{\mathrm{I}, \mathrm{t}}^{1-\alpha}\right)^{1-\mu-\mathrm{u}-\mathrm{v}}-\mathrm{Y}_{\mathrm{t}}\right) .
\end{aligned}
$$

Patient labor demand:

$$
\mathrm{w}_{\mathrm{t}}^{\mathrm{P}}=\frac{\alpha(1-\mu-\mathrm{v}-\mathrm{u}) \mathrm{Y}_{\mathrm{t}}}{\mathrm{X}_{\mathrm{t}} \mathrm{L}_{\mathrm{t}}^{\mathrm{P}}} .
$$

Impatient labor demand:

$$
w_{t}^{I}=\frac{(1-\alpha)(1-\mu-v-u) Y_{t}}{X_{t} L_{t}^{I}} .
$$

Investment schedule:

$$
\frac{1}{c_{\mathrm{t}}^{\mathrm{E}}}\left(1+\frac{\psi_{K}}{\delta}\left(\frac{\mathrm{I}_{\mathrm{t}}}{\mathrm{K}_{\mathrm{t}-1}}-\delta\right)\right)=E_{t}\left(\frac{\beta^{\mathrm{E}}}{c_{\mathrm{t}+1}^{\mathrm{E}}} \frac{\mu Y_{t+1}}{x_{t+1} K_{t}}+(1-\delta) \frac{\beta^{\mathrm{E}}}{c_{\mathrm{t}+1}^{\mathrm{E}}}\left(1+\frac{\psi_{K}}{\delta}\left(\frac{\mathrm{I}_{\mathrm{t}}}{\mathrm{K}_{\mathrm{t}-1}}-\delta\right)\right)-\frac{1}{c_{\mathrm{t}+1}^{\mathrm{E}}}\left(\frac{\psi_{K}}{2 \delta}\left(\frac{\mathrm{I}_{\mathrm{t}}}{\mathrm{K}_{\mathrm{t}-1}}-\delta\right)-\frac{\psi_{K}}{\delta}\left(\frac{\mathrm{I}_{\mathrm{t}}}{\mathrm{K}_{\mathrm{t}-1}}-\delta\right) \frac{\mathrm{I}_{\mathrm{t}+1}}{\mathrm{~K}_{\mathrm{t}}}\right)\right) .
$$

$$
\frac{\mathrm{q}_{\mathrm{t}}^{\mathrm{E}}}{c_{\mathrm{t}}^{\mathrm{E}}}=\left(\frac{\beta^{\mathrm{E}}}{c_{\mathrm{t}+1}^{\mathrm{E}}} \frac{v Y_{t+1}}{X_{t+1} h_{t}^{E}}+\beta^{\mathrm{E}} \frac{\mathrm{q}_{\mathrm{t}+1}^{\mathrm{h}}}{c_{\mathrm{t}+1}^{\mathrm{E}}}+\left(\frac{1}{c_{\mathrm{t}}^{\mathrm{E}} \mathrm{R}_{\mathrm{t}}}-\beta^{\mathrm{E}} \frac{1}{c_{\mathrm{t}+1}^{\mathrm{E}} \pi_{\mathrm{t}+1}}\right) \mathrm{m}_{\mathrm{t}}^{\mathrm{E}} \pi_{\mathrm{t}+1} \mathrm{q}_{\mathrm{t}+1}^{\mathrm{h}}\right)
$$




\section{APPENDIX D. OPTIMIZATION PROBLEM OF PATIENT HOUSEHOLDS IN THE MODIFIED MODEL}

$\mathcal{L}=E_{0} \sum_{t=0}^{\infty} \beta^{p^{\mathrm{t}}}\left(\ln c_{t}^{\mathrm{p}}+\mathrm{j}_{\mathrm{t}} \ln \mathrm{h}_{\mathrm{t}}^{\mathrm{p}}-\frac{\mathrm{L}_{\mathrm{t}}^{\mathrm{p} \eta}}{\eta}\right)+\lambda_{\mathrm{t}}^{\mathrm{E}}\left(\mathrm{b}_{\mathrm{t}}^{\mathrm{p}}+\mathrm{w}_{\mathrm{t}}^{\mathrm{p}} \mathrm{L}_{\mathrm{t}}^{\mathrm{p}}+\mathrm{r}_{\mathrm{t}}^{\mathrm{P}} \mathrm{Z}_{\mathrm{t}-1}^{\mathrm{p}}+\mathrm{F}_{\mathrm{t}}+\mathrm{T}_{\mathrm{t}}^{\mathrm{p}}-\mathrm{c}_{\mathrm{t}}^{\mathrm{p}}-\mathrm{q}_{\mathrm{t}}^{\mathrm{h}}\left(\mathrm{h}_{\mathrm{t}}^{\mathrm{p}}-\mathrm{h}_{\mathrm{t}-1}^{\mathrm{p}}\right)-\mathrm{q}_{\mathrm{t}}^{\mathrm{Z}}\left(\mathrm{Z}_{\mathrm{t}}^{\mathrm{p}}-\mathrm{Z}_{\mathrm{t}-1}^{\mathrm{p}}\right)-\mathrm{R}_{\mathrm{t}-1} \frac{\mathrm{b}_{\mathrm{t}-1}^{\mathrm{p}}}{\pi_{\mathrm{t}}}\right)$.

Labor supply:

$$
\mathrm{L}_{\mathrm{t}}^{\mathrm{p} \eta-1}=\frac{\mathrm{w}_{\mathrm{t}}^{\mathrm{P}}}{\mathrm{c}_{\mathrm{t}}^{\mathrm{P}}}
$$

Housing demand:

$$
\frac{q_{t}^{h}}{c_{t}^{p}}=\frac{j_{t}}{h_{t}^{p}}+\beta^{P} E_{t} \frac{q_{t+1}^{h}}{c_{t+1}^{P}} .
$$

Euler equation:

$$
\frac{1}{c_{t}^{\mathrm{P}}}=\beta^{\mathrm{P}} \mathrm{E}_{\mathrm{t}} \frac{\mathrm{R}_{\mathrm{t}}}{\mathrm{c}_{\mathrm{t}+1}^{\mathrm{P}} \pi_{\mathrm{t}+1}}
$$

Land-consumption ratio:

$$
\frac{q_{t}^{Z}}{c_{t}^{p}}=\beta^{P} E_{t}\left(\frac{q_{t+1}^{Z}+r_{t+1}^{p}}{c_{t+1}^{P}}\right)
$$

\section{APPENDIX E. OPTIMIZATION PROBLEM OF IMPATIENT HOUSEHOLDS IN THE MODIFIED MODEL}

$$
\begin{aligned}
\mathcal{L}=\mathrm{E}_{0} \sum_{\mathrm{t}=0}^{\infty} \beta^{\mathrm{I}^{\mathrm{t}}}\left(\ln \mathrm{c}_{\mathrm{t}}^{\mathrm{I}}+\mathrm{j}_{\mathrm{t}} \ln \mathrm{h}_{\mathrm{t}}^{\mathrm{I}}-\frac{\mathrm{L}_{\mathrm{t}}^{\mathrm{I}}}{\eta}\right) & +\lambda_{\mathrm{t}}^{\mathrm{I}}\left(\mathrm{b}_{\mathrm{t}}^{\mathrm{I}}+\mathrm{w}_{\mathrm{t}}^{\mathrm{I}} \mathrm{L}_{\mathrm{t}}^{\mathrm{I}}+\mathrm{r}_{\mathrm{t}}^{\mathrm{I}} \mathrm{Z}^{\mathrm{I}}+\mathrm{T}_{\mathrm{t}}^{\mathrm{I}}-\mathrm{c}_{\mathrm{t}}^{\mathrm{I}}-\mathrm{q}_{\mathrm{t}}^{\mathrm{h}}\left(\mathrm{h}_{\mathrm{t}}^{\mathrm{I}}-\mathrm{h}_{\mathrm{t}-1}^{\mathrm{I}}\right)-\mathrm{q}_{\mathrm{t}}^{\mathrm{Z}}\left(\mathrm{Z}_{\mathrm{t}}^{\mathrm{I}}-\mathrm{Z}_{\mathrm{t}-1}^{\mathrm{I}}\right)-\mathrm{R}_{\mathrm{t}-1} \frac{\mathrm{b}_{\mathrm{t}-1}^{\mathrm{I}}}{\pi_{\mathrm{t}}}\right) \\
& +\mu_{\mathrm{t}}^{\mathrm{I}}\left(\mathrm{m}_{\mathrm{t}} \pi_{\mathrm{t}+1}\left(\mathrm{q}_{\mathrm{t}+1}^{\mathrm{h}} \mathrm{h}_{\mathrm{t}}^{\mathrm{I}}+\mathrm{q}_{\mathrm{t}+1}^{\mathrm{Z}} \mathrm{Z}_{\mathrm{t}}^{\mathrm{I}}\right)-\mathrm{R}_{\mathrm{t}} \mathrm{b}_{\mathrm{t}}^{\mathrm{I}}\right) .
\end{aligned}
$$

Labor supply:

$$
L_{t}^{I^{\eta-1}}=\frac{w_{t}^{I}}{c_{t}^{I}}
$$

Housing demand:

$$
\frac{\mathrm{q}_{\mathrm{t}}^{\mathrm{h}}}{c_{\mathrm{t}}^{\mathrm{I}}}=\frac{j_{\mathrm{t}}}{\mathrm{h}_{\mathrm{t}}^{\mathrm{I}}}+\beta^{\mathrm{I}} \mathrm{E}_{\mathrm{t}} \frac{\mathrm{q}_{\mathrm{t}+1}^{\mathrm{h}}}{c_{\mathrm{t}+1}^{\mathrm{I}}}+\left(\frac{1}{c_{\mathrm{t}}^{\mathrm{I}} \mathrm{R}_{\mathrm{t}}}-\beta^{\mathrm{I}} \mathrm{E}_{\mathrm{t}} \frac{1}{c_{\mathrm{t}+1}^{\mathrm{I}} \pi_{\mathrm{t}+1}}\right) \mathrm{E}_{\mathrm{t}} \mathrm{m}_{\mathrm{t}} \pi_{\mathrm{t}+1} \mathrm{q}_{\mathrm{t}+1}^{\mathrm{h}} .
$$

Land-consumption ratio:

$$
\frac{\mathrm{q}_{\mathrm{t}}^{\mathrm{Z}}}{\mathrm{c}_{\mathrm{t}}^{\mathrm{I}}}=\beta^{\mathrm{I}} \mathrm{E}_{\mathrm{t}}\left(\frac{\mathrm{q}_{\mathrm{t}+1}^{\mathrm{Z}}+\mathrm{r}_{\mathrm{t}+1}^{\mathrm{I}}}{\mathrm{c}_{\mathrm{t}+1}^{\mathrm{I}}}\right)+\left(\frac{1}{c_{\mathrm{t}}^{\mathrm{I}} \mathrm{R}_{\mathrm{t}}}-\beta^{\mathrm{I}} \mathrm{E}_{\mathrm{t}} \frac{1}{c_{\mathrm{t}+1}^{\mathrm{I}} \pi_{\mathrm{t}+1}}\right) \mathrm{E}_{\mathrm{t}} \mathrm{m}_{\mathrm{t}} \pi_{\mathrm{t}+1} \mathrm{q}_{\mathrm{t}+1}^{\mathrm{Z}} .
$$




\section{APPENDIX F. OPTIMIZATION PROBLEM OF ENTREPRENEURS IN THE MODIFIED MODEL}

$$
\begin{gathered}
\mathcal{L}=\mathrm{E}_{0} \sum_{\mathrm{t}=0}^{\infty} \beta^{\mathrm{E}^{\mathrm{t}}} \ln c_{\mathrm{t}}^{\mathrm{E}} \\
+\lambda_{\mathrm{t}}^{\mathrm{E}}\left(\frac{\mathrm{Y}_{\mathrm{t}}}{\mathrm{X}_{\mathrm{t}}}+\mathrm{b}_{\mathrm{t}}^{\mathrm{E}}-\mathrm{c}_{\mathrm{t}}^{\mathrm{E}}-\mathrm{q}_{\mathrm{t}}^{\mathrm{h}}\left(\mathrm{h}_{\mathrm{t}}^{\mathrm{E}}-\mathrm{h}_{\mathrm{t}-1}^{\mathrm{E}}\right)-\mathrm{q}_{\mathrm{t}}^{\mathrm{Z}}\left(\mathrm{Z}_{\mathrm{t}}^{\mathrm{E}}-\mathrm{Z}_{\mathrm{t}-1}^{\mathrm{E}}\right)-\mathrm{R}_{\mathrm{t}-1} \frac{\mathrm{b}_{\mathrm{t}-1}^{\mathrm{E}}}{\pi_{\mathrm{t}}}-\mathrm{w}_{\mathrm{t}}^{\mathrm{I}} \mathrm{L}_{\mathrm{t}}^{\mathrm{L}}-\mathrm{w}_{\mathrm{t}}^{\mathrm{P}} \mathrm{L}_{\mathrm{t}}^{\mathrm{P}}-\mathrm{r}_{\mathrm{t}}^{\mathrm{L}} \mathrm{Z}_{\mathrm{t}-1}^{\mathrm{L}}+\mathrm{r}_{\mathrm{t}}^{\mathrm{P}} \mathrm{Z}_{\mathrm{t}-1}^{\mathrm{P}}-\mathrm{I}_{\mathrm{t}}-\frac{\psi}{2 \delta}\left(\frac{\mathrm{I}_{\mathrm{t}}}{\mathrm{K}_{\mathrm{t}-1}}-\delta\right)^{2} \mathrm{~K}_{\mathrm{t}-1}\right) \\
+\mu_{\mathrm{t}}^{\mathrm{E}}\left(\mathrm{m}_{\mathrm{t}} \pi_{\mathrm{t}+1}\left(\mathrm{q}_{\mathrm{t}+1}^{\mathrm{h}} \mathrm{h}_{\mathrm{t}}^{\mathrm{E}}+\mathrm{q}_{\mathrm{t}+1}^{\mathrm{Z}} \mathrm{Z}_{\mathrm{t}}^{\mathrm{E}}\right)-\mathrm{R}_{\mathrm{t}} \mathrm{b}_{\mathrm{t}}^{\mathrm{E}}\right)+\mathrm{u}_{\mathrm{t}}^{\mathrm{E}}\left(\mathrm{I}_{\mathrm{t}}-\mathrm{K}_{\mathrm{t}}+(1-\delta) \mathrm{K}_{\mathrm{t}-1}\right)+\mathrm{s}_{\mathrm{t}}^{\mathrm{E}}\left(\mathrm{A}_{\mathrm{t}} \mathrm{K}_{\mathrm{t}-1}^{\mathrm{\mu}} \mathrm{h}_{\mathrm{E}, \mathrm{t}-1}^{\mathrm{v}}\left(\mathrm{Z}_{\mathrm{E}, t-1}^{\varphi} \mathrm{Z}_{\mathrm{P}, \mathrm{t}-1}^{\mathrm{d}} \mathrm{Z}_{\mathrm{t}, \mathrm{t}-1}^{1-\varphi-\mathrm{d}}\right)^{\mathrm{u}}\left(\mathrm{L}_{\mathrm{P}, \mathrm{t}}^{\alpha} \mathrm{L}_{\mathrm{L}, \mathrm{t}}^{1-\alpha}\right)^{1-\mu-\mathrm{u}-\mathrm{v}}-\mathrm{Y}_{\mathrm{t}}\right) .
\end{gathered}
$$

Demand for patient households' labor:

$$
w_{t}^{\mathrm{P}}=\frac{\alpha(1-\mu-v-u) Y_{t}}{X_{t} L_{t}^{P}}
$$

Demand for impatienthouseholds'labor:

$$
\mathrm{W}_{\mathrm{t}}^{\mathrm{I}}=\frac{(1-\alpha)(1-\mu-\mathrm{v}-\mathrm{u}) \mathrm{Y}_{\mathrm{t}}}{\mathrm{X}_{\mathrm{t}} \mathrm{L}_{\mathrm{t}}^{\mathrm{I}}}
$$

Demand for patient households' land:

$$
r_{t+1}^{P}=\frac{d u Y_{t+1}}{X_{t+1} z_{t}^{P}}
$$

Demand for impatient households' land:

$$
r_{t+1}^{I}=\frac{(1-\varphi-d) u Y_{t+1}}{X_{t+1} Z_{t}^{I}}
$$

Land-consumption relation: $\quad \frac{\mathrm{q}_{\mathrm{t}}^{\mathrm{Z}}}{\mathrm{c}_{\mathrm{t}}^{\mathrm{E}}}=\left(\frac{\beta^{\mathrm{E}}}{c_{\mathrm{t}+1}^{\mathrm{E}}} \frac{\varphi u Y_{t+1}}{X_{t+1} Z_{t}^{E}}+\beta^{\mathrm{E}} \frac{\mathrm{q}_{\mathrm{t}+1}^{\mathrm{Z}}}{c_{\mathrm{t}+1}^{\mathrm{E}}}+\left(\frac{1}{c_{\mathrm{t}}^{\mathrm{E}} \mathrm{R}_{\mathrm{t}}}-\beta^{\mathrm{E}} \frac{1}{c_{\mathrm{t}+1}^{\mathrm{E}} \pi_{\mathrm{t}+1}}\right) \mathrm{m}_{\mathrm{t}} \pi_{\mathrm{t}+1} \mathrm{q}_{\mathrm{t}+1}^{\mathrm{Z}}\right)$.

Optimal investment schedule:

$$
\frac{1}{c_{\mathrm{t}}^{\mathrm{E}}}\left(1+\frac{\psi_{K}}{\delta}\left(\frac{\mathrm{I}_{\mathrm{t}}}{\mathrm{K}_{\mathrm{t}-1}}-\delta\right)\right)=E_{t}\left(\frac{\beta^{\mathrm{E}}}{\mathrm{c}_{\mathrm{t}+1}^{\mathrm{E}}} \frac{\mu Y_{t+1}}{X_{t+1} K_{t}}+(1-\delta) \frac{\beta^{\mathrm{E}}}{\mathrm{c}_{\mathrm{t}+1}^{\mathrm{E}}}\left(1+\frac{\psi_{K}}{\delta}\left(\frac{\mathrm{I}_{\mathrm{t}}}{\mathrm{K}_{\mathrm{t}-1}}-\delta\right)\right)-\frac{1}{\mathrm{c}_{\mathrm{t}+1}^{\mathrm{E}}}\left(\frac{\psi_{K}}{2 \delta}\left(\frac{\mathrm{I}_{\mathrm{t}}}{\mathrm{K}_{\mathrm{t}-1}}-\delta\right)-\frac{\psi_{K}}{\delta}\left(\frac{\mathrm{I}_{\mathrm{t}}}{\mathrm{K}_{\mathrm{t}-1}}-\delta\right) \frac{\mathrm{I}_{\mathrm{t}+1}}{\mathrm{~K}_{\mathrm{t}}}\right)\right) .
$$

Housing-consumption relation: $\frac{q_{t}^{\mathrm{h}}}{c_{\mathrm{t}}^{\mathrm{E}}}=\left(\frac{\beta^{\mathrm{E}}}{c_{\mathrm{t}+1}^{\mathrm{E}}} \frac{v Y_{t+1}}{X_{t+1} h_{t}^{E}}+\beta^{\mathrm{E}} \frac{\mathrm{q}_{\mathrm{t}+1}^{\mathrm{h}}}{c_{\mathrm{t}+1}^{\mathrm{E}}}+\left(\frac{1}{c_{\mathrm{t}}^{\mathrm{E}} \mathrm{R}_{\mathrm{t}}}-\beta^{\mathrm{E}} \frac{1}{c_{\mathrm{t}+1}^{\mathrm{E}} \pi_{\mathrm{t}+1}}\right) \mathrm{m}_{\mathrm{t}} \pi_{\mathrm{t}+1} \mathrm{q}_{\mathrm{t}+1}^{\mathrm{h}}\right)$. 
APPENDIX G. THE STEADY-STATE RATIOS OF THE FINAL MODEL

$$
\begin{gathered}
\frac{I}{Y}=\frac{\beta^{e} \mu}{\left(1-\beta^{e}-\delta \beta^{e}\right) X} \delta \stackrel{\text { def }}{=} \xi_{1} \delta \\
\frac{q^{h} h^{E}}{Y}=\frac{\beta^{E} v}{X\left(1-\beta^{E}-m \beta^{P}+\beta^{E} m\right)} \stackrel{\text { def }}{=} \xi_{5} \\
\frac{q^{h} h^{P}}{Y}=\frac{j}{\left(1-\beta^{P}\right)} \frac{c^{p}}{Y} \stackrel{\text { def }}{=} \xi_{6} \frac{c^{p}}{Y} \\
\frac{c^{\mathrm{h}} h^{I}}{Y}=\frac{\mu+\vartheta+\varphi u}{X}+\left(\beta^{P}-1\right) m \xi_{5}-\xi_{1} \delta \\
\frac{c^{I}}{Y}=\frac{((1-\alpha)(1-\mu-v-u)+(1-\varphi-t) u)}{X\left(1-\left(\beta^{P}-1\right) m \xi_{7}\right)} \\
\frac{\left.c^{P}+\beta^{I} m\right) \frac{c^{I}}{Y} \stackrel{\text { def }}{=} \xi_{7} \frac{c^{I}}{Y}}{Y}=1-\frac{c^{I}}{Y}-\frac{c^{E}}{Y}-\frac{I}{Y} .
\end{gathered}
$$




\section{APPENDIX H. EQUILIBRIUM DYNAMICS FOR THE INITIAL MODEL}

$$
\begin{aligned}
& \widetilde{Y}_{t}=\frac{c^{E}}{Y} \tilde{c}_{t}^{E}+\frac{c^{P}}{Y} \tilde{c}_{t}^{p}+\frac{c^{I}}{Y} \tilde{c}_{t}^{I}+\frac{I}{Y} \tilde{I}_{t} \\
& \tilde{c}_{t+1}^{\mathrm{P}}=\tilde{c}_{\mathrm{t}}^{\mathrm{P}}+\widetilde{\mathrm{R}}_{\mathrm{t}}-\widetilde{\pi}_{\mathrm{t}+1} \\
& \tilde{\mathrm{q}}_{t}^{\mathrm{h}}=\beta^{\mathrm{P}} \tilde{\mathrm{q}}_{\mathrm{t}+1}^{\mathrm{h}}+\tilde{\mathrm{c}}_{\mathrm{t}}^{\mathrm{P}}-\beta^{\mathrm{P}} \tilde{\mathrm{c}}_{\mathrm{t}+1}^{\mathrm{P}}+\left(1-\beta^{\mathrm{P}}\right)\left(\tilde{\mathrm{I}}_{\mathrm{t}}+\frac{\mathrm{h}^{\mathrm{E}}}{\mathrm{h}^{\mathrm{P}}} \tilde{\mathrm{h}}_{\mathrm{t}}^{\mathrm{E}}+\frac{\mathrm{h}^{\mathrm{I}}}{\mathrm{h}^{\mathrm{P}}} \tilde{\mathrm{h}}_{\mathrm{t}}^{\mathrm{I}}\right) \\
& \tilde{\mathrm{q}}_{\mathrm{t}}^{\mathrm{h}}=\gamma_{\mathrm{h}} \tilde{\mathrm{q}}_{\mathrm{t}+1}^{\mathrm{h}}+\left(1-\gamma_{\mathrm{h}}\right)\left(\tilde{\mathrm{y}}_{\mathrm{t}}-\tilde{\mathrm{h}}_{\mathrm{t}}^{\mathrm{I}}\right)+\left(1-\beta^{\mathrm{P}} \mathrm{m}\right) \tilde{\mathrm{c}}_{\mathrm{t}}^{\mathrm{I}}+\left(\beta^{\mathrm{I}} \mathrm{m}-\beta^{\mathrm{P}}\right) \tilde{\mathrm{c}}_{\mathrm{t}+1}^{\mathrm{I}}+\beta^{\mathrm{P}} \mathrm{m}\left(\widetilde{\pi}_{\mathrm{t}+1}-\widetilde{\mathrm{R}}_{\mathrm{t}}\right)+\mathrm{m}\left(\beta^{\mathrm{P}}-\beta^{\mathrm{I}}\right) \widetilde{\mathrm{m}}_{\mathrm{t}} \\
& \tilde{\mathrm{q}}_{\mathrm{t}}^{\mathrm{h}}=\gamma_{\mathrm{e}} \tilde{\mathrm{q}}_{\mathrm{t}+1}^{\mathrm{h}}+\left(1-\gamma_{\mathrm{e}}\right)\left(\widetilde{\mathrm{Y}}_{\mathrm{t}+1}-\widetilde{\mathrm{X}}_{\mathrm{t}+1}-\tilde{\mathrm{h}}_{\mathrm{t}}^{\mathrm{E}}\right)-\left(1-\beta^{\mathrm{P}} \mathrm{m}\right)\left(\tilde{\mathrm{c}}_{\mathrm{t}+1}^{\mathrm{E}}-\tilde{\mathrm{c}}_{\mathrm{t}}^{\mathrm{E}}\right)-\beta^{\mathrm{P}} \mathrm{m}\left(\widetilde{\mathrm{R}}_{\mathrm{t}}-\widetilde{\pi}_{t+1}\right)+\mathrm{m}\left(\beta^{\mathrm{E}}-\beta^{\mathrm{I}}\right) \widetilde{\mathrm{m}}_{\mathrm{t}} \\
& \widetilde{\mathrm{K}}_{\mathrm{t}}=(1-\delta) \widetilde{\mathrm{K}}_{\mathrm{t}-1}+\delta \tilde{\mathrm{I}}_{\mathrm{t}} \\
& \tilde{\mathrm{b}}_{\mathrm{t}}^{\mathrm{E}}=\widetilde{\mathrm{m}}_{\mathrm{t}}+\tilde{\mathrm{q}}_{\mathrm{t}+1}^{\mathrm{h}}+\widetilde{\mathrm{h}}_{\mathrm{t}}^{\mathrm{E}}+\widetilde{\pi}_{\mathrm{t}+1}-\widetilde{\mathrm{R}}_{\mathrm{t}} \\
& \widetilde{\mathrm{b}}_{\mathrm{t}}^{\mathrm{I}}=\widetilde{\mathrm{m}}_{\mathrm{t}}+\tilde{\mathrm{q}}_{\mathrm{t}+1}^{\mathrm{h}}+\tilde{\mathrm{h}}_{\mathrm{t}}^{\mathrm{I}}+\widetilde{\pi}_{\mathrm{t}+1}-\widetilde{\mathrm{R}}_{\mathrm{t}} \\
& \frac{((1-\alpha)(1-\mu-v-u)+(1-\varphi-d) u) Y}{X}\left(\widetilde{Y}_{t}-\widetilde{X}_{t}\right)+b^{I} \tilde{b}_{t}^{I}=c^{I} \widetilde{c}_{t}^{I}+q^{h} h^{I}\left(\widetilde{h}_{t}^{I}-\tilde{h}_{t-1}^{I}\right)+R b^{I}\left(\tilde{b}_{t-1}^{I}-\widetilde{\pi}_{t}+\widetilde{R}_{t-1}\right) \\
& \frac{(\mu+v+\varphi u) Y}{X}\left(\tilde{Y}_{t}-\tilde{X}_{t}\right)+b^{E} \tilde{b}_{t}^{E}=c^{E} \tilde{c}_{t}^{E}+q^{h} \mathrm{~h}^{\mathrm{E}}\left(\tilde{\mathrm{h}}_{\mathrm{t}}^{\mathrm{E}}-\tilde{\mathrm{h}}_{\mathrm{t}-1}^{\mathrm{E}}\right)+\mathrm{Rb}^{\mathrm{E}}\left(\tilde{b}_{t-1}^{E}-\tilde{\pi}_{t}+\tilde{R}_{t-1}\right)+I \tilde{I}_{t} \\
& \tilde{Y}_{t}=\frac{\eta}{\eta-1+\mu+u+v}\left(\tilde{A}_{t}+\mu \widetilde{K}_{t-1}+v \tilde{h}_{t-1}^{E}\right)-\frac{1-\mu-v-u}{\eta-1+\mu+u+v}\left(\tilde{X}_{t}+\alpha \tilde{c}_{t}^{P}+(1-\alpha) \tilde{c}_{t}^{I}\right) \\
& \tilde{\pi}_{t}=\beta^{\mathrm{P}} E_{t} \tilde{\pi}_{t+1}+\frac{(1-\theta)\left(1-\beta^{\mathrm{P}} \theta\right)}{\theta} \tilde{X}_{t} \\
& \tilde{R}_{t}=r_{R} \tilde{R}_{t-1}+\left(1-r_{R}\right)\left(\left(1+r_{\pi}\right) \tilde{\pi}_{t-1}+r_{Y} \tilde{Y}_{t-1}\right)+\tilde{e}_{R, t} \\
& \widetilde{\mathrm{A}}_{\mathrm{t}}=\rho_{\mathrm{A}} \widetilde{\mathrm{A}}_{\mathrm{t}-1}+\widetilde{\varepsilon}_{\mathrm{A}, \mathrm{t}} \\
& \tilde{\mathrm{j}}_{\mathrm{t}}=\rho_{\mathrm{h}} \tilde{\mathrm{t}}_{\mathrm{t}-1}+\tilde{\varepsilon}_{\mathrm{h}, \mathrm{t}} \\
& \tilde{\mathrm{e}}_{\mathrm{R}, \mathrm{t}}=\rho_{\mathrm{e}} \tilde{\mathrm{e}}_{\mathrm{R}, \mathrm{t}-1}+\tilde{\varepsilon}_{\mathrm{R}, \mathrm{t}} \\
& \widetilde{\mathrm{m}}_{\mathrm{t}}=\rho_{\mathrm{m}} \widetilde{\mathrm{m}}_{\mathrm{t}-1}+\tilde{\varepsilon}_{\mathrm{m}, \mathrm{t}} \\
& \text { where } \gamma_{h}=\beta^{\mathrm{I}}+\beta^{\mathrm{P}} \mathrm{m}-\beta^{\mathrm{I}} \mathrm{m}, \gamma_{e}=\beta^{\mathrm{E}}+\beta^{\mathrm{P}} \mathrm{m}-\beta^{\mathrm{E}} \mathrm{m}
\end{aligned}
$$


APPENDIX I. THE STEADY-STATE RATIOS OF THE MODIFIED MODEL

$$
\begin{aligned}
& \frac{\mathrm{I}}{\mathrm{Y}}=\frac{\beta^{\mathrm{e}} \mu}{\left(1-\beta^{\mathrm{e}}-\delta \beta^{\mathrm{e}}\right) \mathrm{X}} \delta \stackrel{\text { def }}{=} \xi_{1} \delta \\
& \frac{\mathrm{q}^{\mathrm{z}} \mathrm{Z}^{\mathrm{P}}}{\mathrm{Y}}=\frac{\mathrm{du}}{\mathrm{X}\left(1-\beta^{\mathrm{P}}\right)} \stackrel{\text { def }}{=} \xi_{2} \\
& \frac{\mathrm{q}^{\mathrm{Z}} \mathrm{Z}^{\mathrm{I}}}{\mathrm{Y}}=\frac{\beta^{\mathrm{P}}(1-\varphi-\mathrm{d}) \mathrm{u}}{\mathrm{X}\left(1-\beta^{\mathrm{I}}-\mathrm{m} \beta^{\mathrm{P}}+\beta^{\mathrm{I}} \mathrm{m}\right)} \stackrel{\text { def }}{=} \xi_{3} \\
& \frac{\mathrm{q}^{\mathrm{z}} \mathrm{Z}^{\mathrm{e}}}{\mathrm{Y}}=\frac{\beta^{\mathrm{E}} \varphi \mathrm{u}}{\mathrm{X}\left(1-\beta^{\mathrm{E}}-\mathrm{m} \beta^{\mathrm{P}}+\beta^{\mathrm{E}} \mathrm{m}\right)} \stackrel{\text { def }}{=} \xi_{4} \\
& \frac{\mathrm{q}^{\mathrm{h}} \mathrm{h}^{\mathrm{E}}}{\mathrm{Y}}=\frac{\beta^{\mathrm{E}} \mathrm{v}}{\mathrm{X}\left(1-\beta^{\mathrm{E}}-\mathrm{m} \beta^{\mathrm{P}}+\beta^{\mathrm{E}} \mathrm{m}\right)} \stackrel{\text { def }}{=} \xi_{5} \\
& \frac{\mathrm{q}^{\mathrm{h}} \mathrm{h}^{\mathrm{P}}}{\mathrm{Y}}=\frac{\mathrm{j}}{\left(1-\beta^{\mathrm{P}}\right)} \frac{\mathrm{c}^{\mathrm{p}}}{\mathrm{Y}} \stackrel{\text { def }}{=} \xi_{6} \frac{\mathrm{c}^{\mathrm{p}}}{\mathrm{Y}} \\
& \frac{q^{\mathrm{h}} h^{\mathrm{I}}}{\mathrm{Y}}=\frac{j}{\left(1-\beta^{\mathrm{I}}-\mathrm{m} \beta^{\mathrm{P}}+\beta^{\mathrm{I}} \mathrm{m}\right)} \frac{\mathrm{c}^{\mathrm{I}}}{\mathrm{Y}} \stackrel{\text { def }}{=} \xi_{7} \frac{\mathrm{c}^{\mathrm{I}}}{\mathrm{Y}} \\
& \frac{c^{\mathrm{E}}}{\mathrm{Y}}=\frac{\mu+\vartheta+\varphi \mathrm{u}}{\mathrm{X}}+\left(\beta^{\mathrm{P}}-1\right) \mathrm{m}\left(\xi_{4}+\xi_{5}\right)-\xi_{1} \delta \\
& \frac{c^{\mathrm{I}}}{\mathrm{Y}}=\frac{((1-\alpha)(1-\mu-v-u)+(1-\varphi-t) u)+X\left(\beta^{\mathrm{P}}-1\right) \mathrm{m} \xi_{3}}{\mathrm{X}\left(1-\left(\beta^{\mathrm{P}}-1\right) \mathrm{m} \xi_{7}\right)} \\
& \frac{c^{\mathrm{P}}}{\mathrm{Y}}=1-\frac{\mathrm{c}^{\mathrm{I}}}{\mathrm{Y}}-\frac{\mathrm{c}^{\mathrm{E}}}{\mathrm{Y}}-\frac{\mathrm{I}}{\mathrm{Y}}
\end{aligned}
$$




\section{APPENDIX J. EQUILIBRIUM DYNAMICS FOR THE MODIFIED MODEL}

$$
\begin{aligned}
& \widetilde{Y}_{t}=\frac{c^{E}}{Y} \tilde{c}_{t}^{E}+\frac{c^{P}}{Y} \tilde{c}_{t}^{p}+\frac{c^{I}}{Y} \tilde{c}_{t}^{I}+\frac{I}{Y} \tilde{I}_{t} \\
& \widetilde{c}_{t+1}^{\mathrm{P}}=\widetilde{\mathrm{c}}_{\mathrm{t}}^{\mathrm{P}}+\widetilde{\mathrm{R}}_{\mathrm{t}}-\widetilde{\pi}_{\mathrm{t}+1} \\
& \tilde{\mathrm{q}}_{\mathrm{t}}^{\mathrm{h}}=\beta^{\mathrm{P}} \tilde{\mathrm{q}}_{\mathrm{t}+1}^{\mathrm{h}}+\tilde{\mathrm{c}}_{\mathrm{t}}^{\mathrm{P}}-\beta^{\mathrm{P}} \tilde{\mathrm{c}}_{\mathrm{t}+1}^{\mathrm{P}}+\left(1-\beta^{\mathrm{P}}\right)\left(\tilde{\mathrm{j}}_{\mathrm{t}}+\frac{\mathrm{h}^{\mathrm{E}}}{\mathrm{h}^{\mathrm{P}}} \tilde{\mathrm{h}}_{\mathrm{t}}^{\mathrm{E}}+\frac{\mathrm{h}^{\mathrm{I}}}{\mathrm{h}^{\mathrm{P}}} \tilde{\mathrm{h}}_{\mathrm{t}}^{\mathrm{I}}\right) \\
& \tilde{\mathrm{q}}_{\mathrm{t}}^{\mathrm{Z}}=\beta^{\mathrm{P}} \widetilde{\mathrm{q}}_{\mathrm{t}+1}^{\mathrm{Z}}+\widetilde{\mathrm{c}}_{\mathrm{t}}^{\mathrm{P}}-\beta^{\mathrm{P}} \widetilde{\mathrm{c}}_{\mathrm{t}+1}^{\mathrm{P}}+\left(1-\beta^{\mathrm{P}}\right)\left(\widetilde{\mathrm{Y}}_{\mathrm{t}+1}-\widetilde{\mathrm{X}}_{\mathrm{t}+1}+\frac{\mathrm{Z}^{\mathrm{E}}}{\mathrm{Z}^{\mathrm{P}}} \widetilde{\mathrm{Z}}_{\mathrm{t}}^{\mathrm{E}}+\frac{\mathrm{Z}^{\mathrm{I}}}{\mathrm{Z}^{\mathrm{P}}} \widetilde{\mathrm{Z}}_{\mathrm{t}}^{\mathrm{I}}\right) \\
& \tilde{\mathrm{q}}_{\mathrm{t}}^{\mathrm{h}}=\gamma_{\mathrm{h}} \tilde{\mathrm{q}}_{\mathrm{t}+1}^{\mathrm{h}}+\left(1-\gamma_{\mathrm{h}}\right)\left(\tilde{\mathrm{j}}_{\mathrm{t}}-\tilde{\mathrm{h}}_{\mathrm{t}}^{\mathrm{I}}\right)+\left(1-\beta^{\mathrm{P}} \mathrm{m}\right) \tilde{\mathrm{c}}_{\mathrm{t}}^{\mathrm{I}}+\left(\beta^{\mathrm{I}} \mathrm{m}-\beta^{\mathrm{P}}\right) \tilde{\mathrm{c}}_{\mathrm{t}+1}^{\mathrm{I}}+\beta^{\mathrm{P}} \mathrm{m}\left(\widetilde{\pi}_{\mathrm{t}+1}-\widetilde{\mathrm{R}}_{\mathrm{t}}\right)+\mathrm{m}\left(\beta^{\mathrm{P}}-\beta^{\mathrm{I}}\right) \widetilde{\mathrm{m}}_{\mathrm{t}} \\
& \tilde{\mathrm{q}}_{\mathrm{t}}^{\mathrm{Z}}=\gamma_{\mathrm{h}} \tilde{\mathrm{q}}_{\mathrm{t}+1}^{\mathrm{Z}}+\left(1-\gamma_{\mathrm{h}}\right)\left(\widetilde{\mathrm{Y}}_{\mathrm{t}+1}-\widetilde{\mathrm{X}}_{\mathrm{t}+1}-\widetilde{\mathrm{Z}}_{\mathrm{t}}^{\mathrm{I}}\right)+\left(1-\beta^{\mathrm{P}} \mathrm{m}\right) \tilde{\mathrm{c}}_{\mathrm{t}}^{\mathrm{I}}+\left(\beta^{\mathrm{I}} \mathrm{m}-\beta^{\mathrm{P}}\right) \tilde{\mathrm{c}}_{\mathrm{t}+1}^{\mathrm{I}}+\beta^{\mathrm{P}} \mathrm{m}\left(\widetilde{\pi}_{\mathrm{t}+1}-\widetilde{\mathrm{R}}_{\mathrm{t}}\right)+\mathrm{m}\left(\beta^{\mathrm{P}}-\beta^{\mathrm{I}}\right) \widetilde{\mathrm{m}}_{\mathrm{t}} \\
& \tilde{\mathrm{q}}_{\mathrm{t}}^{\mathrm{h}}=\gamma_{\mathrm{e}} \tilde{\mathrm{q}}_{\mathrm{t}+1}^{\mathrm{h}}+\left(1-\gamma_{\mathrm{e}}\right)\left(\widetilde{\mathrm{Y}}_{\mathrm{t}+1}-\widetilde{\mathrm{X}}_{\mathrm{t}+1}-\tilde{\mathrm{h}}_{\mathrm{t}}^{\mathrm{E}}\right)-\left(1-\beta^{\mathrm{P}} \mathrm{m}\right)\left(\widetilde{c}_{\mathrm{t}+1}^{\mathrm{E}}-\tilde{c}_{\mathrm{t}}^{\mathrm{E}}\right)-\beta^{\mathrm{P}} \mathrm{m}\left(\widetilde{\mathrm{R}}_{\mathrm{t}}-\widetilde{\pi}_{\mathrm{t}+1}\right)+\mathrm{m}\left(\beta^{\mathrm{E}}-\beta^{\mathrm{I}}\right) \widetilde{\mathrm{m}}_{\mathrm{t}} \\
& \widetilde{\mathrm{K}}_{\mathrm{t}}=(1-\delta) \widetilde{\mathrm{K}}_{\mathrm{t}-1}+\delta \tilde{\mathrm{I}}_{\mathrm{t}} \\
& \mathrm{Rb}^{\mathrm{E}}\left(\tilde{\mathrm{b}}_{\mathrm{t}}^{\mathrm{E}}+\widetilde{\mathrm{R}}_{\mathrm{t}}\right)=m q^{\mathrm{h}} \mathrm{h}^{\mathrm{E}}\left(\widetilde{\mathrm{m}}_{\mathrm{t}}+\tilde{\mathrm{q}}_{\mathrm{t}+1}^{\mathrm{h}}+\tilde{\mathrm{h}}_{\mathrm{t}}^{\mathrm{E}}+\widetilde{\pi}_{\mathrm{t}+1}\right)+m q^{\mathrm{Z}} \mathrm{Z}^{\mathrm{E}}\left(\widetilde{\mathrm{m}}_{\mathrm{t}}+\widetilde{\mathrm{q}}_{\mathrm{t}+1}^{\mathrm{Z}}+\tilde{\mathrm{Z}}_{\mathrm{t}}^{\mathrm{E}}+\widetilde{\pi}_{\mathrm{t}+1}\right) \\
& \mathrm{Rb}^{\mathrm{I}}\left(\tilde{\mathrm{b}}_{\mathrm{t}}^{\mathrm{I}}+\widetilde{\mathrm{R}}_{\mathrm{t}}\right)=m q^{\mathrm{h}} \mathrm{h}^{\mathrm{I}}\left(\widetilde{\mathrm{m}}_{\mathrm{t}}+\tilde{\mathrm{q}}_{\mathrm{t}+1}^{\mathrm{h}}+\widetilde{\mathrm{h}}_{\mathrm{t}}^{\mathrm{I}}+\widetilde{\pi}_{\mathrm{t}+1}\right)+m q^{\mathrm{Z}} \mathrm{Z}^{\mathrm{I}}\left(\widetilde{\mathrm{m}}_{\mathrm{t}}+\tilde{\mathrm{q}}_{\mathrm{t}+1}^{\mathrm{Z}}+\widetilde{\mathrm{Z}}_{\mathrm{t}}^{\mathrm{I}}+\widetilde{\pi}_{\mathrm{t}+1}\right) \\
& \frac{((1-\alpha)(1-\mu-v-u)+(1-\varphi-d) u) Y}{X}\left(\widetilde{Y}_{t}-\widetilde{X}_{t}\right)+b^{I} \tilde{b}_{t}^{I} \\
& =c^{I} \tilde{c}_{t}^{I}+q^{h} h^{I}\left(\tilde{h}_{t}^{I}-\tilde{h}_{t-1}^{I}\right)+R b^{I}\left(\tilde{b}_{t-1}^{I}-\widetilde{\pi}_{t}+\widetilde{R}_{t-1}\right)+q^{Z} Z^{I}\left(\tilde{Z}_{t}^{I}-\tilde{Z}_{t-1}^{I}\right) \\
& \frac{(\mu+v+\varphi u) Y}{X}\left(\widetilde{Y}_{t}-\widetilde{X}_{t}\right)+b^{E} \tilde{b}_{t}^{E}=c^{E} \widetilde{c}_{t}^{E}+q^{h} h^{E}\left(\widetilde{h}_{t}^{E}-\widetilde{h}_{t-1}^{E}\right)+R b^{E}\left(\tilde{b}_{t-1}^{E}-\widetilde{\pi}_{t}+\widetilde{R}_{t-1}\right)+\tilde{I}_{t}+q^{Z} Z^{E}\left(\widetilde{Z}_{t}^{E}-\tilde{Z}_{t-1}^{E}\right) \\
& \widetilde{Y}_{t}=\frac{\eta}{\eta-1+\mu+u+v}\left(\widetilde{A}_{t}+\mu \widetilde{K}_{t-1}+v \widetilde{h}_{t-1}^{E}\right)-\frac{1-\mu-v-u}{\eta-1+\mu+u+v}\left(\widetilde{X}_{t}+\alpha \widetilde{c}_{t}^{P}+(1-\alpha) \widetilde{c}_{t}^{I}\right) \\
& \widetilde{\pi}_{t}=\beta^{\mathrm{P}} \mathrm{E}_{\mathrm{t}} \widetilde{\pi}_{\mathrm{t}+1}+\frac{(1-\theta)\left(1-\beta^{\mathrm{P}} \theta\right)}{\theta} \widetilde{\mathrm{X}}_{\mathrm{t}} \\
& \widetilde{\mathrm{R}}_{\mathrm{t}}=\mathrm{r}_{\mathrm{R}} \widetilde{\mathrm{R}}_{\mathrm{t}-1}+\left(1-\mathrm{r}_{\mathrm{R}}\right)\left(\left(1+\mathrm{r}_{\pi}\right) \widetilde{\pi}_{\mathrm{t}-1}+\mathrm{r}_{\mathrm{Y}} \widetilde{\mathrm{Y}}_{\mathrm{t}-1}\right)+\widetilde{\mathrm{e}}_{\mathrm{R}, \mathrm{t}} \\
& \widetilde{\mathrm{A}}_{\mathrm{t}}=\rho_{\mathrm{A}} \widetilde{\mathrm{A}}_{\mathrm{t}-1}+\widetilde{\varepsilon}_{\mathrm{A}, \mathrm{t}} \\
& \tilde{\mathrm{J}}_{\mathrm{t}}=\rho_{\mathrm{h}} \tilde{\mathrm{J}}_{\mathrm{t}-1}+\tilde{\varepsilon}_{\mathrm{h}, \mathrm{t}} \\
& \tilde{\mathrm{e}}_{\mathrm{R}, \mathrm{t}}=\rho_{\mathrm{e}} \tilde{\mathrm{e}}_{\mathrm{R}, \mathrm{t}-1}+\tilde{\varepsilon}_{\mathrm{R}, \mathrm{t}} \\
& \widetilde{\mathrm{m}}_{\mathrm{t}}=\rho_{\mathrm{m}} \widetilde{\mathrm{m}}_{\mathrm{t}-1}+\widetilde{\varepsilon}_{\mathrm{m}, \mathrm{t}}
\end{aligned}
$$


APPENDIX K. TABLES

Table K1. Results of the Taylor Rule Estimation

\begin{tabular}{lc}
\hline & Dependent variable: \\
\cline { 2 - 2 } Output & interest \\
\hline Interest (lagged) & $(0.008$ \\
& $0.856^{* * *}$ \\
Inflation & $(0.134)$ \\
& $0.538^{* * *}$ \\
Constant & $(0.111)$ \\
\hline Observations & 2.041 \\
R2 & $(20.568)$ \\
Adjusted R2 & 17 \\
Residual Std. Error & 0.908 \\
F Statistic & 0.887 \\
\hline Note: ${ }^{*} p<0.1 ;{ }^{* *} \mathrm{p}<0.05 ;{ }^{* * *} \mathrm{p}<0.01$ & $2.166(\mathrm{df}=13)$
\end{tabular}

Table K2. Calibration

\begin{tabular}{lcc}
\hline Description & Parameter & Value \\
\hline Patient household discount factor & $\beta^{p}$ & 0.995 \\
Impatient household discount factor & $\beta^{\mathrm{i}}$ & 0.980 \\
Entrepreneur discount factor & $\beta^{\mathrm{e}}$ & 0.940 \\
Housing service utility weight & $\mathrm{j}$ & 0.050 \\
Frisch labor supply elasticity & $\eta$ & 2.000 \\
Capital share & $\mu$ & 0.250 \\
Land share & $\mathrm{u}$ & 0.030 \\
Housing share & $\mathrm{v}$ & 0.020 \\
Capital depreciation & $\delta$ & 0.030 \\
Steady-state LTV ratio & $\mathrm{m}$ & 0.310 \\
Steady-state markup & $\mathrm{X}$ & 1.100 \\
Patient household wage share & $\alpha$ & 0.640 \\
Patient households' rent share & $r_{Y}$ & 0.070 \\
Entrepreneurs' rent share & $r_{R}$ & 0.840 \\
The Taylor rule parameter of inflation response & $\mathrm{d}$ & 0.540 \\
The Taylor rule inertia parameter & $\varphi$ & 0.000 \\
The Taylor rule parameter of output response & & \\
\hline
\end{tabular}


Table K3. Estimation Results

\begin{tabular}{lccc}
\hline Description & Parameter & Value & S.E. \\
\hline Persistence of the technological shock & $\rho_{\mathrm{a}}$ & 0.7719 & 0.1839 \\
Persistence of the monetary shock & $\rho_{\mathrm{e}}$ & 0.1447 & 0.0367 \\
Persistence of the loan-to-value shock & $\rho_{\mathrm{m}}$ & 0.9477 & 0.0262 \\
Persistence of the housing preference shock & $\rho_{\mathrm{j}}$ & 0.9801 & 0.0092 \\
Standard deviation of the technological shock & $\sigma_{\mathrm{a}}$ & 0.0262 & 0.0035 \\
Standard deviation of the monetary shock & $\sigma_{\mathrm{e}}$ & 0.0089 & 0.0038 \\
Standard deviation of the loan-to-value shock & $\sigma_{\mathrm{m}}$ & 2.0002 & 0.3738 \\
Standard deviation of the housing preference shock & $\sigma_{\mathrm{j}}$ & 0.4247 & 0.1250 \\
Capital adjustment costs & $\psi$ & 0.6250 & 0.1403 \\
Price stickiness parameter & $\theta$ & 0.3431 & 0.0822 \\
\hline
\end{tabular}




\section{APPENDIX L. FIGURES}

Figure L1. Asset Price Fluctuations Caused by One Standard Deviation of the Corresponding Shock

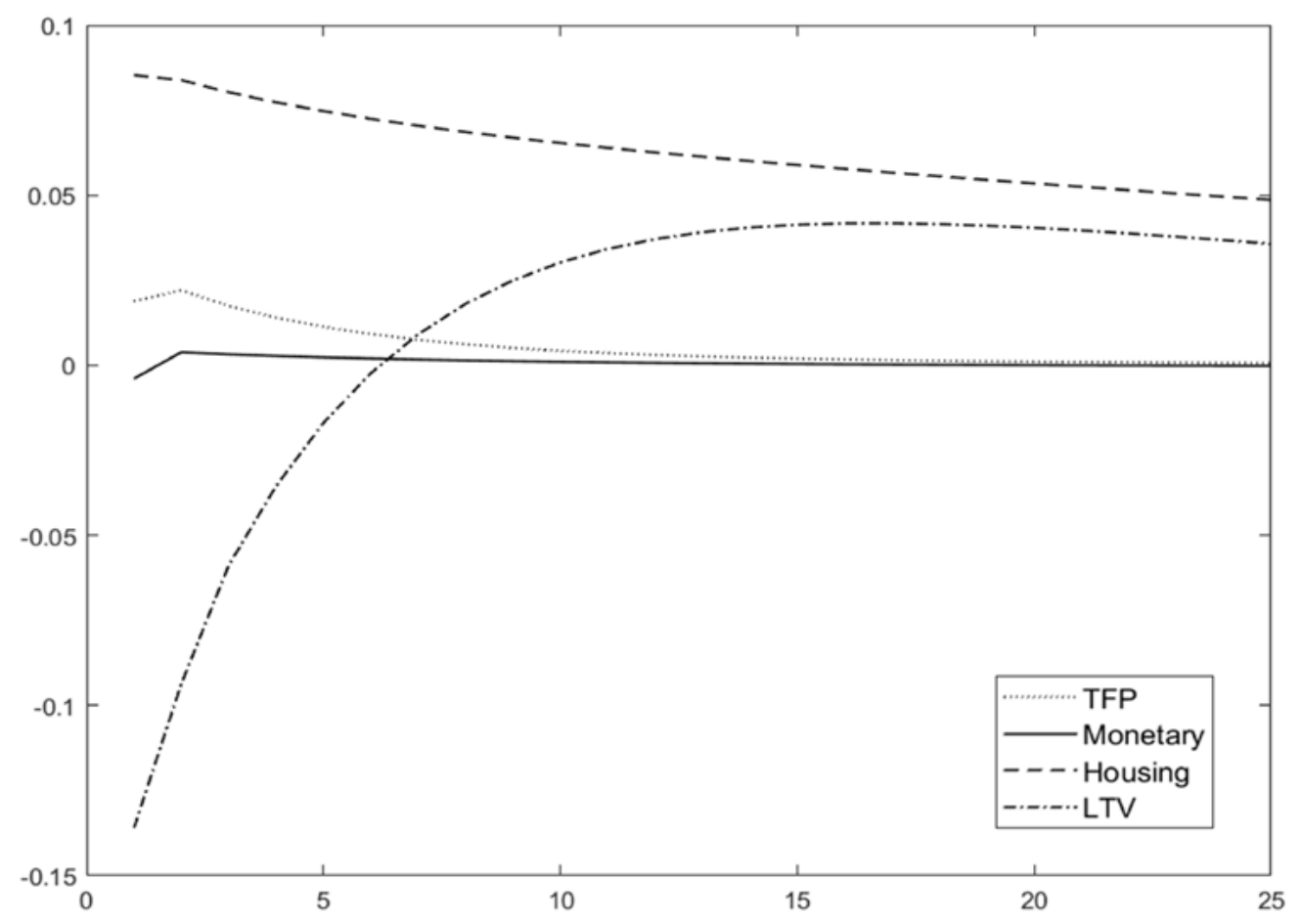

Figure L2. Smoothed Shocks
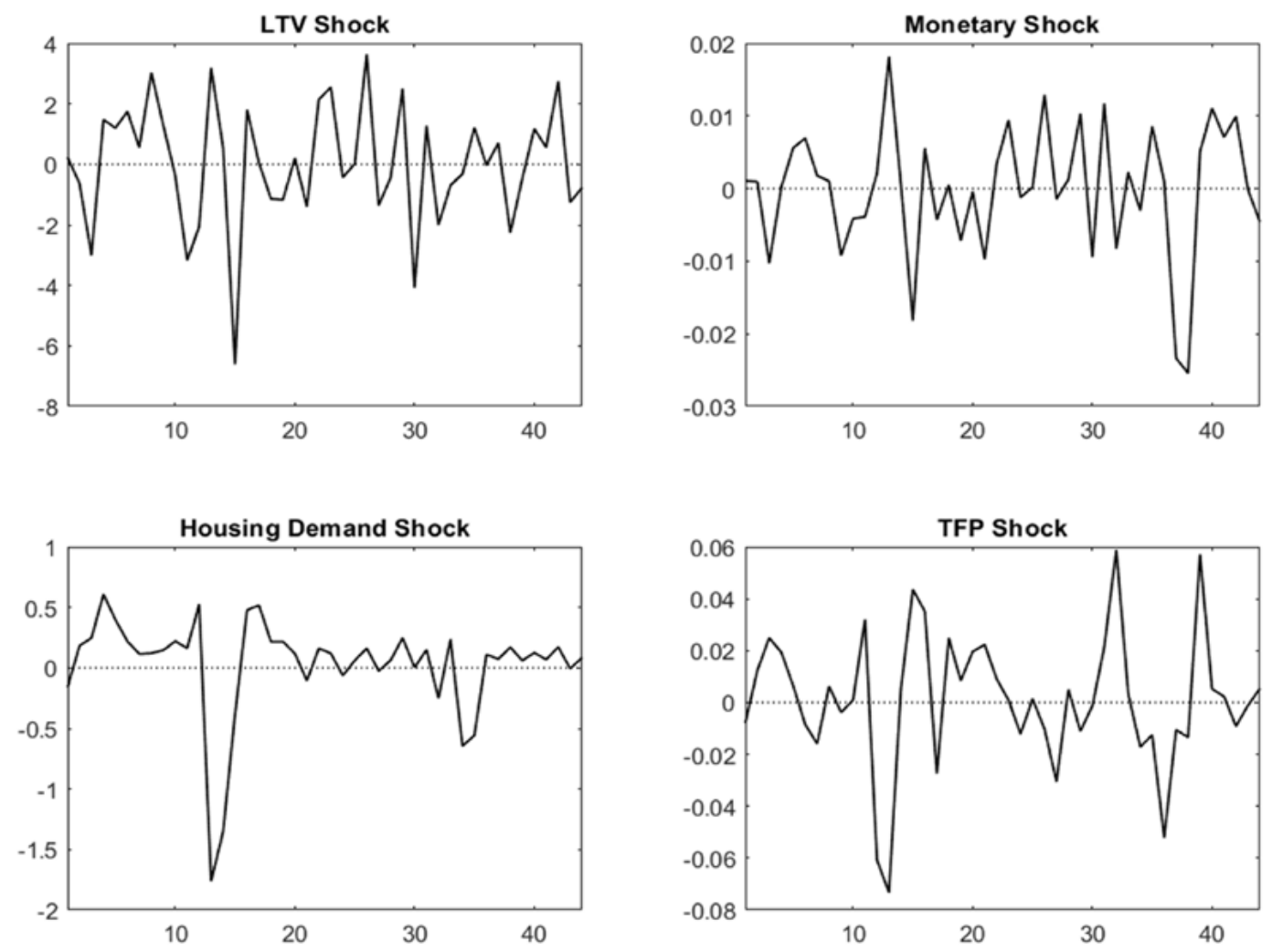
Figure L3. IRFs to TFP Shock of the Initial (Solid) and Modified (Dashed) Models
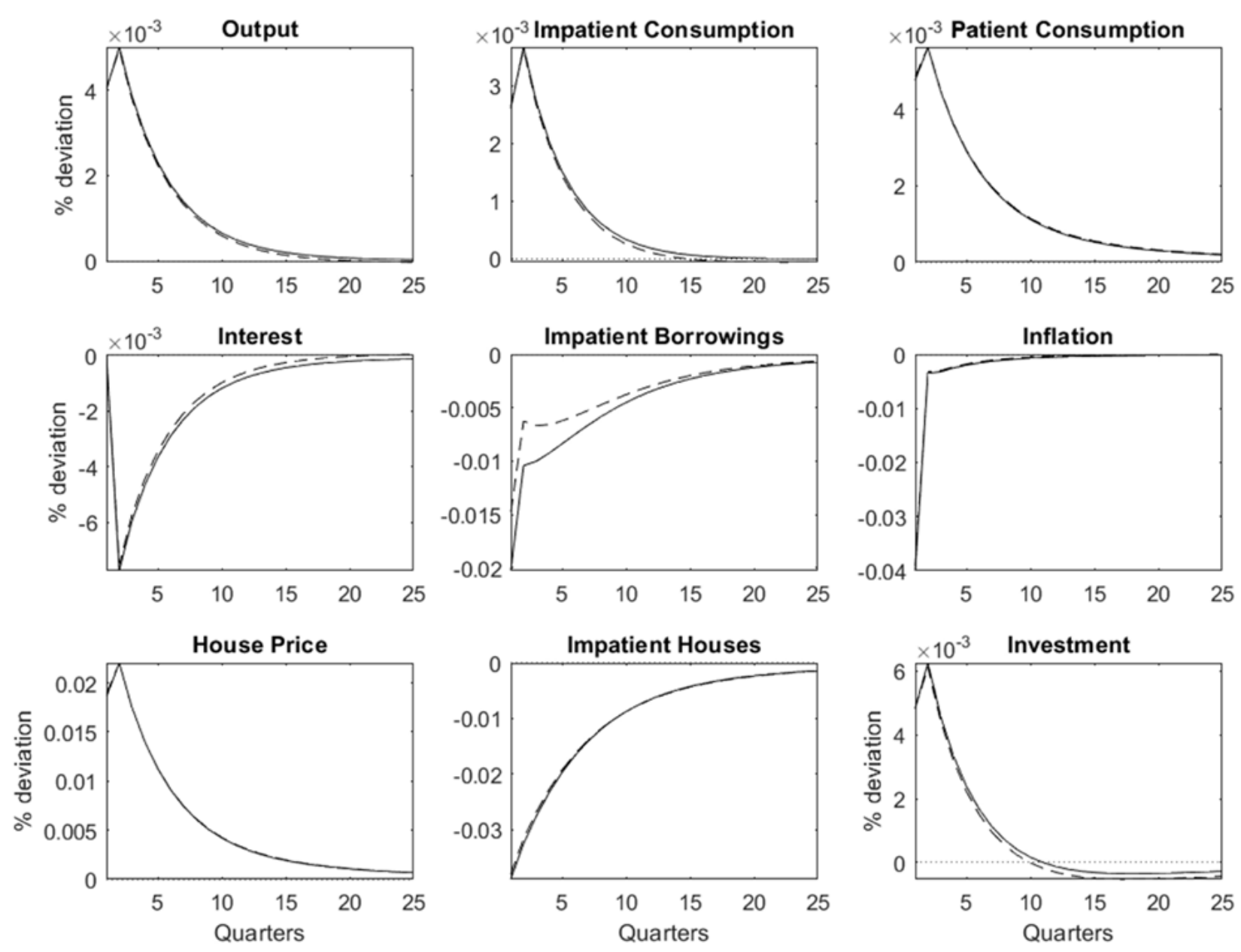

- Initial model ---- Modified model 
Figure L4. IRFs to Monetary Shock of the Initial (Solid) and Modified (Dashed) Models
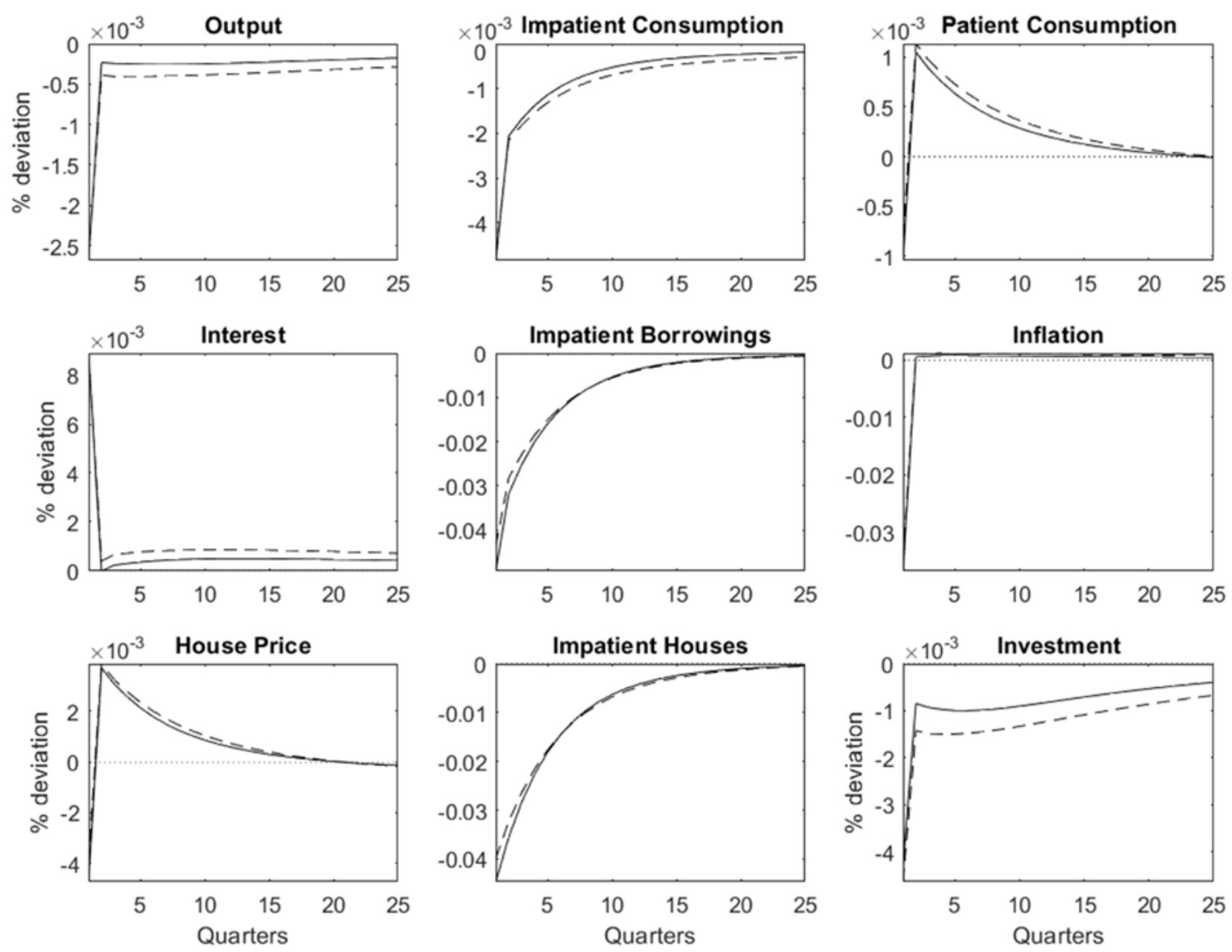

- Initial model ---- Modified model 
Figure L5. IRFs to House Preference Shock of the Initial (Solid) and Modified (Dashed) Models
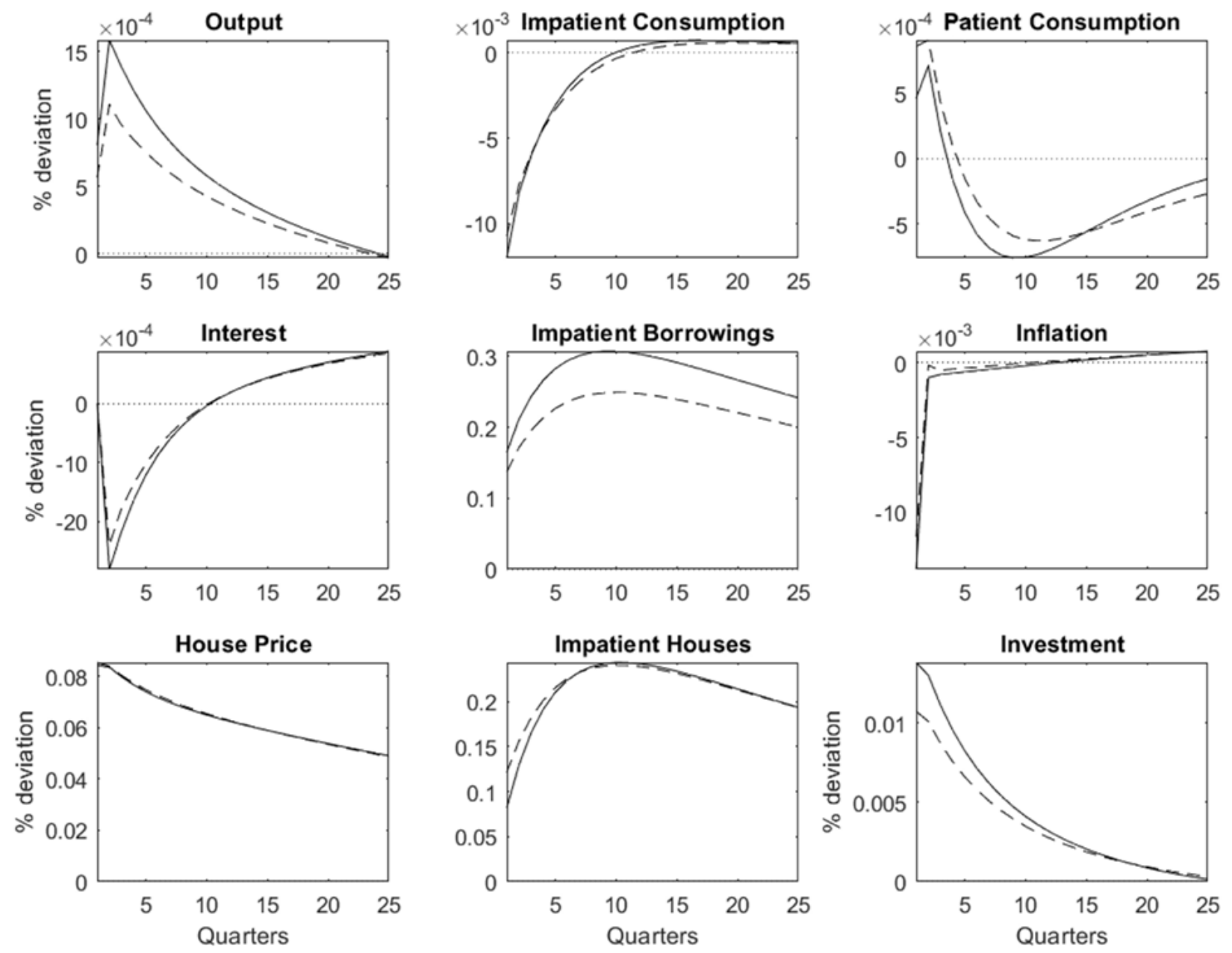

Initial model ---- Modified model 
Figure L6. IRFs to LTV Shock of the Initial (Solid) and Modified (Dashed) Models
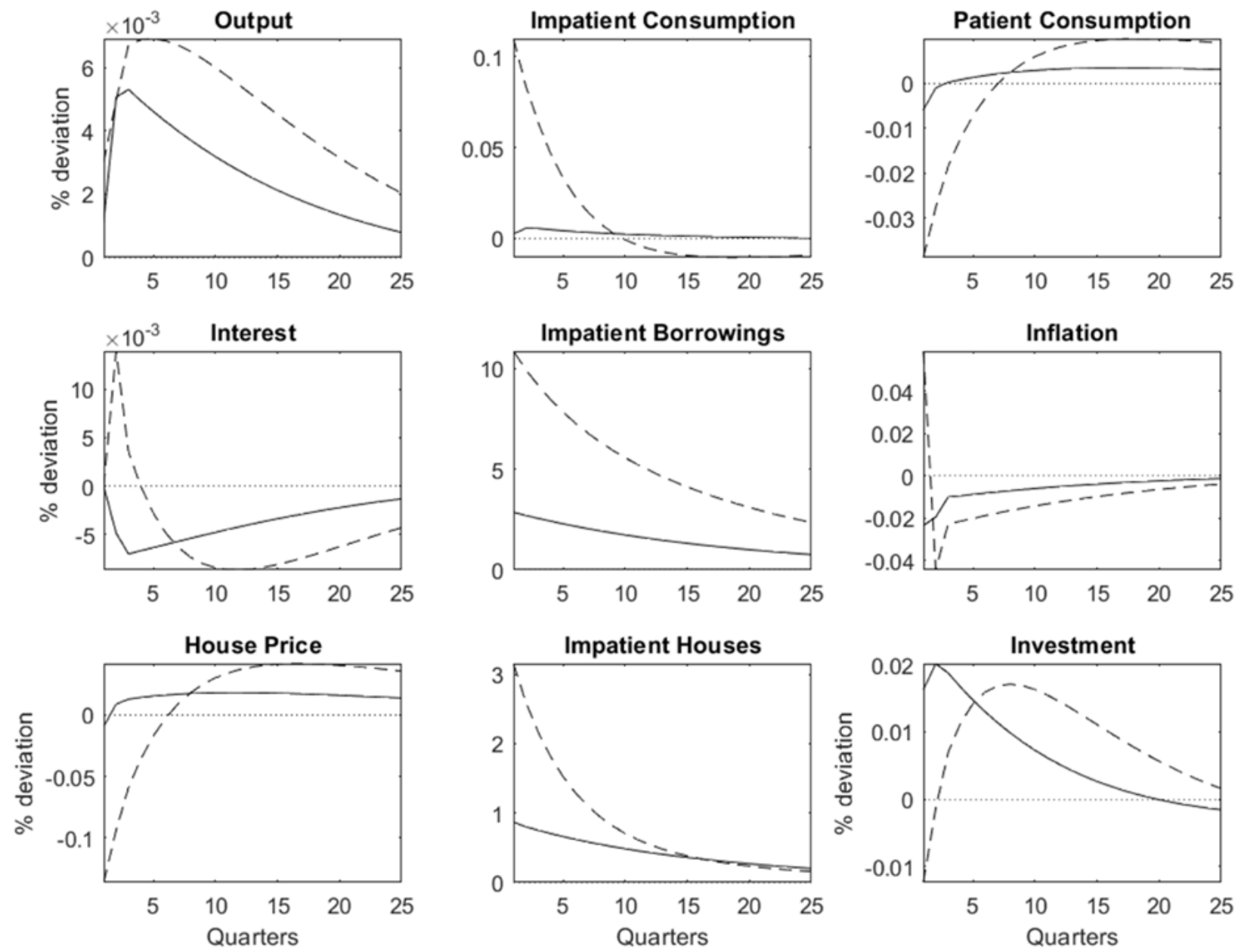

— Initial model [---- Modified model 


\title{
COMMUNICATIVE EFFICIENCY IN UKRAINE'S BANKING SYSTEM: EVIDENCE FROM INDEPENDENT AUDITOR REPORTS
}

\section{OLEKSANDR SUKHOMLYN}

${ }^{a}$ Kyiv School of Economics, GR Capital

Email: osukhomlyn@kse.org.ua; os@gr.capital

\begin{abstract}
This study, based on the quantitative content analysis, examines communicative efficiency in the Ukrainian banking system, i.e. shows how the tone and the readability of independent auditor reports are associated with a bank performance in the next financial year. The study applies a fixed-effects estimator within the regression to an unbalanced panel dataset of Ukrainian banks. The tone of report variable is constructed with the help of Loughran and McDonald's Financial Sentiment Word Lists, while readability is estimated using the FOG and Flesch-Kincaid indices. Based on estimations of 2012-2016, the readability of audit reports is found to have no relationship with a bank's profitability in the next year. However, a more negative tone of auditor report is associated with an increase in bank's ROA and ROE in the subsequent period. This paper concludes with policy implications and remarks on the practical application and execution of the findings.
\end{abstract}

JEL Codes C33, D82, E58, G21, M42

Keywords quantitative content analysis, communicative value, asymmetric information, tone, readability, independent auditor report

\section{INTRODUCTION}

Over the last four years, the Ukrainian banking system has been exposed to numerous shocks caused by political and economic factors. Among the political factors, the annexation of Crimea and Russia's hybrid war in the Donbas region have been the most destructive. On the economic side, the instability of the financial system and the population's panicked outlook for Ukraine's economic situation have introduced substantial threats to the banking system.

Since the Revolution of Dignity in 2014, the number of banks operating in Ukraine has halved (see Figure 1) to 88 as of January 2018, according to the Ministry of Finance. Whether this constitutes a positive or negative development remains to be seen.

Figure 1. Number of Banks Operating in Ukraine

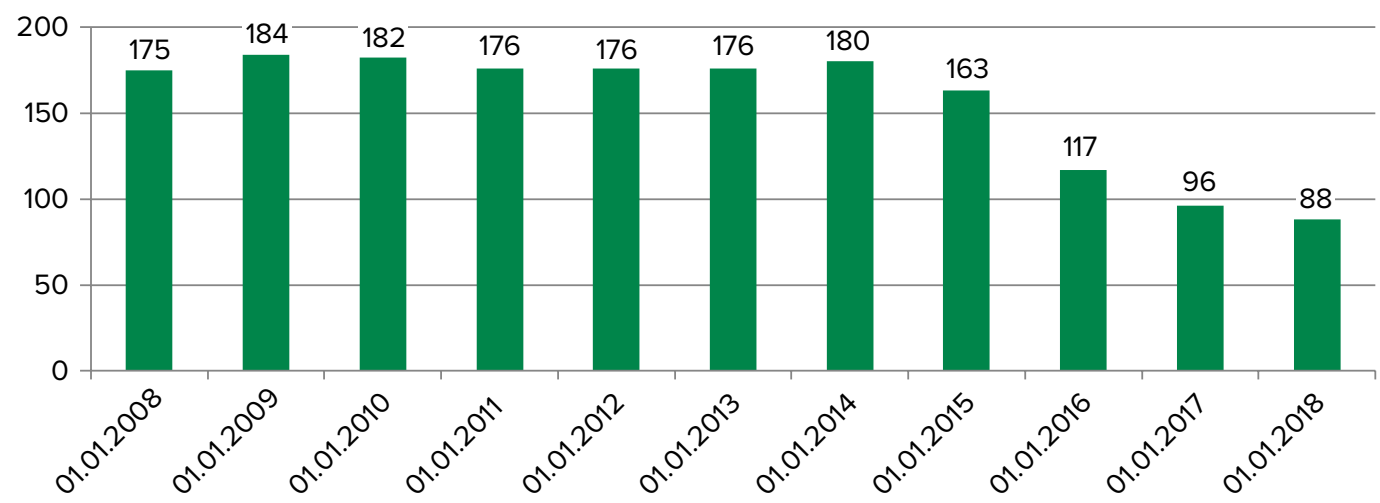

Source: Ministry of Finance of Ukraine ${ }^{1}$ 
A significant and sudden decrease in the number of banking institutions in the Ukrainian financial system is as an unhealthy phenomenon as the complete ignoring of legislative violations by commercial banks. According to the Law of Ukraine On Banks and Banking, ${ }^{2}$ a bank can be liquidated for numerous reasons that include a large reduction of regulatory capital and capital requirements, failure to comply with obligations to depositors and creditors, and a failure to comply with instructions, decisions, or requirements of the $\mathrm{Na}$ tional Bank of Ukraine (NBU). However, many recent bank liquidations in Ukraine were brought about by poor management or because the bank operated as a front (for example, to launder money or withdraw funds abroad).

Since all banks must be audited annually by an external auditor and since the number of banks operating has halved, several questions arise. Why have the liquidated banks not been removed from the banking system previously? Did the auditors have access to information not available to other economic agents? Is there a relationship between the content of the auditor report and a bank's future performance? This paper is more focused on the latter question, attempting to address asymmetric information in the Ukrainian banking system through the analysis of the auditor reports communicative value.

Asymmetric information is one of the most fundamental frictions in economics and finance. One specific manifestation of the asymmetric information is the private knowledge of an auditor concerning the bank. The information obtained by the auditor during the investigation and review of a bank operations is not available to other economic agents.

The recent scandal with PricewaterhouseCoopers (PwC) in Ukraine is a prime example of that asymmetry: the NBU revoked PwC's right to operate in the banking sector owing to the contents of its report on PrivatBank, an institution that later had to be nationalized.

Nevertheless, we cannot state with certainty that independent auditors hide information about banks in their reports. However, there are signs that this may be the case. For example, the audits of PrivatBank by PwC and later Ernst \& Young (EY) differ greatly, especially the tones of each firm's reports.

There main motive is to check how the actual state of affairs may well correlate with what auditors claim in their reports basing on the main indicators of reports' communicative value: tone (a measure that identifies the "a feeling of a communication" from positive to negative) and readability (a measure that identifies whether the reader can understand the message delivered by the auditor) and answer the question how the bank profitability changes in one year after report publication.

To answer that question, we form and test the following hypotheses:

1) $H_{0}$ : the tone of an independent audit report is positively associated with a bank's performance in the subsequent financial year;

2) $\mathrm{H}_{0}$ : the readability of an independent audit report is negatively associated with a bank's performance in the subsequent financial year.
This study is based on a quantitative content analysis of independent audit reports of Ukrainian banks. The study intends to provide the NBU a greater understanding and evidence on the communicative value of audit disclosures from external auditors. This study can also help Ukrainians choose banks and banking institutions choose auditors.

In this paper, we consider an unbalanced panel dataset of Ukrainian banks in 2012-2016 and apply a fixed-effects estimator within a panel regression. The data is from the NBU and bank audit reports, and contains all financial indicators and the full texts of the reports.

The structure of the paper is as follows: Chapter 2 reviews the literature concerning the implementation and description of content analysis, explains how asymmetric information is characterized by the readability of reports in joint-stock companies, and justifies the importance of tone as a key measure of the communicative value of a bank's audit report; Chapter 3 outlines the methodology of the analysis, model specification, and selection of controls and methodology of defining the indices for tone and readability. The processes of data collection and preparation and the descriptive statistics of the variables are discussed in Chapter 4 . The main empirical results and the discussion of findings are presented in Chapter 5. Finally, Chapter 6 provides the main conclusions of the study and policy implications.

\section{LITERATURE REVIEW}

The central topic of this paper (the relationship between the communicative value of independent audit reports and a bank's performance in the subsequent financial year) has not been studied in depth. Although no papers investigate the link between the tone of an auditor's report and a bank's profitability in the next financial period. Still, a few studies that explore some issues of the communicative value of firms' disclosures are relevant and informative for the section of the literature review.

Our study aims to provide practical evidence of the influence of the communicative value of auditor reports on a bank profitability, and to contribute to the existing literature about the quantitative content analysis in economics and finance, and the phenomenon of the information asymmetry in the banking system by an analysis of independent auditor reports.

This review of the literature is split into three parts. The first explores content analysis as a research approach and identifies its limitations. The second describes asymmetric information in joint-stock companies. The final group outlines the importance of the tone of the auditor's reports in the fields of finance, economics, and audit.

\subsection{Content Analysis}

An approach called content analysis can be used to analyze written texts (books, papers), oral texts (speeches), iconic texts (drawings, paintings), audio-visual texts (movies, videos), and hypertexts (internet-based texts) manually or via machine Learning. The approach is used mainly to investigate naturally-occurring data, so it could be considered as an unostentatious method for research (Insch et al., 1997; Harris, 2001). This method is a simple analytical approach and unobtrusive in the process of gathering information. 
Possible limitations of content analysis include the sampling process and coding. The public availability of the documents used in the analysis could introduce bias in the estimations. Moreover, problems in a content analysis may emerge because of the abstraction of word groups from the context; when a phrase or word become isolated from other related parts of a text, meaning may be lost. Additionally, content analysis can ignore what is not said in a particular part of the text. As a result, significant parts of a text could be omitted from the analysis (Insch et al., 1997).

\subsection{Asymmetric Information in Joint-Stock Companies}

Various papers have analyzed the tone and readability of speeches by independent directors of joint-stock companies. Those two characteristics are considered the primary indicators of the quality of the communication between directors and other economic agents.

Drawing parallels, it should be noticed that both independent directors of joint-stock companies and independent auditors have access to non-public information of the institution (company and bank, respectively). Both are also aware of the institution's true financial situation and the expectations of senior management, of which other economic agents (i.e. customers and clients) are not aware. Therefore, a review of the literature concerning join-stock companies is relevant to our study of banks (an independent director corresponds to an independent auditor and a shareholder corresponds to a bank client).

Most research on the topic of information asymmetry and communicative efficiency at joint-stock companies focuses on the assertion that an analysis of communication from directors can help stakeholders that are not engaged in the firm's decision-making to understand the behavior of the firm (Simon, 1999). Further developing that point, directors' disclosures of a firm's internal information have a direct and significant relationship with that firm's profitability and earnings quality (Li, 2010).

Additionally, Li (2008) examined and brought into the financial literature the FOG Readability Index, which was developed by Robert Gunning in 1952. Li showed a link between an institution's financial performance and the readability of its annual report. In that paper, Li demonstrated that profitable firms have more readable reports than loss-making companies (i.e. showing a negative relationship between the FOG Index and profitability). Continuing that thread, Bloomfield (2008) discussed possible explanations for that negative relationship: ontology (bad news is more complicated to communicate) and obfuscation (bad news is easier to hide behind a text that is difficult to read).

\subsection{The Tone of Auditor Report}

Coram et al. (2011) and Mock et al. (2009) posited that an audit report is the main source of information for analysts of a firm. Those papers showed that financial analysts value the unqualified opinion included in an auditor's report. At the same time, recent analyses have shown that users of financial statements often have some difficulty understanding audit reports, which can negatively affect the communicative value of auditor reports (Church et al., 2008; Gray et al., 2011; Coram et al., 2011; Asare and Wright, 2012; Manson and Zaman, 2001; Hermanson et al., 1991).
Academic studies by Doogar et al. (2015) and Sikka (2009) showed that auditor reports do not always inform readers of all financial risks present during a crisis. Most of the failed financial institutions included in those studies received lowqualified external audit opinions.

According to Henry (2008), the tone of an auditor's report is the main measure that defines the "effect or feeling of a communication." Literature in the field of finance has introduced the tone of reports as an appropriate method to further understand the impact of written texts on the behavior of stakeholders and investors (Antweiler and Frank, 2004; Tetlock, 2007; Tetlock et al., 2008; Loughran and McDonald, 2011). Loughran and McDonald's Negative, Positive, and Uncertainty Word Dictionaries are widely used for calculating the tone of an auditor's report: risk-related content is associated with words that show negativity and uncertainty. In our research paper, we also rely on Loughran and McDonald's Word Dictionaries to identify the tone of auditor reports.

\section{METHODOLOGY}

In this section, we outline parts of our methodology (the processes of securing and preparing the data are presented in the Data Description section). The methodology for generating the continuous variable of the tone of audit reports is based on:

1) Loughran and McDonald's Dictionary of Positive and Negative Words for the main analysis;

2) A multilingual dictionary for a further robustness check of the model.

The methodology of generating the continuous variable of the readability of audit reports is based on:

1) The FOG Readability Index for the main analysis;

2) The Flesch-Kincaid Readability Index for a further robustness check of the model.

When the key variables are generated, we explain and justify the choice of control variables used in the regression analysis. Finally, when all the variables are ready, we apply a five-year panel data analysis.

\subsection{Constructing the Tone and Readability Variables}

Readability is a concept used in economics, law, linguistics, medicine, and other areas. For this paper, Loughran and McDonald (2014) offer the most relevant definition, which focuses on the business context. The authors define readability as "the ability of individual investors and analysts to assimilate valuation-relevant information from a financial disclosure." Simply put, readability is the ease with which a reader can understand the text of an auditor report.

With no precise definition of readability, we focus on ways to measure it. In that vein, however, there is no consensus as to the best measure. For that reason, we introduce the two most common approaches for readability: the Gunning Fog Index (FOG) and the Flesch-Kincaid Grade Level (Flesch-Kincaid). 
In computational linguistics, the FOG Index is a function of the number of words per sentence plus the percentage of complex words. The sum is then multiplied by a constant (0.4) to approximate the years of education required to understand a text fragment. The FOG Index is calculated as follows:

$$
F O G=0.4 \times\left(\frac{\text { number of } \text { words }}{\text { number of sentences }}\right)+
$$

$+40 \times\left(\frac{\text { number of words with more than two syllables }}{\text { number of words }}\right)$

The Flesch-Kincaid Grade Level is a function of the number of words per sentence and the proportion of complex words in an auditor's report. The index reflects the difficulty in understanding a passage in the English language based on word and sentence length. The Flesch-Kincaid Grade Level is calculated as follows:

$$
\begin{gathered}
\text { Flesch }- \text { Kincaid }=0.39 \times\left(\frac{\text { number of } \text { words }}{\text { number of sentences }}\right)+ \\
+11.8 \times\left(\frac{\text { number of syllables }}{\text { number of } \text { words }}\right)-15.59
\end{gathered}
$$

We calculate the tone of reports using a dictionarybased approach, which matches word sentiment. We first segment positive and negative words using Loughran and McDonald's Financial Sentiment Word Lists (a specialized dictionary frequently used in economics, accounting and finance) and the multilingual dictionary of positive and negative words (a review of words from a multilingual dictionary). Then, using econometric software, we identify the number of positive and negative words in a report. Finally, we calculate the tone of every report using the formula below:

Tone $=\frac{\text { number of positive words }- \text { number of negative words }}{\text { number of positive words }+ \text { number of negative words }}$

After constructing core regressors, we can choose the variables that will help us clarify the relationship between a report's communicative value and a bank's profitability in the subsequent period.

\subsection{Selection of Control Variables}

In selecting control variables, we considered studies that investigate the factors that influence a bank's profitability. Arellano and Bond (1991) show that the use of a logarithmic transformation of total assets is an effective tool for capturing bank size. Later, a number of academic papers identified a positive significant relationship between bank size and profitability (Kosmidou, 2008; Flamini et al., 2009; Pervan and Pervan, 2010; Adusei, 2015; Pervan et al., 2015). That result leads us to conclude that banks should use their size to generate cost advantages and increase efficiencies, thus increasing profitability. On the other hand, in their study using the Random Effects model, Naceur and Goaied (2008) found that a bank's size is negatively correlated with profitability. This inverse relationship could be the result of diseconomies of scale that often occur in large banking institutions (Kosak and Cok, 2008). Additionally, while studying the profitability of Chinese banks, Heffernan and Fu (2008) used system GMM and found that the size of a bank has no significant relationship with financial performance.

Liquidity is an important factor that influences bank profitability: a bank's ability to fund asset increases and manage decreases in liabilities is material. Bourke (1989) showed a positive relationship between profitability and liquidity as credits to firms and households are riskier (and have higher expected returns) than, for example, government bonds. On the other hand, Eichengreen and Gibson (2001) considered that a bank's higher profitability may be explained by a lower amount of funds allocated to liquid investments.

In terms of cost management practices at banks, studies show a negative relationship between profitability and operating expenses, or that a bank's profitability grows as expenses decrease (Bourke, 1989). Nevertheless, Molyneux and Thornton (1992) showed a positive relationship between the two variables, suggesting that greater profitability leads to larger payroll expenditures on more productive personnel.

\subsection{Model Specification}

To estimate the relationship between tone and readability and a bank's future-year earnings, we formulate the following hypotheses:

1) $H_{0}$ : the tone of an independent audit report is positively associated with a bank's performance in the subsequent financial year;

2) $H_{0}$ : the readability of an independent audit report is negatively associated with a bank's performance in the subsequent financial year.

We focus our research on the relationship between a bank's performance and lagged values of report readability and tone. This is logical because independent audit reports are published in March or April of the next year.

For further research we use the following model:

$$
\begin{gathered}
\text { Bank Performance }_{i, t}=\beta_{0}+\beta_{1} \times \text { Tone }_{i, t-1}+ \\
+\beta_{2} \times \text { Readability }_{i, t-1}+\beta_{3} \times \text { Controls }_{i . t-1}+ \\
+\beta_{4} \times \text { Dummies }_{i . t-1}+\varepsilon_{i, t}
\end{gathered}
$$

where: Bank Performance $i, t$ is measured as:

1) ROA (Net income after tax/Total Assets) in bank $i$ at year $t$;

2) ROE (Net income after tax/Total Equity) in bank $i$ at year $t$.

Tone $_{i, t-1}$ is the tone of the independent audit report in bank $i$ at year $t-1$. We generate the tone for each audit report using the "quanteda" package in R econometric software and domain-specific word dictionaries: Loughran and McDonald's Financial Sentiment Word Lists and the multilingual dictionary of positive and negative words. This is a continuous variable, ranged from -1 (negative) to 1 (positive) and mean 0 as the neutral view.

Readability $_{i, t-1}$ is a readability index measured by the FOG Index and Flesch-Kincaid Index. This is a continuous 
variable as well; the higher the index value, the more difficult it is to read an auditor report.

Controls $_{i, t-1}$ are control variables of the bank: log(total assets) indicate bank size, log(operating expense) help explain cost management, and the Cash/Total Liabilities ratio presents the amount of the most liquid funds for covering liabilities. These profitability determinants are widely used as control variables of ROA and ROE and were examined in the previous section.

Dummies $_{i, t-1}$ are dummy variables: Time (2012-2016 years), Auditor (whether an audit was conducted by a Big Four firm), Solvency (whether a bank is solvent or insolvent), Ownership (identifies banks with state participation/banks belonging to foreign banking groups/banks belonging to Ukrainian banking groups) in bank $i$ at year $t-1$.

\section{DATA DESCRIPTION}

In this study, we use a five-year unbalanced panel dataset of Ukrainian banks. The data used is publicly available and obtained from the NBU and the annual reports of operating, liquidated, and closed Ukrainian banks from 2012 to 2016 . On the financial side, for assets, we used cash and equivalents, loans and receivables from entities and individuals, and total assets; for liabilities, we used amounts due to banks, amounts due to entities, amounts due to individuals, and total liabilities; for equity, we used authorized capital, retained earnings, and total equity. To conduct the quantitative content analysis and shed a light on the issue of communicative efficiency of auditor reports in Ukraine, we use 514 independent auditor reports from the websites of Ukrainian banks.

\subsection{Data Collection}

Before estimating the report tone, the appropriate data must be collected and prepared. The data must be prepared to create a variable that will describe the tone of a report using sentiment analysis. First, we classified banks using their MFO Code. Then, we identified each bank's operating status (operating, liquidated, closed) using data from Ukraine's Ministry of Finance. We then sourced auditors' annual reports from the annual reports of banks and eliminated unneces- sary parts of the reports. Since most banks disclose in PDF format, we then translate those files to Text format (.txt) to be analyzed using econometric software. Under Ukrainian law, annual reports must be published in the Ukrainian language, so we then translated the auditor reports into English.

The documents were translated using the Python programming language using Yandex Translator API. We used this translation method on all 514 auditor reports, taking into account Yandex's limitations on the free usage of API. We imported the required libraries and created a loop to read through all the files. To translate using Python, each text file must be opened, read, saved as a string variable. We then split the text into sections no larger than 3,000 symbols (owing to Yandex's API free-usage limitations) and created a new text file into which we stored the translated text. We then created a loop to translate each part of the split text separately and appended the translated sections into a newly created text file.

\subsection{Data Preparation}

Using the newly created text files, we create a column of string variables with the texts of the audit reports. We then sub-string the year and the bank's MFO from the file name to get two additional variables.

To analyze the data, we needed to create a monolingual corpus - a large set of texts containing all the independent audit reports from Ukrainian banks over the last five years. The main characteristics of that body are the number of types, tokens, and sentences.

The next step is to create a document-feature matrix after all the features are abstracted from the text corpus. Creating this type of matrix is important because it significantly simplifies the process of sentiment analysis. After creating the document-feature matrix, we scrubbed the text of the report by removing punctuation and all numbers and words

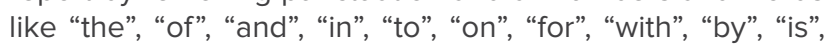
"as", "a", "that", "at", "which" etc.

After scrubbing the documents, we built a word cloud (see Figure 2) to show the most frequently used words.

Figure 2. The 50 Most Frequently Used Words in Audit Reports

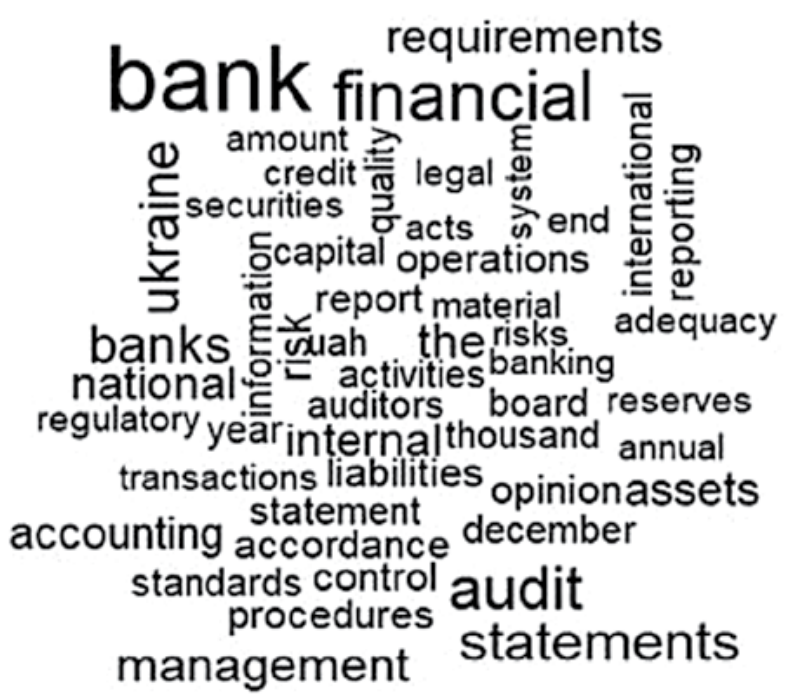




\subsection{Demonstration of Zipf's Law}

Zipf's Law states that in a large sample of words, the frequency of any word is inversely proportional to its rank in the frequency table. In other words, the most frequently used word will occur approximately twice as often as the second most used word, three times as often as the third most used word, and so on. We test Zipf's Law in our study by plotting the data on a log-log graph, where the axes are log (rank order) and log (word frequency). As shown in Figure 3 below, our text data reflects a linear distribution, confirming Zipf's Law for our 100 most used words.

\subsection{The Lexical Diversity of Reports}

The lexical diversity of texts is also known as a Type-Token Ratio. This term is equivalent to the lexical richness and is calculated as a ratio of the different unique word stems to the total number of words in the auditor reports.
Type-Token Ratios for the audit reports of Ukrainian banks in 2012-2016 cluster near 4-5\% (see Figure 4). That means that every twentieth or twenty-fifth word in the report is new, which is normal considering the sizes of the documents and the repetitive financial lexicon.

\subsection{Descriptive Statistics of Financials}

Let consider the statistics of key variables from the dataset we use. Since bank performance is a dependent variable, we need to know financial indicators that can be used to construct the dependent variable. If we choose ROA (return on assets) or ROE (return on equity) as a dependent variable, we should consider such financial indicators as total assets, total equity, and net income. ROA we obtain by dividing net income by total assets, ROE - by dividing net income by total equity. These ratios are used by the Central Banks of developed countries as well as by the NBU as the most appropriate ones that describe bank financial performance (see Table 1).

Figure 3. Frequency-Rank Graph

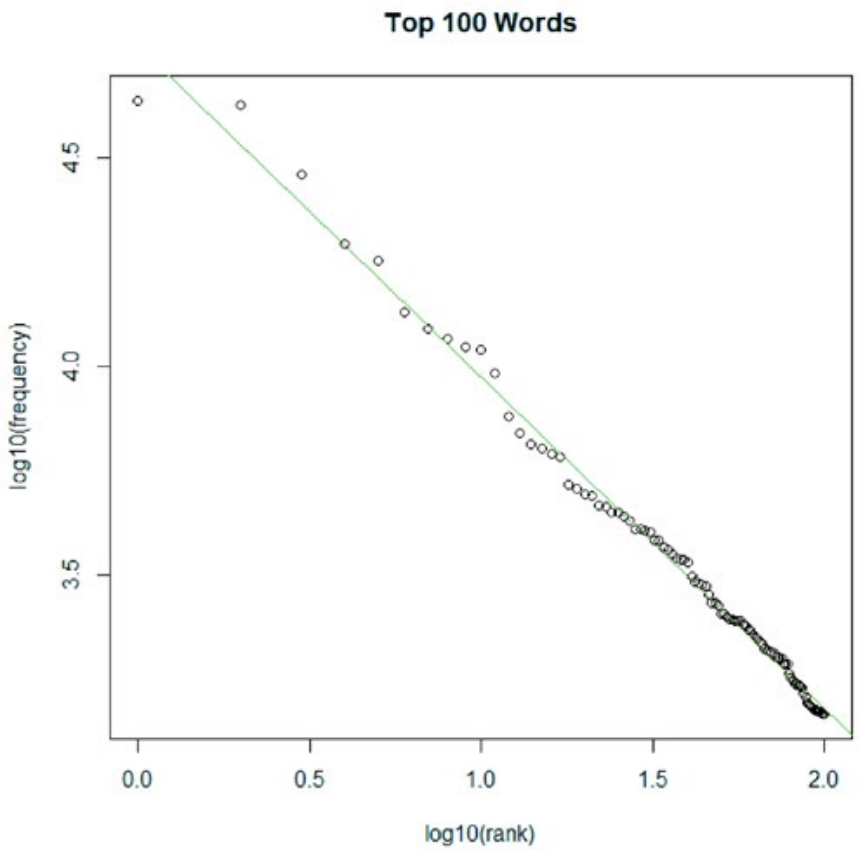

Figure 4. Type-Token Ratio

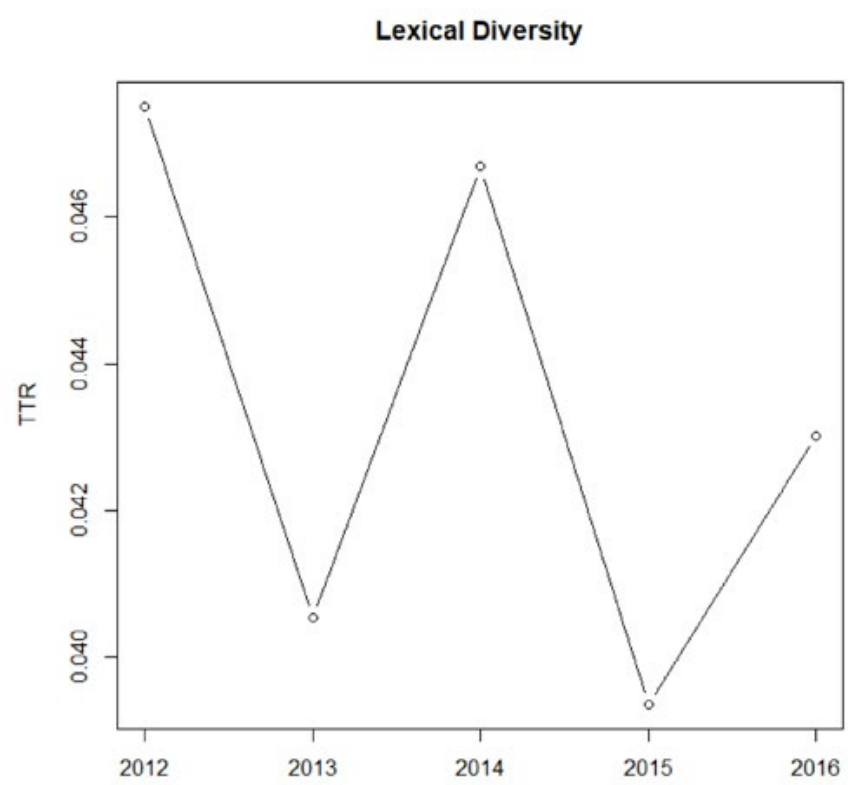


Using this dataset comprised of bank financials and the newly created variables, we run a regression to explain changes in a bank's profitability in the year after the publication of a report. See Appendix A for detailed descriptive statistics of the financial indicators of banks.

\section{EMPIRICAL RESULTS}

The results are estimated using the fixed-effects estimator within the panel regression, where the panel variable is the bank's MFO sort code and year is the time variable. The results for ROA are presented in Table 2.
The regression was built with controls that are widely used by economists in studies that estimate bank profitability. We control our regression for bank size (expressed as a lagged value of the logarithm of Total Assets), cost management (expressed as a lagged value of the logarithm of a bank's Operating Expenses), the adequacy of most liquid funds that could be used to cover liabilities (expressed as a lagged value of the Cash-to-Total Liabilities ratio). All these control variables fit the model, and we explore them in detail below.

Bank size matters since the amount of assets is statistically significant at the $10 \%$ significance level. The relation-

Table 1. Descriptive Statistics of Financial Indicators for Banks

\begin{tabular}{lccccc}
\hline Variable & Obs & Mean & Std. Dev. & Min & Max \\
\hline Total_Assets & 718 & $8,648,717$ & $25,454,958$ & 81,341 & $264,886,279$ \\
Total_Equity & 718 & $1,014,867$ & $2,894,417$ & $-12,269,344$ & $27,487,223$ \\
Net_Income & 718 & $-51,293$ & $5,126,298$ & $-135,309,076$ & $8,781,142$ \\
Total_Liabilities & 718 & $7,633,850$ & $23,130,762$ & 1 & $237,399,056$ \\
Cash & 718 & $1,092,439$ & $3,544,165$ & 29 & $410,482,098$ \\
Oper_exp & 711 & 200,037 & 683,106 & 1,235 & $9,287,553$ \\
\hline
\end{tabular}

Table 2. Estimation Results for ROA

\begin{tabular}{lcc}
\hline & Original model & $\begin{array}{c}\text { Model with added } \\
\text { cross-terms }\end{array}$ \\
\hline Lagged Tone (ML) & $-0.066^{*}$ & $-0.060^{* *}$ \\
Lagged Readability (FOG) & $(0.039)$ & $(0.028)$ \\
& -0.001 & -0.001 \\
Lagged Tone*Auditor & $(0.002)$ & $(0.001)$ \\
& & 0.029 \\
Lagged Tone*Bank status & & $(0.026)$ \\
& & 0.060 \\
Lagged Tone*Ownership & & $(0.078)$ \\
& & -0.025 \\
Lagged Tone*Auditor*Status & & $(0.048)$ \\
& & $-0.188^{* *}$ \\
Lagged log (Total Assets) & $0.027^{*}$ & $(0.075)$ \\
& $(0.016)$ & $0.001^{* * *}$ \\
Lagged Cash Ratio & $0.001^{* * *}$ & $(0.000)$ \\
& $(0.000)$ & $0.001^{* * *}$ \\
Lagged log (Operating Expenses) & $-0.033^{* * *}$ & $(0.000)$ \\
Constant term & $(0.011)$ & $-0.033^{* * *}$ \\
\hline Sample size & -0.046 & $(0.011)$ \\
Adjusted R & $(0.192)$ & -0.059 \\
\hline
\end{tabular}

Note: Additional controls for this regression are dummies for auditor type (Big Four/other), bank status (solvent/ insolvent), ownership (with foreign capital/with Ukrainian capital). The base auditor type is "other", the base bank status is "solvent", the base ownership status is "with Ukrainian capital"; ${ }^{*}$ if $p$-value $<0.1,{ }^{* *}$ if $p$-value $<0.05,{ }^{* * *} p<0.01$. 
ship is positive, which is logical: larger banks frequently have higher returns since they are better organized, more efficient, and enjoy economies of scale. According to the results of the regression, holding all other variables constant, on average, a $100 \%$ increase in a bank's assets is associated with a 0.03 increase in ROA in the one-year period.

The Cash-to-Total Liabilities ratio is found to be positively correlated with ROA. From a theoretical point of view, the relationship between extra cash and profitability is ambiguous. On one hand, profitable banks should have adequate cash and equivalents to handle a significant decrease in liabilities. On the other hand, the more liquidity a bank has, the less risky these funds are, which yields lower returns. The results of the regression show that the positive relationship holds at a highly significant level $(p<0.01)$. However, the coefficient before this variable influences the model imperceptibly because it is mathematically insignificant, which may be caused by the occurrence of both the factors discussed above.

The results of the regression show a highly statistically significant $(p<0.01)$ negative association between operating expenditures and profitability. Holding all other variables constant, on average, a $10 \%$ increase in operating expenditures is associated with a 0.003 decrease in ROA in the subsequent year. Other academic studies have also found a positive relationship, so the relationship is inconclusive. Generally, the literature posits that a reduction in operating expenditures improves profitability and vice versa (greater current spending reduces future returns). However, a positive relationship is also possible if profits are directed to more productive personnel. In our study, we believe the negative relationship between operating expenditures and profitability is rather a product of poor cost management at Ukrainian banks.

In terms of the explanatory variables, the results of the regression show a negative relationship between the tone of auditor reports and profitability, while the relationship between readability and profitability is found to be insignificant.

The readability (complexity) of reports has no definite relationship with ROA in one year due to the low communicative efficiency of reports, even though a review of the literature does show a negative relationship between readability and profitability (in other words, more profitable firms have more readable reports).

The tone of reports is found to be significantly $(0.1 \mathrm{sig}$ nificance level) negatively associated with next-period ROA, meaning that a worse report tone is associated with better returns in the next year.

When we subdivide the sample of banks by adding interaction terms based on the auditor (Big Four/other), bank status (solvent/insolvent), and ownership (with foreign capital/ with Ukrainian capital), the coefficient before the tone of the audit report becomes significant at a $5 \%$ significance level. However, adding interaction terms does not imply that the effect of the tone of the audit report for these groups statistically differs from the effect on the ROA of other groups. Nevertheless, the difference in effects is statistically significant when we choose a bank with Ukrainian capital audited not by a Big Four auditor: the tone of the reports for these banks is, on average, worse.

Results for ROE are presented in Table 3.

Table 3. Estimation Results for ROE

\begin{tabular}{lcc}
\hline & Original model & $\begin{array}{c}\text { Model with added } \\
\text { cross-terms }\end{array}$ \\
\hline Lagged Tone (ML) & $-1.531^{*}$ & $-1.476^{*}$ \\
Lagged Readability (FOG) & $(0.779)$ & $(0.766)$ \\
Lagged Tone*Auditor & -0.020 & -0.008 \\
Lagged Tone*Bank status & $(0.018)$ & $(0.018)$ \\
Lagged Tone*Auditor*Status & & 0.621 \\
& & $(0.484)$ \\
Lagged log (Total Assets) & & -1.952 \\
& & $(3.836)$ \\
Lagged Cash Ratio & -1.753 \\
& -0.116 & $(1.277)$ \\
Lagged log (Operating Expenses) & $(0.283)$ & $(-0.054$ \\
& $0.001^{* *}$ & $(0.248)$ \\
Constant term & $(0.000)$ & 0.002 \\
& $-0.296^{* * *}$ & $(0.002)$ \\
Sample size & $(0.105)$ & $-0.304^{* * *}$ \\
Adjusted R & 4.302 & $(0.103)$ \\
\hline
\end{tabular}

Notes: Additional controls for this regression are dummies for auditor type (Big Four/other), bank status (solvent/ insolvent), ownership (with foreign capital/with Ukrainian capital). The base auditor type is "other", the base bank status is "solvent", the base ownership status is "with Ukrainian capital"; * if p-value $<0.1,{ }^{* *}$ if p-value $<0.05,{ }^{* * *} p<0.01$. 
As with ROA, the ROE regression is controlled for bank size (expressed as a lagged value of the logarithm of Total Assets), cost management (expressed as a lagged value of the logarithm of operating expenses), the adequacy of the most liquid funds that can be used to cover liabilities (expressed as a lagged value of the Cash-to-Total Liabilities ratio).

The amount of assets is statistically insignificant; ROE is found to be independent of bank size.

The Cash-to-Total Liabilities ratio is found to be positively correlated with ROE; greater Cash and Cash Equivalents relative to Total Liabilities result in higher ROE in the next year. However, the coefficient before this variable influences our model imperceptibly because it is mathematically insignificant, even though it is highly significant $(p<0.01)$. This is explained by the fact that profitable banks should have adequate amount of Cash and Equivalents to handle a decrease in liabilities. However, greater liquidity equals lower risk and lower returns.

We find a highly statistically significant $(p<0.01)$ negative association between operating expenditures and profitability. Holding all other variables constant, on average, a $10 \%$ increase in operating expenditures is associated with a 0.03 decrease in ROE in the next year.

The readability of reports shows no association with next-period ROE, meaning that the complexity of a report does not impact profitability, even though a review of the literature does show a negative relationship between readability and profitability.
The main finding is that the tone of the report is found to be marginally significant ( 0.05 significance level) and negatively associated with ROE in the next period. This means that a worse tone of auditor report is associated with better returns in the next financial year.

When we subdivide the sample of banks by adding interaction terms based on the auditor (Big Four/other), bank status (solvent/insolvent), and ownership (with foreign capital/with Ukrainian capital), the coefficient before the tone remains marginally significant at a $5 \%$ significance level. However, adding interaction terms does not imply that the effect of the tone of the auditor report for these groups differs statistically from the effect on ROE for the other groups of banks.

To check if tone and readability variables are constructed correctly, we conduct the validation test. Since some banking institutions (Industrialbank, Citi, KredoBank, BTA Bank, Creditwest Bank, Bank Vostok etc.) publish their reports both in Ukrainian and English, we check how coefficients for tone and readability indices may well correlate for translated from Ukrainian into English reports and reports published initially in English with the help of Student's t-test. During the test, we find that the results are valid due to extremely low P-values obtained from two-tail t-test: 0.006 and 0.001 for tone and readability, respectively. In other words, we reject the hypotheses that both tone and readability samples of coefficients statistically differ for translated and originally English reports.

Table 4. Tests of the Robustness of Regressors for ROA

\begin{tabular}{|c|c|c|c|}
\hline & $\begin{array}{l}\text { Original model (Loughran } \\
\text { and McDonald's dictionary, } \\
\text { FOG Index) }\end{array}$ & $\begin{array}{l}\text { Tone identified } \\
\text { using the Multilingual } \\
\text { dictionary }\end{array}$ & $\begin{array}{c}\text { Readability calculated } \\
\text { using Flesch-Kincaid } \\
\text { Index }\end{array}$ \\
\hline Lagged Tone (ML) & $\begin{array}{c}-0.066^{*} \\
(0.039)\end{array}$ & & $\begin{array}{l}-0.067^{*} \\
(0.039)\end{array}$ \\
\hline Lagged Readability (FOG) & $\begin{array}{c}-0.001 \\
(0.002)\end{array}$ & $\begin{array}{c}0.000 \\
(0.002)\end{array}$ & \\
\hline Lagged log (Total Assets) & $\begin{array}{l}0.027^{*} \\
(0.016)\end{array}$ & $\begin{array}{l}0.027^{*} \\
(0.016)\end{array}$ & $\begin{array}{c}0.026 \\
(0.016)\end{array}$ \\
\hline Lagged Cash Ratio & $\begin{array}{l}0.001^{* * *} \\
(0.000)\end{array}$ & $\begin{array}{l}0.001^{* * *} \\
(0.000)\end{array}$ & $\begin{array}{l}0.001^{* * *} \\
(0.000)\end{array}$ \\
\hline Lagged log (Operating Expenses) & $\begin{array}{c}-0.033^{* * *} \\
(0.011)\end{array}$ & $\begin{array}{c}-0.034^{* * *} \\
(0.011)\end{array}$ & $\begin{array}{c}-0.033^{* * *} \\
(0.011)\end{array}$ \\
\hline Lagged Tone (Multilingual) & & $\begin{array}{l}-0.049 \\
(0.033)\end{array}$ & \\
\hline Lagged Readability (FK) & & & $\begin{array}{c}-0.001 \\
(0.002)\end{array}$ \\
\hline Constant term & $\begin{array}{l}-0.046 \\
(0.192)\end{array}$ & $\begin{array}{l}0.004 \\
(0.194)\end{array}$ & $\begin{array}{c}-0.055 \\
(0.191)\end{array}$ \\
\hline Sample size & 391 & 391 & 391 \\
\hline Adjusted $\mathrm{R}^{2}$ & 0.133 & 0.126 & 0.133 \\
\hline
\end{tabular}

Notes: ${ }^{*}$ if $\mathrm{p}$-value $<0.1,{ }^{* *}$ if $\mathrm{p}$-value $<0.05,{ }^{* * *} \mathrm{p}<0.01$ 
We conduct a Hausman test for the fixed versus random effects model and find that the fixed-effects model is appropriate in the case of the unbalanced panel dataset of Ukrainian banks (i.e. we reject the null hypothesis that random effects is the preferred model). The Wald test identifies the presence of heteroscedasticity, but since this is a common issue, we mitigate it using robust standard errors. After testing the main two independent variables (tone and readability) on the multicollinearity, we find an absence of intercorrelations or inter-associations, meaning the issue will not adversely affect the results of the regression. Finally, the Durbin-Wu-Hausman test for endogeneity shows no correlation between the independent variable and the residual term, meaning we correctly identified the style of our model and we can expect an absence of endogeneity bias in the regression results.

\subsection{Tests of the Robustness of the Regressors}

We examined the validity of our core regressors, report tone and readability, by substituting:

1) Tone of the report estimated using the Loughran and McDonald's Dictionary of Positive and Negative Words with tone as calculated with the help of a multilingual dictionary of positive and negative words;

2) The readability of the FOG Index with the Flesch-Kincaid Readability Index.
When testing both regressors for the model with ROA as the dependent variable, the control variables, lagged logarithm of Total Assets and Cash/Total Liabilities, are found to hold their signs and significance levels when testing the tone. The same result is observed when checking for readability. Also, while testing readability, the lagged logarithm of Total Assets remains marginally significant, as previously. Meanwhile, the coefficient of the lagged logarithm of operating expenses slightly increases without a change in sign and significance when altering the tone of the report.

The robustness test for the model with ROE as the dependent variable reflects the same general pattern as the ROA test, with some differences in controls. For instance, the lagged logarithm of Total Assets remains insignificant for both tests of tone and readability and remains negative. The lagged logarithm of operating expenses holds its sign and significance level when testing for readability and tone, but changes slightly in magnitude when testing for tone. Moreover, changing the method of calculating tone decreases the significance of the cash ratio and makes it insignificant at more than $90 \%$ confidence level.

One of the core regressors, readability, is insignificant and negatively correlated with ROA and ROE in all tests. The other main independent variable, tone, is found to be insignificant $(p=0.14)$ in testing, however, it holds its sign and the level of significance when testing readability.

Tables 4 and 5 below show the detailed results of the test of the robustness of the regressors for ROA and ROE.

Table 5. Tests of the Robustness of Regressors for ROE

\begin{tabular}{|c|c|c|c|}
\hline & $\begin{array}{l}\text { Original model (Loughran } \\
\text { and McDonald's dictionary, } \\
\text { FOG Index) }\end{array}$ & $\begin{array}{l}\text { Tone identified } \\
\text { using the Multilingual } \\
\text { dictionary }\end{array}$ & $\begin{array}{c}\text { Readability calculated } \\
\text { using Flesch-Kincaid } \\
\text { Index }\end{array}$ \\
\hline Lagged Tone (ML) & $\begin{array}{l}-1.531^{*} \\
(0.779)\end{array}$ & & $\begin{array}{l}-1.528^{*} \\
(0.778)\end{array}$ \\
\hline Lagged Readability (FOG) & $\begin{array}{l}-0.019 \\
(0.018)\end{array}$ & $\begin{array}{l}-0.014 \\
(0.019)\end{array}$ & \\
\hline Lagged log (Total Assets) & $\begin{array}{c}-0.116 \\
(0.283)\end{array}$ & $\begin{array}{c}-0.111 \\
(0.283)\end{array}$ & $\begin{array}{c}-0.117 \\
(0.282)\end{array}$ \\
\hline Lagged Cash Ratio & $\begin{array}{l}0.001^{* *} \\
(0.000)\end{array}$ & $\begin{array}{c}0.001 \\
(0.000)\end{array}$ & $\begin{array}{c}0.001^{* *} \\
(0.000)\end{array}$ \\
\hline Lagged log (Operating Expenses) & $\begin{array}{c}-0.296^{* * *} \\
(0.105)\end{array}$ & $\begin{array}{c}-0.311^{* * *} \\
(0.109)\end{array}$ & $\begin{array}{c}-0.296 * * * \\
(0.105)\end{array}$ \\
\hline Lagged Tone (Multilingual) & & $\begin{array}{l}-0.234 \\
(0.331)\end{array}$ & \\
\hline Lagged Readability (FK) & & & $\begin{array}{l}-0.020 \\
(0.019)\end{array}$ \\
\hline Constant term & $\begin{array}{c}4.302 \\
(3.983)\end{array}$ & $\begin{array}{l}5.296 \\
(4.461)\end{array}$ & $\begin{array}{c}4.211 \\
(3.967)\end{array}$ \\
\hline Sample size & 391 & 391 & 391 \\
\hline Adjusted $\mathrm{R}^{2}$ & 0.038 & 0.013 & 0.038 \\
\hline
\end{tabular}

Notes: ${ }^{*}$ if $\mathrm{p}$-value $<0.1,{ }^{* *}$ if $\mathrm{p}$-value $<0.05,{ }^{* * *} \mathrm{p}<0.01$ 


\section{CONCLUSIONS}

In our study, we apply a quantitative content analysis to independent audit reports of Ukrainian banks to identify the relationship between the tone of the reports and the bank's profitability in the subsequent year. The data have been sourced from the NBU and the annual audit reports of Ukrainian banks from 2012 to 2016 . The final dataset consists of financial data from those same sources, as well as of newly created variables that embody the communicative value of auditor reports through readability and tone. We built a fixed-effects model within a panel regression to test the relationship between audit report readability and tone and bank performance in the next financial period.

The readability of financial reports is widely used in the literature as a determinant of the performance of financial institutions. However, no quantitative content analyses have been conducted for Ukraine's banking system. Moreover, incorporating the tone of audit reports is unique and has not been studied before. Thus, the research sufficiently contributes to the existing literature and provides practical evidence that helps understand the influence of the communicative value of the reports on bank profitability.

We have observed that both readability indices (the FOG Index and the Flesch-Kincaid Index) have increased slightly over time. This trend reflects a worsening of readability, or that reports are becoming more complicated to read as sentences increase in length and more sophisticated financial terms are used. According to the literature, this decreases the communicative value of reports, which is associated with a lower ROA. However, our study of the Ukrainian banking system suggests that the change in readability has not had a significant impact on the performance of banks.

This study also finds that the tone of audit reports has generally remained steady over time, judging by the Loughran and McDonald's Dictionary of Positive and Negative Words. On the other hand, an ordinary multilingual dictionary of positive and negative words does show that, on average, the tone of reports written in 2014 and 2015 is much lower than before that period (2012) or after (2016). That difference may be the result of the difficult conditions on Ukrainian financial markets and the liquidation of 63 banks during that period.

In the result of our research, we reject at the $10 \%$ significance level the initial hypothesis that posits that the tone of independent auditor reports is positively associated with ROA in the next financial period; the relationship is found to be negative. Tone is found to be marginally significant at the 0.05 significance level and negatively correlated with ROE in the next period, meaning that a worse tone in a report is associated with better returns in the next financial year. For both ROA and ROE, we reject the null hypothesis that readability has a negative correlation with bank performance in the subsequent financial year; our study found no relationship.
Thus, we conclude that Ukrainian banks internalize the information in auditor reports when considering a change in policies related to key financial indicators. Since independent auditor reports are usually made public in March or April, a bank's management has almost nine months until the next auditor report. This is an adequate amount of time to revise policies and fine-tune the direction of development efforts if the tone has proven negative.

Despite appropriate econometric specification, our model has limitations stemming from Ukraine's financial environment. For instance, in Ukraine, banks have more power than auditors, which creates a serious obstacle for the actual independence of auditors in the preparation of reports.

Since the tone of reports is found to be a significant factor in determining the profitability of banks in Ukraine, this paper aims to bring more attention to independent auditor reports in Ukraine. An increase in the importance of the reports can benefit key stakeholders within Ukraine, like the $\mathrm{NBU}$, auditors, commercial banks, and bank clients (individuals and legal entities), international financial organizations, and Ukrainians in general.

Tone can also become an additional indicator for the NBU of the improper functioning of both the auditor and the bank being audited. If a report's tone were to differ substantially from the findings of the NBU's Department of Bank Supervision, the Committee on Bank Audit should examine the case and rule on both economic agents. A deterioration in tone from year to year would also be reason to further investigate the activity of a bank.

An increase in the importance of the tone of auditor reports would potentially increase the responsibility of auditors, while the adoption of proper regulations would empower auditors and eliminate the influence banks can impose on the conclusions of auditors. That would make audit reports a reliable source for international organizations to rank Ukrainian banks. Transparency and profitability can help banks attract funding at lower rates on international markets. More accessible and meaningful auditor reports would simplify their usage by bank clients, which would help develop their financial maturity.

This study contributes to the existing financial, economic, and audit literature on the determinants of bank profitability, quantitative content analysis, and the topic of asymmetric information in the banking system through an analysis of the communicative value of independent auditor reports. This study identifies areas for further investigations, especially the link between the negative tone of reports and violations of banking legislation by Ukrainian banks. 


\section{REFERENCES}

- Adusei M. (2015). Bank Profitability: Insights From the Rural Banking Industry in Ghana. Cogent Economics \& Finance, Vol. 3, No. 1: 1078270. https://doi.org/10.1080/233 22039.2015.1078270

- Antweiler W., Frank M. (2004). Is All That Talk Just Noise? The Information Content of Internet Stock Message Boards. Journal of Finance, Vol. 59, No. 3, pp. 1259-1294. https://doi.org/10.1111/j.1540-6261.2004.00662.x

- Arellano M., Bond S. (1991). Some Tests of Specification for Panel Data: Monte Carlo Evidence and an Application to Employment Equations. TheRreview of Economic Studies, Vol. 58, No. 2, pp. 277-297. https://doi.org/10.2307/2297968

- Asare S. K., Wright A. M. (2012). Investors', Auditors', and Lenders' Understanding of the Message Conveyed by the Standard Audit Report on the Financial Statements. Accounting Horizons, Vol. 26, No. 2, pp. 193-217. https://doi. org/10.2308/acch-50138

- Bloomfield R. (2008). Discussion of "Annual Report Readability, Current Earnings, and Earnings Persistence". Journal of Accounting and Economics, Vol. 45, No. 2-3, pp. 248-252. https://doi.org/10.1016/j.jacceco.2008.04.002

- Bourke P. (1989). Concentration and Other Determinants of Bank Profitability in Europe, North America and Australia. Journal of Banking \& Finance, Vol. 13, No. 1, pp. 65-79.

- Church B. K., Shawn M. D, McCracken S. A. (2008). The Auditor's Reporting Model: A Literature Overview and Research Synthesis. Accounting Horizons, Vol. 22, No. 1, pp. 69-90. https://doi.org/10.2308/acch.2008.22.1.69

- Coram P. J., Mock T.J, Turner J. L, Gray G. L. (2011). The Communicative Value of the Auditor's Report. Australian Accounting Review, Vol. 21, No. 3, pp. 235-252. https://doi. org/10.1111/j.1835-2561.2011.00140.x

- Doogar R., Rowe S. P, Sivadasan P. (2015). Asleep at the Wheel (Again)? Bank Audits During the Lead-Up to the Financial Crisis. Contemporary Accounting Research, Vol. 32, No. 1, pp. 358-391. https://doi.org/10.1111/1911-3846.12101

- Eichengreen B., Gibson H. (2001). Greek Banking at the Dawn of the New Millennium. CEPR Discussion Paper, No. 2791.

- Fakhfakh M. (2015). The readability of international illustration of auditor's report: An advanced reflection on the compromise between normative principles and linguistic requirements. Journal of Economics, Finance and Administrative Science, Vol. 20, No. 38, pp. 21-29. https:// doi.org/10.1016/j.jefas.2015.02.001

- Flamini V., McDonald C., Schumacher L. (2009). The Determinants of Commercial Bank Profitability in Sub-Saharan Africa. Working Paper, No. 9-15, International Monetary Fund.

- Gray G. L., Turner J. L., Coram P. J., Mock T. J. (2011). Perceptions and misperceptions regarding the unqualified auditor's report by financial statement preparers, users, and auditors. Accounting Horizons, Vol. 25, No. 4, pp. 659-684. https://doi.org/10.2308/acch-50060
- Harris H. (2001). Content Analysis of Secondary Data: A Study of Courage in Managerial Decision Making. Journal of Business Ethics, Vol. 34, No. 3-4, pp. 191-208. https://doi. org/10.1023/A:1012534014727

Heffernan S., Fu M. (2008). The Determinants of Bank Performance in China. 21st Australasian Finance and Banking Conference 2008 Paper http://dx.doi.org/10.2139/ ssrn.1247713

Henry E. (2008). Are Investors Influenced by how Earnings Press Releases are Written? Journal of Business Communication, Vol. 45, No. 4, pp. 363-407. https://doi. org/10.1177/0021943608319388

- Hermanson D.R., Duncan P., Carcello J. V. (1991). Does the new audit report improve communication with investors? Ohio CPA Journal, (May/June): pp. 32-37.

- Insch G. S., Moore J. E., Murphy L. D. (1997). Content Analysis in Leadership Research: Examples, Procedures, and Suggestions for Future Use. The Leadership Quarterly, Vol. 8, No. 1, pp. 1-25. https://doi.org/10.1016/S1048-9843(97)90028-X

- Kosak M., Cok M. (2008). Ownership Structure and Profitability of the Banking Sector: The Evidence from the SEE-6 Region. Proceedings of Rijeka Faculty of Economics, Journal of Economics and Business, Vol. 26, No. 1, 2008, pp. 93-122 https://ssrn.com/abstract=2268462

- Kosmidou K. (2008). The Determinants of Banks' Profits in Greece During the Period of EU Financial Integration. Managerial Finance, Vol. 34, No. 3, pp. 146-159. https://doi. org/10.1108/03074350810848036

- Li F. (2008). Annual Report Readability, Current Earnings, and Earnings Persistence. Journal of Accounting and Economics, Vol. 45, No. 2-3, pp. 221-247. https://doi. org/10.1016/j.jacceco.2008.02.003

- Li F. (2010). The Information Content of Forward-Looking Statements in Corporate Filings-A Narve Bayesian Machine Learning Approach. Journal of Accounting Research, Vol. 48, No. 5, pp. 1049-1102. https://doi.org/10.1111/j.1475679X.2010.00382.x

- Loughran T., McDonald B. (2011). When is a Liability Not a Liability? Textual Analysis, Dictionaries, and 10-Ks. Journal of Finance, Vol. 66, No, 1, pp. 35-65. https://doi.org/10.1111/ j.1540-6261.2010.01625.x

- Loughran T., McDonald B. (2014). Measuring Readability in Financial Disclosures. Journal of Finance, Vol. 69, No. 4, pp. 1643-1671. https://doi.org/10.1111/jofi.12162

- Manson S., Zaman M. (2001). Auditor Communication in an Evolving Environment: Going Beyond SAS 600 Auditors' Reports on Financial Statements. The British Accounting Review, Vol. 33, No. 2, pp. 113-136. https://doi.org/10.1006/ bare.2001.0157

- Mock T. J., Bédard J., Coram P.J., Davis S. M., Espahbodi R., Warne R. C. (2013). The Audit Reporting Model: Current Research Synthesis and Implications. Auditing: A Journal of Practice \& Theory, Vol. 32, No. Supplement 1, pp. 323-351. https://doi.org/10.2308/ajpt-50294 
- Mock T. J., Turner J. L, Gray G. L, Coram P. J. (2009). The Unqualified Auditor's Report: A Study of User Perceptions, Effects on User Decisions and Decision Processes, and Directions for Further Research. A Report to the Auditing Standards Board and the 42 International Auditing and Assurance Standards Board (June), New York, NY.

- MolyneuxP., Thornton J. (1992). Determinants of European Bank Profitability: A Note. Journal of Banking \& Finance, Vol. 16, No. 6, pp. 1173-1178. https://doi.org/10.1016/03784266(92)90065-8

- Naceur B. S., Goaied M. (2008). The Determinants of Commercial Bank Interest Margin and Profitability: Evidence From Tunisia. Frontiers in Finance and Economics, Vol. 5, No. 1, pp. 106-130. https://ssrn.com/abstract=1538810

- Pervan M., Pervan I. (2010). Market Structure and Profitability of Croatian Commercial Banks. The Business Review, Vol. 20, No. 1, pp. 209-216.

- Pervan M., Pelivan I., Arnerić J. (2015). Profit Persistence and Determinants of Bank Profitability in Croatia. Economic Research-Ekonomska Istraživanja, Vol. 28, No. 1, pp. 284-298. https://doi.org/10.1080/1331677X.2015.1041778
- Sikka P. (2009). Financial Crisis and the Silence of the Auditors. Accounting, Organizations and Society, Vol. 34, No. 6-7, pp. 868-873. https://doi.org/10.1016/j.aos.2009.01.004

- Simon H. A. (1999). Administrative Behavior: A Study of Decision-making Processes in Administrative Organization. Free Press; 4th edition.

- Smith K. W. (2016). Tell Me More: A Content Analysis of Expanded Auditor Reporting in the United Kingdom. http://dx.doi.org/10.2139/ssrn.2821399

- Tetlock P. C. (2007). Giving Content to Investor Sentiment: The Role of Media in the Stock Market. Journal of Finance, Vol. 62, No. 3, pp. 1139-1168. https://doi.org/10.1111/ j.1540-6261.2007.01232.x

- Tetlock P. C., Saar-Tsechansky, and Sofus MacSkassy. (2008). More Than Words: Quantifying Language to Measure Firms' Fundamentals. Journal of Finance, Vol. 63, No. 3, pp.1437-1467. https://doi.org/10.1111/j.1540-6261.2008.01362.x 
APPENDIX A. DESCRIPTIVE STATISTICS OF FINANCIAL INDICATORS Table A1. Extended Descriptive Statistics of Key Financial Indicators of Ukrainian Banks Year $=2012$

\begin{tabular}{lccccc}
\hline Variable & Obs & Mean & Std. Dev. & Min & Max \\
\hline Total_Assets & 175 & $6,441,025$ & $17,485,094$ & 122,171 & $172,428,712$ \\
Total_Equity & 175 & 972,551 & $2,553,103$ & $-670,739$ & $18,300,761$ \\
Net_Income & 175 & 104,176 & 282,932 & $-15,325$ & $2,575,402$ \\
Total_Liabilities & 175 & $5,468,475$ & $15,049,505$ & 36 & $154,127,951$ \\
Cash & 175 & 941,477 & $2,898,498$ & 4,524 & $26,957,511$ \\
Oper_exp & 173 & 76,243 & 183,412 & 13,645 & $1,535,691$ \\
\hline
\end{tabular}

Year $=2013$

\begin{tabular}{|c|c|c|c|c|c|}
\hline Variable & Obs & Mean & Std. Dev. & Min & Max \\
\hline Total_Assets & 180 & 7,097,270 & $20,505,984$ & 121,081 & $214,490,857$ \\
\hline Total_Equity & 180 & $1,069,994$ & $2,909,194$ & 68,673 & $20,455,511$ \\
\hline Net_Income & 180 & 94,441 & 260,013 & $-25,967$ & $2,208,615$ \\
\hline Total_Liabilities & 180 & $6,027,276$ & $18,040,102$ & 1 & $194,179,236$ \\
\hline Cash & 180 & 830,753 & $2,631,464$ & 467 & $32,157,251$ \\
\hline Oper_exp & 176 & 87,332 & 210,453 & 1,235 & $1,944,492$ \\
\hline
\end{tabular}

Year $=2014$

\begin{tabular}{|c|c|c|c|c|c|}
\hline Variable & Obs & Mean & Std. Dev. & Min & Max \\
\hline Total_Assets & 157 & $8,341,840$ & $23,640,582$ & 84,765 & $204,585,002$ \\
\hline Total_Equity & 157 & 938,075 & $3,032,732$ & $-7,132,649$ & $22,749,157$ \\
\hline Net_Income & 157 & 106,033 & 330,211 & $-250,098$ & 2,779,612 \\
\hline Total_Liabilities & 157 & 7,403,765 & $20,849,815$ & 112 & $181,888,643$ \\
\hline Cash & 157 & 938,554 & $2,870,072$ & 839 & $27,075,551$ \\
\hline Oper_exp & 156 & 111,936 & 273,731 & 130,977 & 2,333,561 \\
\hline
\end{tabular}




\section{Table A1 continued}

\begin{tabular}{|c|c|c|c|c|c|}
\hline Variable & Obs & Mean & Std. Dev. & Min & Max \\
\hline Total_Assets & 113 & $11,167,334$ & $33,010,876$ & 121,359 & $264,886,279$ \\
\hline Total_Equity & 113 & 839,946 & $3,304,855$ & $-12,269,344$ & $27,487,223$ \\
\hline Net_Income & 113 & 617,486 & $1,428,050$ & $-668,166$ & $8,781,142$ \\
\hline Total_Liabilities & 113 & $10,217,887$ & $30,830,887$ & 128 & $237,399,056$ \\
\hline Cash & 113 & $1,363,400$ & $4,338,635$ & 359 & $36,260,225$ \\
\hline Oper_exp & 113 & 411,369 & 992,886 & 2,836 & $8,181,155$ \\
\hline
\end{tabular}

Year $\mathbf{2} \mathbf{2 0 1 6}$

\begin{tabular}{lccccc}
\hline Variable & Obs & Mean & Std. Dev. & Min & Max \\
\hline Total_Assets & 93 & $13,436,554$ & $36,586,102$ & 81,341 & $220,017,620$ \\
Total_Equity & 93 & $1,329,973$ & $2,728,832$ & 21,460 & $14,932,547$ \\
Net_Income & 93 & $-1,704,102$ & $14,198,623$ & $-135,309,076$ & $3,820,644$ \\
Total_Liabilities & 93 & $12,026,554$ & $34,208,734$ & 216 & $207,408,290$ \\
Cash & 93 & $1,813,551$ & $5,551,158$ & 29 & $410,482,098$ \\
Oper_exp & 93 & 534,618 & $1,273,828$ & 9,031 & $9,287,553$ \\
\hline
\end{tabular}




\title{
ESTIMATING THE FISCAL IMPULSE IN UKRAINE
}

\author{
ARTEM VDOVYCHENKOa * \\ aNational Bank of Ukraine \\ Email: artem.vdovychenko@bank.gov.ua
}

\begin{abstract}
This paper estimates the fiscal impulse for Ukraine following the methodology of the OECD, which disaggregates budget revenues and expenditures into categories that are driven by economic cycles. To estimate the fiscal impulse the author calculates both long-term and short-term elasticities of various budget items with respect to GDP. This approach allows the author (i) to identify the fiscal policy response to economic crises in Ukraine in 2008-2009 and in 2014, and (ii) to reveal those budget items that remain sensitive to the fluctuations in the business cycle. The fiscal policy response to the 2014 crisis is found to be significantly tighter than the response to the crisis of 2008-2009. In addition, corporate income tax shows the strongest response to economic cycles among budget revenue categories, while VAT has the greatest contribution to the cyclical component of Ukraine's budget balance.
\end{abstract}

JEL Codes E62, H3, H61, C22

Keywords fiscal stance, fiscal impulse, dynamic least squares, autoregressive distributed lag model

\section{INTRODUCTION}

The economic shocks that have hit Ukraine in recent years are having a direct impact on fiscal policy, which has tightened. The system of public finance itself has become the sphere for conducting a range of radical reforms aimed at raising the efficiency of tax administration and budget expenditures. Such rapid changes on the fiscal front raise the issue of evaluating fiscal policy itself and the nature of its economic impact.

The standard approach to fiscal policy assessment is to calculate the fiscal impulse - a measure of change in the budget deficit that is adjusted for the automatic effects of various economic processes. The fiscal impulse measure describes the nature of the government's discretionary fiscal policy, which may seek to stimulate the economy (a loose fiscal policy) or restrain it (a tight fiscal policy). Researchers calculate and use this fiscal policy indicator in economic studies so as to understand the links between fiscal policy and other variables, and to predict inflation, GDP growth, and sovereign debt. However, the fiscal impulse is an estimated value, which raises a number of theoretical and empirical issues regarding consistency in its estimation.

This study focuses on estimating the fiscal impulse for Ukraine to identify periods of tight and loose fiscal policy in the country and to gain additional insight into predicting future movements in other macroeconomic indicators. To demonstrate our results, we test the hypothesis that Ukraine's fiscal policy response to the economic crisis of 2014 was tighter than that in the crisis of 2008-2009.

This study estimates the fiscal impulse using OECD methodology (Bouthevillain et al., 2001). This approach pinpoints the budget's cyclical components with greater accuracy by disaggregating them. To compare and test the robustness of our results, we also apply the methodology that has long been used by the IMF (Heller et al., 1986). The calculations use quarterly data from 2004-2016, which allows the estimation of the cyclical component of the budget balance during the crises of 2008 and 2014, and the fiscal policy response to these crises. As data sources, we used budgetary statistics from the State Treasury Service of Ukraine and GDP data from the State Statistics Service of Ukraine. The first research contribution of this study is an estimation of the fiscal impulse for Ukraine, making it possible to identify the extent of the tightening of fiscal policy in various periods. The second contribution is an estimation of the elasticities of a set of budget categories with respect to GDP, so as to obtain insights into how various budget revenue and expenditure items influence the structural budget balance.

The paper's structure is as follows: section two reviews the fiscal impulse estimation literature and methodologies; section three outlines the approach we use to estimate the fiscal impulse; section four describes the statistical attributes of the data; section five presents the results, and the last section discusses the results and gives the conclusions.

\section{LITERATURE REVIEW: MAIN APPROACHES TO ESTIMATING FISCAL POLICY STANCE}

Problems in determining the magnitude of the fiscal impulse arise from the fact that the nominal budget balance is a misleading measure of fiscal policy, as this measure is influenced by economic cycle fluctuations (Bouthevillain et al., 2001). A simple view on the budget balance structure allows for the identification of a cyclical component, which emerges as a result of the actions of automatic stabilizers, and a trend that is an approximate indicator of the discretionary fiscal policy itself. The actions of the automatic stabilizers are triggered by the economic nature of certain categories of budget expenditures and revenues. Revenues 
from the value-added tax (VAT) increase as final consumption rises, the latter positively correlating with the phase of the economic cycle. Among public sector expenditures, the classic example is unemployment benefit payments, which rise in periods of economic downturn. We can thus observe an automatic response of tax receipts to economic fluctuations that are unconnected to the government's fiscal policy decisions. The action of automatic stabilizers may obscure the real state of affairs in fiscal policy and distort the decisions of the officials in charge. The conventional approach to preventing these distortions is to calculate the cyclically adjusted primary balance (CAPB), which includes a structural component and the unanticipated discretionary fiscal decisions of the government. The CAPB is also frequently referred to as the fiscal stance (FS). The fiscal impulse (FI) is obtained by taking the first differences of the FS and indicates the direction and extent of the change in fiscal policy against the previous period.

Gali and Perotti (2003) argue that the budget deficit can be represented as the sum of the cyclical and structural components. The cyclical (nondiscretionary) deficit varies as processes beyond the government's control take place: cyclical fluctuations in the level of employment and tax bases. Along with this, cyclical fluctuations mainly affect tax receipts, as tax bases are very frequently connected to the economic cycle. As for budget expenditure categories, an obvious link exists between unemployment benefits and economic cycles, with the former acting as automatic stabilizers. ${ }^{1}$ Public debt servicing payments can also be viewed as a part of the "nondiscretionary component", as the government has no influence on their magnitude in the current period.

The cyclically adjusted (discretionary) deficit is a budget deficit that corresponds to the economy's potential GDP. ${ }^{2}$ In the literature, this indicator is frequently referred to as the fiscal stance. The fiscal stance is conventionally broken down into two parts: structural (endogenous) and non-systemic (exogenous). The endogenous component is the systemic response of the government to current or anticipated economic events. In other words, unlike the cyclical component, this deficit is a consequence of a fiscal policy decision by the government, rather than a mechanical reaction to economic developments. The exogenous component contains random changes to fiscal policy that do not result from systemic government decisions, but rather arise from exogenous political events or extraordinary circumstances (elections, hostilities, etc.). As the fiscal impulse is obtained by taking the first differences of fiscal stance, estimating fiscal stance is the first step in replicating fiscal impulse dynamics.

One of the fiscal stance estimation approaches that we are familiar with is the model that was in use by the IMF for a certain period (Heller et al., 1986):

$$
\begin{gathered}
\mathrm{FB}_{\mathrm{t}}=\left(\mathrm{R}_{\mathrm{t}}-\mathrm{G}_{\mathrm{t}}\right) \\
\mathrm{FB}_{\mathrm{t}}=\left(\mathrm{r}_{0} \mathrm{Y}_{\mathrm{t}}^{*}-\mathrm{g}_{0} \mathrm{Y}_{\mathrm{t}}^{*}\right)-\left[\mathrm{r}_{0}\left(\mathrm{Y}_{\mathrm{t}}^{*}-\mathrm{Y}_{\mathrm{t}}\right)\right]-\mathrm{FS}_{\mathrm{t}}
\end{gathered}
$$

where $F B_{t}$ is the primary budget balance, $\mathrm{r}_{0}=\mathrm{R}_{0} / \mathrm{Y}_{0}$ is the ratio between budget revenues and base-year nominal
GDP, $\mathrm{g}_{0}=\left(\mathrm{G}_{0}-\mathrm{UIB}_{0}\right) / \mathrm{Y}_{0}$ is the ratio between primary budget expenditures and base-year nominal GDP, $U I B_{0}$ - are base-year unemployment insurance benefits, $Y_{t}$ is nominal GDP in year $t, Y_{t}^{*}$ is potential nominal GDP in year $t, R_{t}$ are budget revenues, $G_{t}$ are primary budget expenditures, and $F S_{t}$ is fiscal stance in year $t$. The base year is the period in which GDP was closest to its potential value. This approach assumes a unit nominal elasticity of budget revenues with respect to GDP and a unit elasticity of budget expenditures with respect to potential GDP, net of unemployment insurance benefits. Budget expenditures, apart from unemployment benefits, are thus assumed to be acyclic, and deviations in their growth rate from the growth rate of potential GDP are evidence of tight/loose discretionary fiscal policy. Budget revenues, in turn, are assumed to have a unit elasticity with respect to the cycle.

One drawback of this approach is that not all budget revenues are cyclical, and elasticity with respect to GDP does not equal one for all taxes. In fact, this elasticity is very often greater than one. Model (2) thus produces a fiscal stance indicator that includes the automatic response of a number of taxes to changes in output. Another downside is the assumption that unemployment benefits are cyclical, even though they are only partially cyclical, due to the so-called natural rate of unemployment. Model (2) identifies as a fiscal stance the indicator that contains, besides discretionary component, the "fiscal drag", which reflects the growth in the tax burden that occurs as output rises under progressive taxation (Schinasi and Lutz, 1991).

However, the IMF has already taken a new approach to estimate the CAPB. This approach adjusts budget expenditures for the impact of the GDP gap on social security payments, which grow during economic downturns. The IMF methodology also envisages a broader set of factors for which the budget balance has to be adjusted to separate out the discretionary component. These factors include asset price dynamics, price movements in global commodities markets, and changes in the structure of the economy. ${ }^{3}$ Making these adjustments allows the estimation of the structural budget balance (SBB), a fiscal policy measure that requires more complicated estimates than the CAPB, which we estimate in this paper. ${ }^{4}$

The approach of the European Commission is rather widespread among the studies on CAPB. This is the disaggregation-based approach to estimating the elasticity of budget revenues with respect to GDP and capturing the cyclical component of unemployment insurance benefits:

$$
B_{c, t} / Y_{t}=R_{t} / Y_{t} \varepsilon_{R, Y_{r}} \times y_{r, c, t}-\left(\overline{X^{u} / Y}\right) \varepsilon_{X^{U}, Y_{r}} \times y_{r, c, t},
$$

where $B_{c, t}$ is the cyclical fiscal balance, $Y_{t}$ is GDP, $R_{t}$ are budget revenues, $\varepsilon_{R, Y_{r}}$ is the elasticity of budget revenues with respect to output, $X_{t}^{U}$ are unemployment-related budget expenditures, $\overline{X^{u} / Y}$ is the mean for 1970-1994, a reference indicator that reflects a neutral value of the ratio between unemployment insurance benefits and GDP, $\varepsilon_{X^{U}, Y_{r}}$ is the elasticity of unemployment-related budget expenditures with respect to output, and $y_{r, c, t}$ is the real-GDP gap (Bouthevillain et al., 2001).

${ }^{1}$ Automatic stabilizers not always belong to the cyclical part of the budget. For instance, wages in the public sector are acyclic, but they are a stabilizer that supports demand in times of recession (Fatás, 2009).

${ }^{2}$ One can read more about the nature of the potential GDP level and its estimation using the Kalman filter used in this study at Nikolaichuk and Mariiko (2007) and the NBU (2016).

${ }^{3}$ For more on the logic and technical aspects of this adjustment, see Bornhorst et al., (2011). 
The OECD approach extends Model (3) by further disaggregating budget expenditures and by estimating the elasticities of major tax receipts with respect to GDP, and the respective elasticity of unemployment benefits:

$$
\begin{gathered}
\mathrm{B}_{\mathrm{c}, \mathrm{t}} / \mathrm{Y}_{\mathrm{t}}=\sum_{\mathrm{j}} \mathrm{R}_{\mathrm{t}}^{\mathrm{j}} / \mathrm{Y}_{\mathrm{t}} \times \varepsilon_{\mathrm{R}^{\mathrm{j}, \mathrm{V}^{j}}} \times \varepsilon_{\mathrm{V}^{\mathrm{j}}, \mathrm{Y}_{\mathrm{r}}} \mathrm{y}_{\mathrm{r}, \mathrm{c}, \mathrm{t}}- \\
-\mathrm{X}_{\mathrm{t}}^{\mathrm{U}} / \mathrm{Y}_{\mathrm{t}} \times \varepsilon_{\mathrm{X}^{\mathrm{U}}, \mathrm{U}} \times \varepsilon_{\mathrm{u}, \mathrm{Y}_{\mathrm{r}}} \times \mathrm{y}_{\mathrm{r}, \mathrm{c}, \mathrm{t}},
\end{gathered}
$$

where $B_{c, t}$ is the cyclical fiscal balance, $Y_{t}$ is GDP, $R_{t}^{j}$ is a budget revenue item, $\varepsilon_{R^{j}, V^{j}}$ is the elasticity of budget revenues with respect to the relevant macroeconomic base $V_{i}, \varepsilon_{V^{j}, Y_{r}}$ is the elasticity of the macroeconomic base with respect to real GDP, $U$ is the number of unemployed, $X_{t}^{U}$ are unemploymentrelated budget expenditures, and $y_{r, c, t}$ is the real-GDP gap.

The distinguishing feature of the model (4) is its use of cross-elasticities, as it first calculates the elasticities of the relevant tax bases with respect to GDP, and then the elasticities of the relevant budget revenues with respect to the tax bases. Overall, the OECD approach comes closer to removing all automatic responses from the primary budget balance, as the elasticities of cyclical budget components can be greater than one. The IMF approach (Heller et al., 1986), which specifically applies to fiscal stance estimation based on primary-balance calculations, is easy to use and requires less detailed data, at the expense of lower accuracy. Model (4), by contrast, returns more accurate estimates and has higher data requirements (van den Noord, 2000; Girouard and André, 2005; Larch and Turrini, 2009).

Bouthevillain et. al. suggest an augmented version of model (4) (2001):

$$
\begin{gathered}
\mathrm{B}_{\mathrm{c}, \mathrm{t}} / \mathrm{Y}_{\mathrm{t}}=\sum_{\mathrm{j}} \mathrm{R}_{\mathrm{t}}^{\mathrm{j}} / \mathrm{Y}_{\mathrm{t}} \times \varepsilon_{\mathrm{R}^{\mathrm{j}}, \mathrm{v}^{\mathrm{j}}} \times \mathrm{v}_{\mathrm{c}, \mathrm{t}}^{\mathrm{j}}-\mathrm{X}_{\mathrm{t}}^{\mathrm{U}} / \mathrm{Y}_{\mathrm{t}} \times \varepsilon_{\mathrm{X}^{\mathrm{U}}, \mathrm{U}} \times \mathrm{u}_{\mathrm{c}, \mathrm{t}}- \\
-\mathrm{X}_{\mathrm{t}}^{\mathrm{G}} / \mathrm{Y}_{\mathrm{t}} \times \varepsilon_{\omega_{\mathrm{g}, \omega_{\mathrm{p}}}} \times \omega_{\mathrm{p}, \mathrm{c}, \mathrm{t}}
\end{gathered}
$$

where $B_{c, t}$ is the cyclical fiscal balance, $Y_{t}$ is GDP, $R_{t}^{j}$ is a budget revenue item, $\varepsilon_{R^{j}, v^{j}}$ is the elasticity of budget revenues with respect to the relevant macroeconomic base $\left(V_{j}\right), v_{c, t}^{j} u_{c, t}$, $\omega_{p, c, t}$, are values cyclical with respect to GDP, $U$ is the number of unemployed, $X_{t}^{U}$ are unemployment-related budget expenditures, $X_{t}^{G}$ - are public sector wages, and $\omega_{g^{\prime}} \omega_{p}$ are the average real wages in the public and private sectors.

The peculiarity of the model (5) is that it suggests removing the cyclical component of public sector wages from expenditures. The authors assume that public sector wages indirectly depend on cyclical output, due to their connection to the level of wages in the private sector. Real wages in the private sector are positively correlated with fluctuations in output, while public sector wages react to changes in private sector wages. The reliability of these assumptions depends on the wages system in place in a given country. The presence of automatic indexation of public sector wages makes this expenditure category elastic with respect to output.

The use of disaggregation approaches in estimating the fiscal stance requires the estimation of a range of elasticities of budget revenues and expenditures with respect to GDP. To estimate dynamic elasticities, Koester and Priesmeier (2012) suggest an approach that accounts for the presence of cointegration between taxes and the relevant tax base.
As the existence of a long-term cointegration relationship between taxes and relevant tax bases or GDP is, in theory, rather obvious, the authors have proposed a two-stage procedure for estimating long-term and short-term elasticities. With this approach, the authors estimate a cointegration equation (6) and an equation with short-term relationships which contains error-correction component (7):

$$
\begin{gathered}
\mathrm{T}_{\mathrm{t}}^{\mathrm{r}}=\beta_{1}^{\mathrm{r}} \mathrm{X}_{\mathrm{t}}^{\mathrm{r}}+\sum_{\mathrm{n}=1}^{\mathrm{N}} \gamma_{\mathrm{n}}^{\mathrm{r}} \mathrm{D}_{\mathrm{n}, \mathrm{t}}^{\mathrm{r}}+\sum_{\mathrm{i}=1}^{\mathrm{I}} \gamma_{\mathrm{i}}^{\mathrm{r}} \mathrm{S}_{\mathrm{i}, \mathrm{t}}^{\mathrm{r}}+\varepsilon_{\mathrm{t}}^{\mathrm{r}} \\
\Delta \mathrm{T}_{\mathrm{t}}^{\mathrm{r}}=\alpha_{0}^{\mathrm{r}}+\sum_{\mathrm{i}=1}^{\mathrm{I}} \pi_{\mathrm{i}}^{\mathrm{r}} S_{\mathrm{i}, \mathrm{t}}^{\mathrm{r}}+\sum_{\mathrm{n}=1}^{\mathrm{N}} \sum_{\mathrm{j}=0}^{\mathrm{q}} \alpha_{1 \mathrm{n}, \mathrm{j}} \Delta \mathrm{X}_{\mathrm{n}, \mathrm{t}-\mathrm{j}}^{\mathrm{r}}+\sum_{\mathrm{i}=1}^{\mathrm{p}} \alpha_{2, \mathrm{i}}^{\mathrm{r}} \Delta \mathrm{T}_{\mathrm{t}-\mathrm{i}}^{\mathrm{r}}+ \\
+\alpha_{3}^{\mathrm{r}} \varepsilon_{\mathrm{t}-1}^{\mathrm{r}}+\mathrm{u}_{\mathrm{t}}^{\mathrm{r}}
\end{gathered}
$$

where $T_{t}^{r}$ are receipts from the $r$ tax, $X_{t}^{r}$ is the tax base of the $r$ tax, $D_{n, t}^{r}$ are the potential deterministic components $n$ in the form of a constant, a linear trend, or a quadratic trend, $S_{i, t}^{r}$ are potential structural breaks in data in the form of impulses, shifts in levels, or changes in trends, $\varepsilon_{t}^{r}$ are stationary errors that denote deviations from the long-term equilibrium relationship, and $u_{t}^{r}$ are i.i.d. residuals. Of the parameters estimated in models (6) and (7), the one that interests us the most is $\beta_{1}{ }^{r}$ - the long-term elasticity of tax receipts with respect to the relevant base. The $\alpha_{1 n, j}$ coefficients, in turn, indicate short-term elasticity, the $\alpha_{2, i}^{r}$ coefficients indicate the persistence of the growth in tax receipts, while the $\alpha_{3}^{r}$ parameter measures the speed of convergence to the equilibrium relationship.

Unlike the long-term relationship between levels, the current impact of a change in the tax base on tax receipts is modeled as a simultaneous relationship among the growth rates of the variables under study (the $\alpha_{1 n, 0}$ coefficient in the model (7)). This coefficient is a conventional measure of the cyclicality of tax receipts (Koester and Priesmeier, 2012) and can be viewed as a direct short-term effect of tax base variation on tax receipts.

The dynamic nature of macroeconomic and fiscal variables, as well as the quantity of factors influencing them, justifies including lags of relevant variables into the model. This allows for the persistence of time series under analysis to be taken into account, mitigates the problems with the model's specification, and enables the removal of autocorrelation from errors.

Methods for estimating fiscal stance that are used in the literature vary by the degree of detail of budget categories that respond to cyclical economic fluctuations, and by their interpretations of the cyclical component of budget expenditures. Moreover, there is a certain consensus about the cyclicality of tax receipts, as the economic nature of the various types of taxes is approximately the same across all countries. However, country-specific features of public finances cause the discrepancies in interpretation of cyclicality of budget expenditures. In addition, fiscal stance estimation comes with a number of methodological issues related to endogeneity and the interpretation of the concept of discretionary fiscal policy.

\section{THE METHOD OF ESTIMATING FISCAL IMPULSE}

Figures $\mathrm{A} 1$ and $\mathrm{A} 2$ (in Appendix A) show the general fiscal policy trends in Ukraine. From the movements in the 
consolidated budget balance, it can be inferred that recent years have seen a rapid decline in Ukraine's budget deficit. Another observation that stands out is the widening of the gap between the nominal and primary budget deficits, especially when the hryvnia depreciates. The dynamics and structure of tax receipts (Figure A2) point to a gradual rise in the share of taxes in GDP, and a shift of the tax system away from direct taxes (the corporate income tax and individual income tax) towards indirect taxes (VAT, excise taxes, and import tariffs). The shift in fiscal policy priorities towards the taxation of consumption is manifested in the drop in the marginal rates of direct taxes. Corporate income tax, in particular, has been cut (Figure A3, in Appendix A). Individual income taxation was also simplified with the introduction in 2004 of the flat rate of the personal income tax, or PIT at a rather low level, which was then gradually raised. Meanwhile, the basic rate of VAT has stood at $20 \%$ without changing, excise taxes have been increased several times to resolve fiscal issues and bring their rates closer to European levels, and, on average, import tariffs have been cut as Ukraine has slowly integrated itself into global trade. The estimation of fiscal impulse assumes identification of these and other effects. Isolating the budget deficit impact of these and other discretionary changes in fiscal policy requires the fiscal impulse to be estimated.

As noted above, the fiscal impulse (FI) is obtained by taking the first differences of the fiscal stance (FS) and indicates the direction and extent of the change in fiscal policy from the previous period. In this study, we estimate the fiscal impulse in the form of the CAPB, which requires the calculation of the elasticities of certain budget categories with respect to GDP. For the purposes of this study, we use the OECD approach (4), which envisages estimating such elasticities and making relevant adjustments to the budget balance. This method yields more information on the cyclicality of budget items by extracting cyclical components from certain types of taxes and budget expenditures with higher accuracy. At the same time, we estimate direct elasticities, rather than cross-elasticities ${ }^{5}$ as suggested by the original methodology. Estimating the cross-elasticities involves using tax bases and generating relevant budget expenditures for the calculations. As a tax base, among others, usually, are used households' disposable income and unemployment. However, there are doubts about the consistency of these data, as during the period 2004-2016 in Ukraine had been multiple changes in the methodologies for calculating these variables.

Two aspects of our study are noteworthy. First, we use the OECD approach, as it is a more comprehensive method for estimating the CAPB and allows the cyclical components of the various categories of budget revenues and expenditures to be analyzed. Second, we compare our results to the simplified IMF approach to CAPB estimation (Heller et al., 1986), as the contemporary IMF methodology for identifying discretionary fiscal policy focuses on a somewhat different measure (SBB) and requires a different set of statistics and estimation methods.
In line with the standard methodology, we eliminate debt servicing payments from the calculations, as these payments do not count as discretionary decisions but rather constitute an obligation to pay for the government's past discretionary decisions. In theory, debt servicing payments are only partially dependent on the level of output, as they will not demonstrate cyclical fluctuations if their interest rates are fixed. ${ }^{6}$ Another factor that further complicates the separation of the cyclical component is the monetary policy response, which can manifest itself in the countercyclical dynamics of the central bank's key policy rate. The impact of the key policy rate on borrowing costs will cause the real effect of the output gap on debt servicing payments to be underestimated in periods of recession and overestimated when the economy overheats. This ambiguity in interpreting the essence of interest payments and their link to economic cycles has led to a consensus that these budget expenditures must be excluded from fiscal stance analysis. Another argument in favor of removing debt servicing payments from the analysis is that they can hardly be qualified as an economic stimulus.

What distinguishes our approach is that, in contrast to model (4), which assumes unemployment benefits are cyclical, we treat as cyclical expenditures to finance the deficit of the Pension Fund of Ukraine (PFU). Unemployment benefits in Ukraine are paid out by the extrabudgetary Fund for Obligatory State Social Insurance, which is not funded by the state budget. During economic downturns, this fund does not generate deficits that require budget financing, but rather reduces the financing of active measures that promote employment. However, the PFU regularly generates a deficit of its own budget, which is funded by the government, as the pension fund cannot make immediate spending cuts, as there is a need for pensions to be indexed to inflation. Since in Ukraine the financing to cover the PFU deficit comes from the state budget, and the level of real wages depends on the phase of the economic cycle, these expenditures can be regarded as cyclical.

To estimate regression equations with the relevant elasticities, we use two approaches: DOLS and ARDL. By comparing the estimated elasticities that these models yield, we can test the robustness of our results.

\subsection{DOLS}

The short-term and long-term elasticities are estimated using a two-stage procedure suggested by Engle and Granger (1987). Stage one estimates the long-term relationship (6) using the super-consistent dynamic ordinary least squares (DOLS) method outlined in Stock and Watson (1993). The approach consists of specifying a regression equation in which the tax receipt ${ }^{7}$ level is a dependent variable, while the tax base level for the same period, the current, past, and future values of the first differences of the tax base, deterministic components, and dummy variables denoting structural breaks in data are all explanatory variables.

${ }^{5}$ The elasticity of a certain tax/expenditure with respect to the respective base multiplied by the elasticity of the tax/expenditure base with respect to GDP

${ }^{6}$ Another argument is that interest payments should be taken out of calculations to minimize the impacts of inflation and the exchange rate on the budget balance. This reasoning is not sufficiently substantiated. Interest payments are indeed rather strongly correlated with the level of prices and exchange rate, but interpreting their exclusion as an adjustment of budget expenditures implies that budget revenues should be adjusted for the same factors. International trade taxes, for instance, are strongly related to exchange rate movements, but this fact is usually ignored when estimating fiscal stance.

7 In the case of tax receipts. 


$$
\begin{aligned}
T_{t}^{r}= & \beta_{1}^{r} X_{t}^{r}+\sum_{n=1}^{N} \gamma_{n}^{r} D_{n, t}^{r}+\sum_{i=1}^{I} \gamma_{i}^{r} S_{i, t}^{r}+ \\
& +\sum_{n=1}^{N} \sum_{j=-p}^{q} \alpha_{n, j} \Delta X_{n, t-j}^{r}+\varepsilon_{t}^{r}
\end{aligned}
$$

where $T_{t}^{r}$ are receipts from the $r$ tax, $X_{t}^{r}-$ is the tax base of the $\mathrm{r}$ tax, $D_{n, t}^{r}$ are the potential deterministic components $\mathrm{n}$ in the form of a constant, a linear trend, or a quadratic trend, $S_{i, t}^{r}$ are potential structural breaks in data in the form of impulses, shifts in levels, or changes in trends, $\varepsilon_{t}^{r}$ are stationary errors that denote deviations from the long-term equilibrium relationship.

Stock and Watson (1993) argue that the DOLS method is superior to OLS and Johansen's approach, especially for small samples, as DOLS accounts for orders of integration higher than the first order, and deals with the endogeneity and autocorrelation problem (Masih and Masih, 1999). Stage two employs a model that includes the short-term dynamics of (7) and deviations from, the equilibrium relationship obtained from the stage-one equation (8). ${ }^{8}$ To come close to the normal distribution and eliminate error autocorrelation, model (7) may be augmented to include lags in the dependent and independent variables. Considering the sample's limitations, we included only the statistically significant lagged variables in the final version of the model.

Applying DOLS to a small number of observations carries the risk of model overparameterization, as the number of lags and leads of an independent variable in the model (6) is usually determined on the basis of information criteria. This approach may result in too many variables being added to the model. To limit the number of parameters without losing too many observations, we chose to include no more than two lags and two leads of the tax base. ${ }^{9}$ Simultaneously, to adjust the results for potential error autocorrelation and heteroscedasticity, we used a heteroscedasticity adjusted variance-covariance matrix (Newey-West HAC matrix).

An approach similar to the one noted above was also employed by Dudine and Jalles (2017), who used Fully Modified Ordinary Least Squares (FMOLS) to model a long-term relationship between the tax base and GDP at the country level. Introduced by Phillips and Hansen (1990), this method involves a semiparametric adjustment to eliminate problems caused by the long-term correlation between deviations from the long-term relationship and the innovations in the stochastic process that follow every regressor.

To take into account the difficulties in identifying cointegration, we introduce into the long-term relationships a constant and a dependent variable. Accordingly, we treat all shocks as transitive and incorporate them as dummy variables into the short-term part of the regressions. For inferences about the statistical significance of the long-term relationships, we use the t-statistics of the explanatory variable in the long-term relationship $\left(\beta_{1}{ }^{r}\right.$ in (6)) and the loading coefficient in the error correction model $\left(\alpha_{3}^{r}\right.$ in (7)).

\subsection{ARDL}

As an alternative method for estimating the long-term and short-term elasticities of taxes with respect to GDP, we ran a set of autoregressions with distributed-lags (ARDL) of the following type:

$$
\begin{aligned}
\mathrm{y}_{\mathrm{t}}=\beta_{0}+ & \sum_{\mathrm{q}=1}^{\mathrm{Q}} \beta_{\mathrm{q}} \mathrm{y}_{\mathrm{t}-\mathrm{q}}+\sum_{\mathrm{n}=0}^{\mathrm{N}} \alpha_{\mathrm{n}} \mathrm{x}_{\mathrm{t}-\mathrm{n}}+ \\
& +\sum_{\mathrm{i}=1}^{\mathrm{I}} \mathrm{c}_{\mathrm{i}} \mathrm{D}_{\mathrm{i}}+\varepsilon_{\mathrm{t}},
\end{aligned}
$$

where $y_{t}$ is an endogenous variable, $x_{t}$ is an exogenous variable that may influence $y_{t}$ without a lag, and $D_{i}$ are deterministic variables that denote trends, structural breaks, and outliers in data.

This approach has a number of advantages over Johansen's method, which employs a vector error correction model (VECM). First, ARDL is better suited for identifying long-term relationships in small samples. VECM is a system of equations and, as such, requires a large number of observations. Second, unlike VECM, ARDL does not require variables to have the same level of integration. Under this approach, regression variables can be I(0) and/or I(1), which eliminates the issue of preliminary testing for stationarity (Pesaran et al., 2001). Specifying a cointegrating relationship under Johansen's approach requires statistical evidence that all of the model's variables are I(1). With short time series and frequent structural breaks in data, stationarity tests lose power significantly. Another serious drawback of the Johansen method is the sensitivity of the cointegration test to the model specification. Specifying VECM requires the choice of a number of endogenous and exogenous variables, the inclusion of deterministic components, and the selection of an optimal quantity of lags. By contrast, the ARDL model has greater flexibility, enabling the use of an optimal number of lags for every variable.

When specifying ARDL, we used the following algorithm:

- for every variable, we conducted unit-root tests to ensure that none of the variables are I(2);

- specifying ARDL in levels with an optimal number of lags basing on the Akaike information criterion (AIC);

- testing for normality and autocorrelation of the residuals;

- in case of detection non-normality or autocorrelation in residuals, the dummy variables and additional lags are included in the model;

- testing for the existence of a long-term relationship between variables (bounds test);

- if a long-term relationship is identified, we use it to calculate the long-term elasticities and estimate the parameters of the error correction model (ECM) - the short-term coefficients of elasticity and the coefficients of convergence;

\footnotetext{
${ }^{8}$ In doing so, we first adjusted the errors to account for the effect of the $\sum_{n=1}^{N} \sum_{j=-p}^{q} \alpha_{n, j} \Delta X_{n, t-j}^{r}$ component from equation (8), as the long-term relationship is expressed
as equation (6), while the actual estimation of its parameters is based on model (8).

${ }^{9}$ Under this approach, automatic responses between the tax base and tax receipts are assumed to take place within two quarters before and after a particular observation. This assumption is sufficiently realistic and applies to such restrictions (Koester and Priesmeier, 2012).
} 
- in the absence of a long-term relationship, the variables are transformed into stationary form, a separate ARDL is specified, and the short-term elasticities are estimated.

The bounds test assesses the probability that a long-term relationship exists between variables, regardless of whether they are I(0) or I(1). The critical values for the bounds test are presented in Pesaran et al. (2001), but they have asymptotic properties. For small samples of data, Narayan (2005) revised the critical values, and we use them in this paper, as our sample comprises no more than 60 observations.

If a long-term relationship between variables is identified, the long-term elasticities are estimated by running a regression based on model (10):

$$
\begin{gathered}
\Delta \mathrm{y}_{\mathrm{t}}=\beta_{0}+\sum_{\mathrm{q}=1}^{\mathrm{Q}} \beta_{\mathrm{q}} \Delta \mathrm{y}_{\mathrm{t}-\mathrm{q}}+\sum_{\mathrm{n}=0}^{\mathrm{N}} \alpha_{\mathrm{n}} \Delta \mathrm{x}_{\mathrm{t}-\mathrm{n}}+ \\
+\sum_{\mathrm{i}=1}^{\mathrm{I}} \mathrm{c}_{\mathrm{i}} \Delta \mathrm{D}_{\mathrm{i}}+\theta_{1} \mathrm{y}_{\mathrm{t}-1}+\theta_{2} \mathrm{x}_{\mathrm{t}-1}+\varepsilon_{\mathrm{t}}
\end{gathered}
$$

where the long-term coefficient equals $\left(-\theta_{2} / \theta_{1}\right)$.

The use of the two approaches to estimating the elasticities ensures the results are more robust. In addition, the proposed econometric models allow for the estimation of the difference between the short-term and long-term elasticities of various budget items with respect to GDP, as well as the rate of convergence of the models' variables to the equilibrium relationship.

\section{DATA TO ESTIMATE FISCAL IMPULSE}

Our estimation relies on quarterly GDP observations and data from Ukraine's consolidated budget for 2004-2016. ${ }^{10}$ The data were seasonally adjusted using the Census X12 algorithm. The data were also adjusted for 2010 prices using a GDP deflator and converted into logs. We did not perform the log transformation of PFU deficit financing, ${ }^{11}$ as these expenditures equaled zero in 2007-2008. We deleted debt service payments from budget expenditures. We calculated potential GDP using the Kalman filter. To obtain estimates using the OECD methodology, we calculate the long-term elasticities with respect to GDP for the following variables: personal income tax (PIT), corporate income tax (CIT), VAT, excise tax, import tariffs, and PFU deficit financing. ${ }^{12}$ The remaining budget revenue and expenditure categories are assumed to be acyclic, as no economic preconditions exist for them to respond automatically to GDP fluctuations.

Tables B1 and B2 (in Appendix B) present a preliminary analysis of log data with descriptive statistics and stationarity tests. The descriptive statistics indicate that the time series of PIT, CIT, VAT on imports, and PFU deficit financing are not normally distributed. Dickey-Fuller GLS and KPSS stationarity tests, with the addition of a constant, were conducted mainly to verify that none of the variables are I(2) processes. The tests are necessary for the consistent construction of the ARDL models that estimate the elasticities. The results of the Dickey-Fuller GLS test indicate that most variables are I(1), apart from excise tax receipts and PFU deficit financing, as these time series do not become stationary after their first differences are taken. The KPSS test returns results that largely confirm those of the Dickey-Fuller GLS test, the difference being that real GDP, gross domestic VAT, and the import tariffs are $I(0)^{13}$, while the excise tax is $I(1)$. The tests yield the overall inference that the time series of the excise tax and PFU deficit financing may be I(2). A visual analysis of movements in these variables shows there are structural breaks in the trends. The Unit Root with Break Test of the first differences of the excise tax and PFU deficit financing points to their stationarity when innovative outliers ${ }^{14}$ in the time series are controlled for (Figure A4, in Appendix A).

The confirmed stationarity, at least in first differences, of the data selected for the study, makes these data eligible for standard time series analysis. However, the time series of the excise tax and PFU deficit financing exemplify the importance of taking account of outliers and breaks when conducting an analysis involving special tests for stationarity.

\section{RESULTS OF ESTIMATIONS}

Table B3 (in Appendix B) presents the estimates of the long-term and short-term elasticities of major tax receipts with respect to GDP for Ukraine, and average estimates for OECD countries provided by Girouard and André (2005) and which are used by the IMF in the relevant estimations. Tables B4 and B5 (in Appendix B) contain more information on the parameters of the models used in the calculation of the elasticities and loading coefficients. The elasticities estimated using DOLS and ARDL are sufficiently close, except in the case of the domestic VAT. In both cases, the elasticity for domestic VAT is close to unity - a value that, in theory, must be manifested by all proportional taxes.

The results in Table 3 demonstrate that we have not been able to capture a statistically significant long-term relationship of GDP with PIT and the excise tax. In the case of the excise tax, the reason may be that this budget revenue item has a significant discretionary component. Excise tax rates are subject to constant revision, and this tax is, in essence, a manual tool for ensuring that budget revenues are received in full. Another reason is that the tax bases for this tax are sufficiently different (alcohol products, tobacco products, and energy) and vary in terms of their relationship with GDP dynamics. The analysis of movements in excise tax receipts and real GDP (Figure $A 5$, in Appendix $A$ ) indicates that the trends in these variables were negatively correlated with each other for a significant number of sample observations. In 2002-2008, excise tax receipts had been falling in real terms, despite the economy growing. Following the crisis of 2008-2009, the government was faced with the need to seek new funding sources, which resulted in excise tax rates being raised and remaining in line with GDP dynamics up until 2014. After the 2014 crisis, excise tax rates were radically revised again, and their growth began to outpace that of GDP.

${ }^{10}$ The resulting estimates might be somewhat skewed towards a tighter fiscal policy for $2014 \mathrm{H} 1$, as the Ukrainian statistics did not account for the GDP of Crimea and the non-government controlled areas of Donetsk and Luhansk oblasts, even though companies located there continued to pay a certain amount of taxes. We partially take account of that structural break in the data by using dummy variables in our regressions, but accurate estimates of tax receipts from government-controlled areas are hard to obtain.

${ }^{11}$ The sample period for these expenditures is 2005-2016.

${ }^{12}$ Data on budget revenues and expenditures was taken from the reports of the State Treasury Service of Ukraine (www.treasury.gov.ua/main/uk/publish/ category/23596).

${ }^{13}$ The discrepancy in the test results for these variables is not important, as the results primarily confirm that the variables are not I(2). 
The difficulties in identifying a long-term relationship between GDP and PIT arise from the fact that the growth of tax receipts was catching up with the growth rate of GDP in 2004-2008 after tax receipts plummeted in 2004 when there was a switch from a progressive tax rate to a flat one (13\%). This was related to the rapid growth in wages, driven in particular by an increase in the minimum wage. Since 2015, PIT tax receipts have been growing more rapidly than GDP (Figure A5), likely due to a higher tax rate. The existence of structural breaks in the PIT and a sharp turnaround in the direction of the trends do not provide statistical evidence sufficient to detect cointegration. The short-term elasticity of 0.7 differs significantly from the analogous average measures for OECD countries (except Slovakia, for which the estimated coefficient is also 0.7). This is attributable to the absence of progressive individual income taxes in Ukraine, and to a significant amount of individual incomes that are taxed on special terms, such as investment returns, business income, etc.

The high elasticities for CIT, VAT on imports, and import tariffs are notable. At the same time, the elasticities for import taxes significantly differ from the analogous coefficients for OECD countries. The high elasticities indicate that the taxes produce excessive responses to the relevant changes in GDP. An analysis of tax dynamics in real terms (Figure A5) suggests that the high elasticities are driven by the drops in taxes that occurred during the economic crises of 20082009 and 2014. Import taxes fell due to the rapid currency depreciation that accompanied the crises and caused sharp drops in imports. ${ }^{15}$ Another contributor to the decline in import tariffs receipts was Ukraine's accession to the World Trade Organization (WTO). The corporate income tax also demonstrates strong respond to declines in GDP, especially after the 2014 crisis. To remove the effect of depreciation on import taxes, we specified ARDL models in line with the algorithm (10), which was used for estimating the coefficients in Table B4. As variables, we used seasonally adjusted nominal GDP, VAT on imports and import tariffs denominated in US dollars basing on the official nominal exchange rate. The resulting elasticities are significantly lower. For VAT on imports, the long-term elasticity equals 1.4 and the short-term elasticity is 1.2. For the import tariffs, the elasticities are 0.66 and 0.7 respectively. ${ }^{16}$ Thus, the significant deviation of the import tax elasticities for Ukraine from the same indicators for OECD countries is attributed to the periods of severe economic crises and depreciation, which are not typical for developed economies.

In line with the obtained results, we use the following values as elasticities to estimate fiscal stance: for budget revenues -1.2 , for PIT -0.7 , for VAT on imports -2.6 , for domestic VAT -1 , for CIT -1.8 , for the import tariffs -0.8 , and for the excise tax -0.7 . These are the average values of the long-term elasticities from Tables B4 and B5. For PIT and excise taxes, we use the short-term elasticity.
Table B5 also has the estimated elasticity of PFU deficit financing with respect to GDP. As the time series of the PFU deficit financing had an unspecified order of integration, we used the ARDL model to estimate the elasticities. Based on the results of the regression, the short-term elasticity of PFU deficit financing with respect to GDP stands at (-1.7).

Figure A6 (in Appendix A) shows the contributions of the budget components that we identified as cyclical to the gap between the primary budget deficit and the fiscal stance measure. ${ }^{17}$ For the sake of clarity, we also present a graph of the GDP gap. The biggest impact on the budget's cyclical component is made by VAT, because of the significant share of this tax in budget revenues and the high elasticity of VAT on imports with respect to GDP. The next biggest contributor to the budget's cyclical component is the corporate income tax. PFU deficit financing increases during economic downturns, widening the budget deficit and decreases in times of economic growth.

Figures $A 7$ and $A 8$ (in Appendix A) present the graphs of the fiscal stance and fiscal impulse estimates for Ukraine obtained by using the approach described by equation (4) and the IMF methodology, the short version of which is expressed by equation (2). We present alternative estimates of the fiscal stance and the fiscal impulse to demonstrate the consistency of our approach. The IMF approach involves estimating the fiscal stance measure on the basis of relative budget indicators in the base year when the GDP gap was minimal. As a base year, we opted for 2004, when the GDP gap stood at $+0.2 \%$. To obtain quarterly estimates of the fiscal stance and the fiscal impulse, we used the annual estimates of $r_{o}$ and $g_{0}{ }^{18}$ To estimate the annual indicators, we applied the same $r_{0}$ and $g_{0}$ to the annual indicators of consolidated budget revenues and expenditures. To smooth out the movements in the indicators of fiscal stance and, hence, the fiscal impulse, we applied a moving average of the previous four quarters (Figures A9 and A10, in Appendix A). We then converted the calculations into annual data by computing the simple means for the four quarters of each year (Figures A11 and A12, in Appendix A).

Figures A8 and A9 show that the different estimates of fiscal stance yield similar dynamics in the indicators, although they differ in their levels. The informative episodes of the government's fiscal policy actions are the periods of 2006-2008 when the economy overheated as global commodity prices rose amid low-interest rates, and 2014-2015 when the severe economic crisis started (Figure A7). In 2006-2008, fiscal policy was becoming increasingly loose, up until the financial and economic crisis, which prompted the government to switch to a tight fiscal policy in 2009. A shift to fiscal policy tightening can also be seen in 2014, but in that year the consolidation was significantly greater than during the 2009 crisis. The loosening of fiscal policy in the second half of 2007 through 2008 is attributed to the fact that tax receipts did not grow in proportion to GDP, as evidenced by the estimated elasticities. The increase in the pri-

\footnotetext{
${ }^{15}$ The growth in the import tariffs in 2015 was the result of a temporary increase of the rates, which came after the 2014 crisis as part of the emergency measures taken to revitalize the economy.

${ }^{16} \mathrm{As}$ an alternative, we ran threshold regressions. As the threshold variable, we chose the first differences of the log of the nominal exchange rate against the US dollar (exch) with a lag that selected so as to minimize the total least squares of the model's errors. For VAT on imports, the threshold value came out at $t \_$exch $h_{t-1}=-0.008$, the elasticity below the threshold value amounted to $e<t_{-}$exch $h_{t-1}=1.7$, and the elasticity above the threshold value came in at $e>t_{-}$exch $=4.1$. For the import tariffs, the relevant indicators were $t_{-}$exch $t_{t-1}=0.006, e<t_{-}$exch $h_{t-1}=1.12$, and e>t_exch $h_{t-1}=2.5$. For CIT: $t_{-}$exch $h_{t-1}=0.006, e<t_{-} e x c h=0.8$, and $e>t_{-}$exch ${ }_{t-1-1}=4.7$. During the rapid currency depreciation that comes with economic crises, elasticities increase dramatically.

${ }^{17}$ The average values of the cyclical components of taxes in relation to potential GDP for $2004-2016$ are: $0.81 \%$ for VAT, 0.21\% for CIT, 0.11\% for IIT, 0.08\% for excise taxes, $0.07 \%$ for PFU deficit financing, and $0.03 \%$ for the import tariffs.

${ }^{18}$ The ratio of budget revenues to nominal GDP in the base year and the ratio of primary budget expenditures to nominal GDP in the base year, respectively.
} 
mary deficit of the consolidated budget in 2009 was driven by the economic downturn, but the cyclically adjusted budget balance points to a tighter fiscal policy. The 2014 crisis led to a point at which the budget's cyclical component became negative (the fall in GDP triggered an automatic drop in tax receipts, inflating the budget deficit). As a result, the fiscal stance measure indicates an even tighter fiscal policy than does the primary budget balance. The tight fiscal policy episodes were seen in the second half of 2014, and especially in 2015, coinciding with the budget cuts of 2014 and the fiscal consolidation of 2015. There was a certain easing of the policy in 2016 compared to the previous two years. Apart from the episodes noted above, the graphs of the annual data indicate a fiscal policy easing in 2010 , driven by presidential elections, a tightening of the policy in 2011, and another easing in 2012, which could be the result of Ukraine hosting the 2012 European football championship.

The two fiscal impulse estimation approaches used in this paper yield similar results - which speaks for their robustness. When compared, the fiscal policy responses to the economic crises indicate that fiscal policy became significantly tighter following the 2014 crisis than during that of 2008 and 2009. The underlying reasons for such government actions are rooted in different scales and nature of the shocks appeared during those crises, and in the specifics of Ukraine's fiscal policy reaction function, which only switches into active (countercyclical) regime when public debt grows to high levels and the GDP gap becomes positive (Vdovychenko, 2017). The tightening of fiscal policy in Ukraine in 2014-2015 is explained by more serious geopolitical and structural consequences for Ukraine's economy compared to the fall in world commodity markets and the liquidity crunch of 2008 , as well as by a protracted period of procyclical fiscal policy and a significant accumulation of public debt since the 2008-2009 crisis, including external public debt.

\section{DISCUSSION OF THE RESULTS AND CONCLUSIONS}

The use of methodologies that are similar to the OECD approach is commonplace when estimating the fiscal impulse. The OECD approach, which was somewhat modified to allow for its application to the case of Ukraine, identifies periods of tight and loose fiscal policy. The use of the OECD disaggregation approach identifies the budget items that are the most important for generating the cyclical component of the fiscal balance. In Ukraine, the strongest cyclical impact on the budget comes from the VAT and the corporate income tax.

The dynamics of the estimated fiscal stance (and the fiscal impulse respectively), indicates that the government's responses to the economic crises of 2008-2009 and 2014 in the fiscal policy context were radically different. In reacting to the 2008-2009 crisis, for instance, the government had to reduce the budget deficit somewhat, but its fiscal policy remained close to neutral and became loose in 2010. This is attributed to the raft of tax benefits that the government enacted to support the economy as it went through the crisis (introducing a special VAT regime for agricultural producers, in particular), as well as to the presidential elections of 2010. The 2014 crisis resulted in a substantial consolidation of the budget and in a tightening of fiscal policy (among other things, by raising interest rates and levying PIT on passive income), which is explained by the large public debt that had been accumulated by that time.

The elasticities of taxes on imports and CIT with respect to GDP are rather high due to their asymmetric response to fluctuations in GDP in periods of economic growth and crises. The elasticity of PIT with respect to GDP is slightly lower than that in developed economies, due to the absence of progressive taxation and a weak emphasis on taxing passive income. The elasticities of other tax receipts we have estimated are in line with the analogous measures for OECD countries.

To test the robustness of the OECD approach used in this study, we estimated the fiscal impulse under the IMF methodology. Both approaches yield results that are similar in value. 


\section{REFERENCES}

- Bornhorst F., Dobrescu G., Fedelino A., Gottschalk J., and Nakata T. (2011). When and How to Adjust Beyond the Business Cycle? A Guide to Structural Fiscal Balances. IMF Technical Notes and Manuals, No. 2011/02

- Bouthevillain C., Cour-Thimann P., van den Dool G., Hernandez De Cos P., Langenus G., Mohr M., Momogliano S., Tujula M. (2001). Cyclically-adjusted Budget Balances: An Alternative Approach. ECB Working Paper Series, No. 77.

- Dudine P., Jalles, J. T. (2017). How Buoyant is the Tax System? New Evidence from a Large Heterogeneous Panel. IMF Working Papers, No. 17/4.

- Engle R., Granger C. (1987). Cointegration and Error Correction: Representation, Estimation and Testing. Econometrica, Vol. 55, No. 2, pp. 251-276.

- Fatás A., Mihov I. (2009). Why Fiscal Stimulus is Likely to Work. International Finance, Vol. 12, No. 1, pp. 57-73. https://doi.org/10.1111/j.1468-2362.2009.01235.x

- Gali J., Perotti R. (2003). Fiscal Policy and Monetary Integration in Europe. Economic Policy, Vol. 18, No. 37, pp. 533-572.

- Girouard N., André C. (2005), Measuring Cyclicallyadjusted Budget Balances for OECD Countries. OECD Economics Department Working Papers, No. 434.

- Heller P. S., Haas R. D., Mansur A. S. (1986). A Review of the Fiscal Impulse Measure. IMF Occasional Paper, No. 44.

- Koester G. B., Priesmeier C. (2012). Estimating Dynamic Tax Revenue Elasticities for Germany. Deutsche Bundesbank Discussion Paper, No. 23.

- Larch M., Turrini A. (2009). The Cyclically-Adjusted Budget Balance in EU Fiscal Policy Making: A Love at First Sight Turned Into a Mature Relationship. European Commission Economic Papers, No. 374.
- Masih A., Masih R. (1999). Are Asian Stock Market Fluctuations Due Mainly to Intra-Regional Contagion Effects? Evidence Based on Asian Emerging Stock Markets. PacificBasin Finance Journal, Vol. 7, No. 3-4, pp. 251-282.

- Narayan P. K. (2005). The Saving and Investment Nexus for China: Evidence from Cointegration Tests. Applied Economics, Vol. 37, No. 17, pp. 1979-1990. https://doi.org/10.1080/00036840500278103

- NBU (2016). Estimating the Potential GDP and the Cyclic Position of the Ukrainian Economy. In: Inflation Report. July, pp. 22-23.

- Nikolaichuk S., Mariiko Y. (2007). Determination of Equilibrium and Cyclic Components of Macroeconomic Indicators Using the Kalman Filter. Visnyk of the National Bank of Ukraine, No. 5, pp. 58-64.

- Pesaran M. H., Smith R. J., Shin Y. (2001). Bounds Testing Approaches to the Analysis of Level Relationships. Journal of Applied Econometrics, Vol. 16, No. 3, pp. 289-326. https://doi.org/10.1002/jae.616

- Phillips P. C. B., Hansen B. E. (1990). Statistical Inference in Instrumental Variables Regressions with I(1) Processes. Review of Economic Studies. Vol. 57, No. 1, pp. 99-125.

- Schinasi G. J., Lutz M. S. (1991). Fiscal impulse. IMF Working Paper, No. 91/91.

- Stock J., Watson M. (1993). A Simple Estimator of Cointegrating Vectors in Higher Order Integrated Systems. Econometrica, Vol. 61, No. 4, pp. 783-820.

- van den Noord P. (2000). The Size and Role of Automatic Fiscal Stabilizers in the 1990s and Beyond. OECD Working Paper, No. 230.

- Vdovychenko A. (2017). Fiscal Policy Reaction Function and Sustainability of Fiscal Policy in Ukraine. Visnyk of the National Bank of Ukraine, No. 240, pp.22-35. https://doi.org/10.26531/vnbu2017.240.022 


\section{APPENDIX A. FIGURES}

Figure A1. Nominal and Primary Balance

of the Consolidated Budget of Ukraine, \% GDP

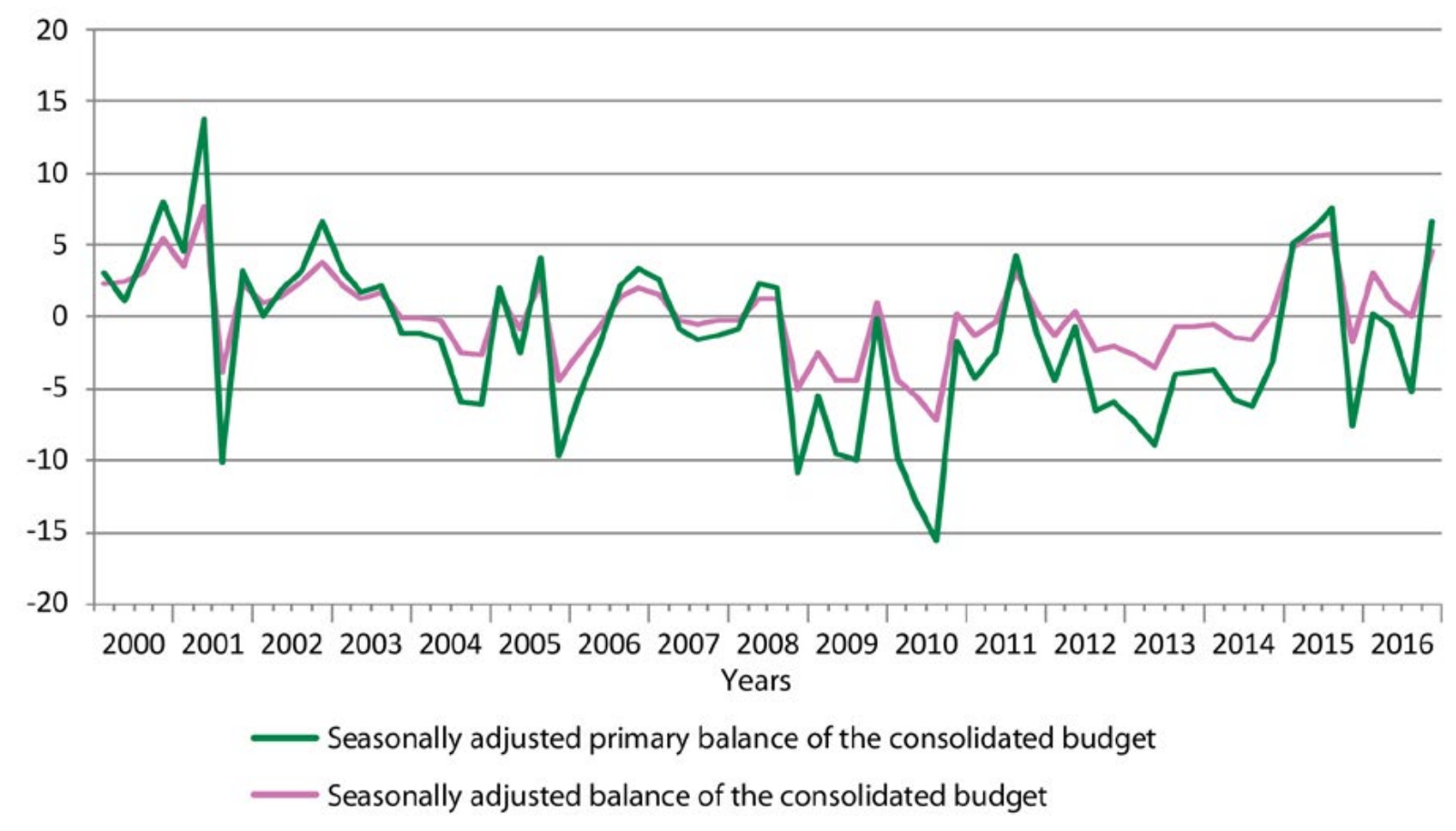

Figure A2. Tax Receipts in Ukraine, \% GDP

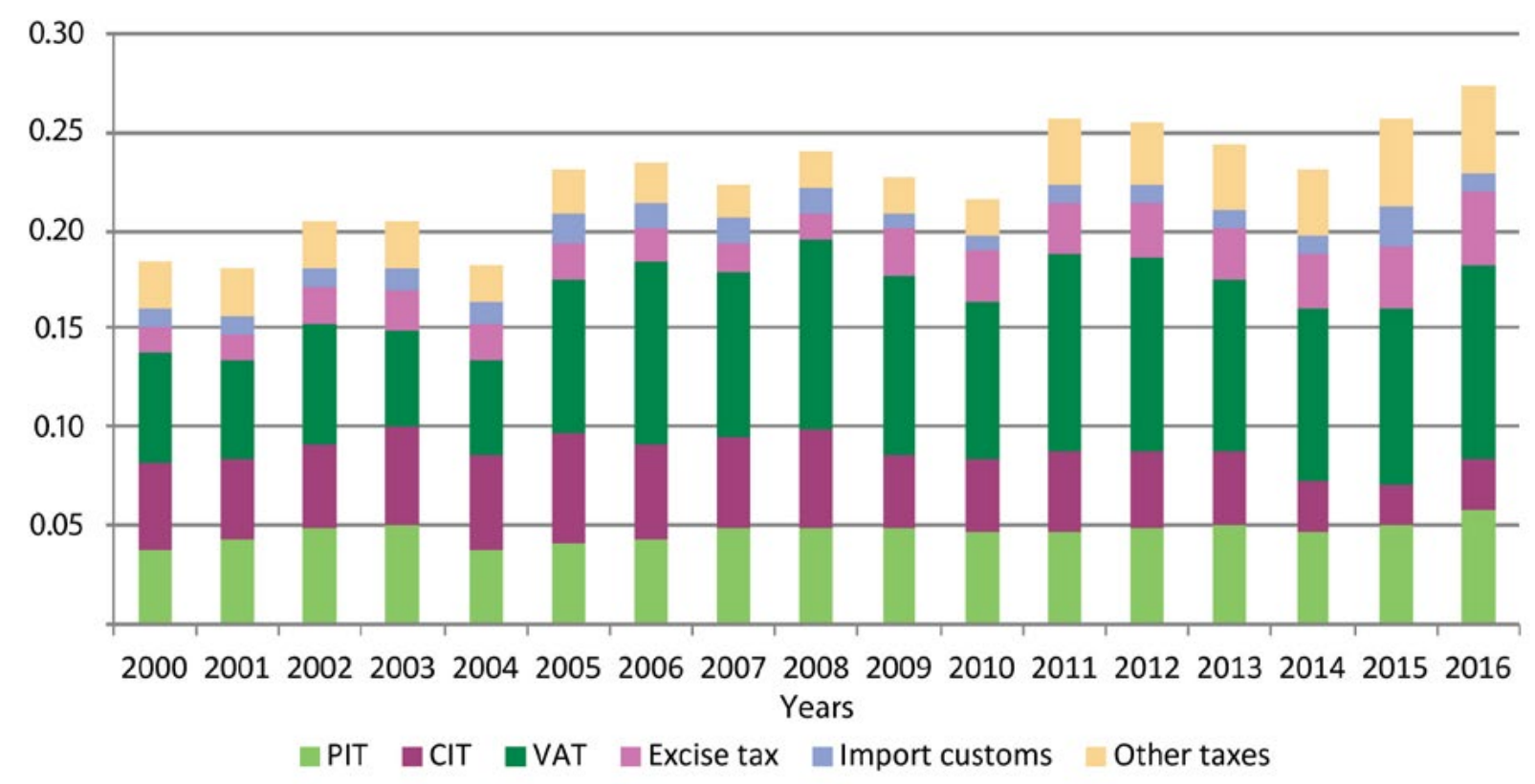


Figure A3. Marginal Tax Rates of CIT and PIT in Ukraine, \%

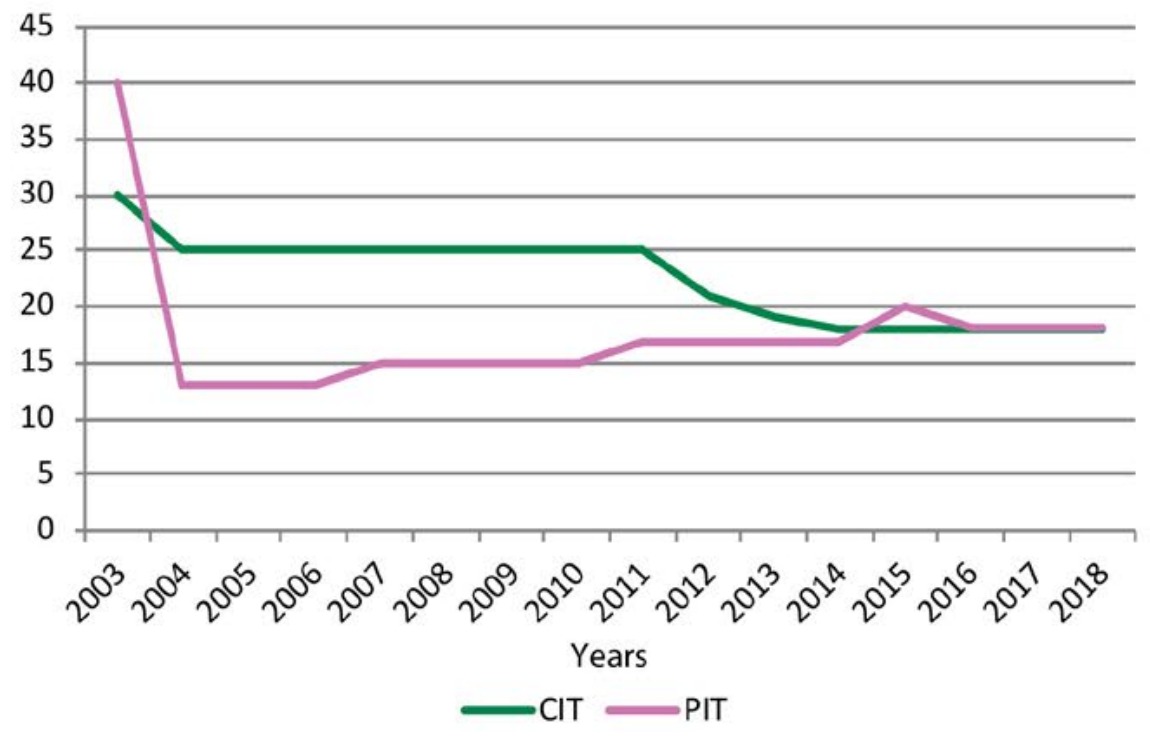

Figure A4. Excise Tax and PFU Deficit Financing with Structural Breaks
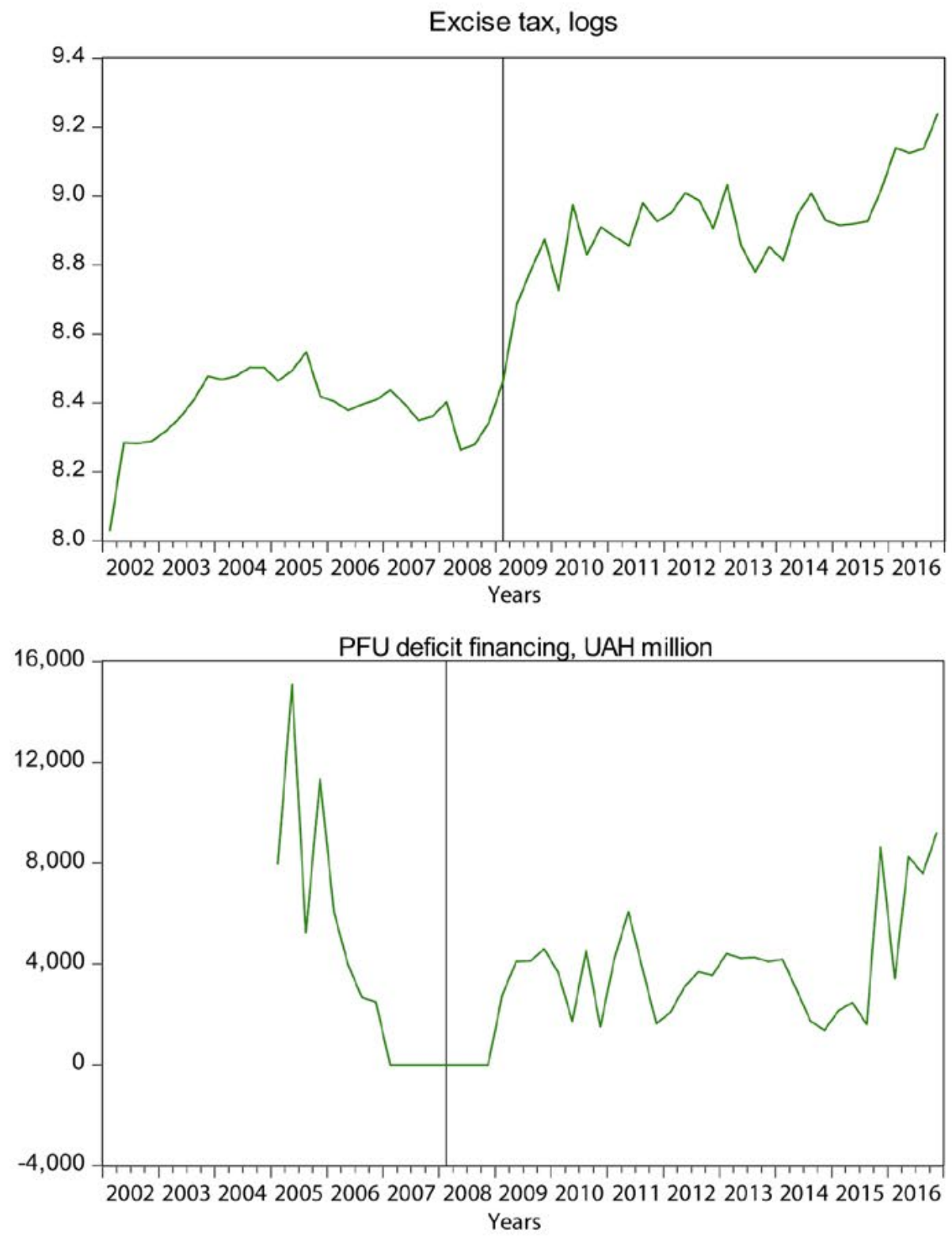
Figure A5. Seasonally Adjusted Real GDP

and Certain Taxes (Logs), 2002-2016
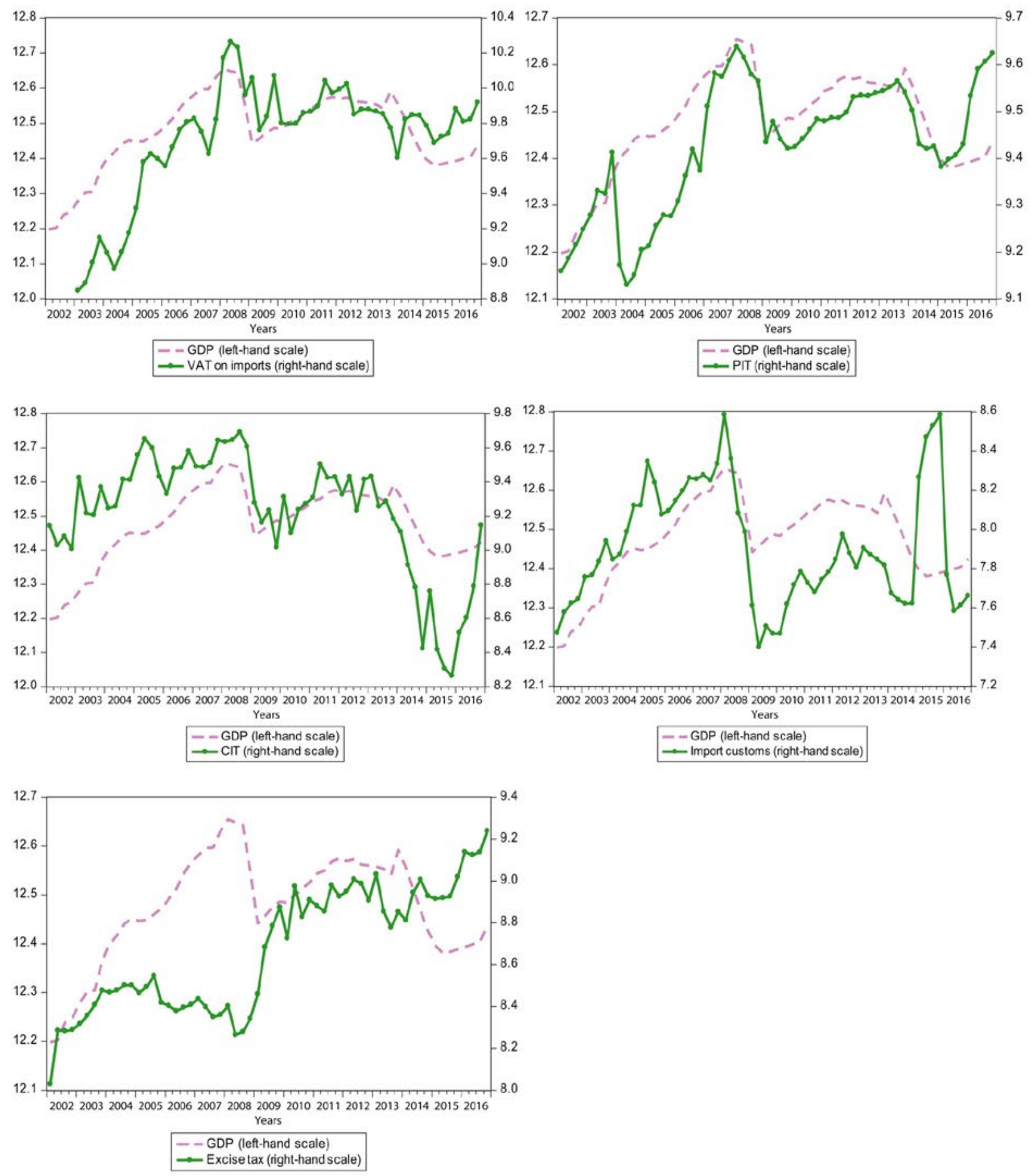
Figure A6. Contributions of Budget Categories to the Cyclical Fiscal Balance

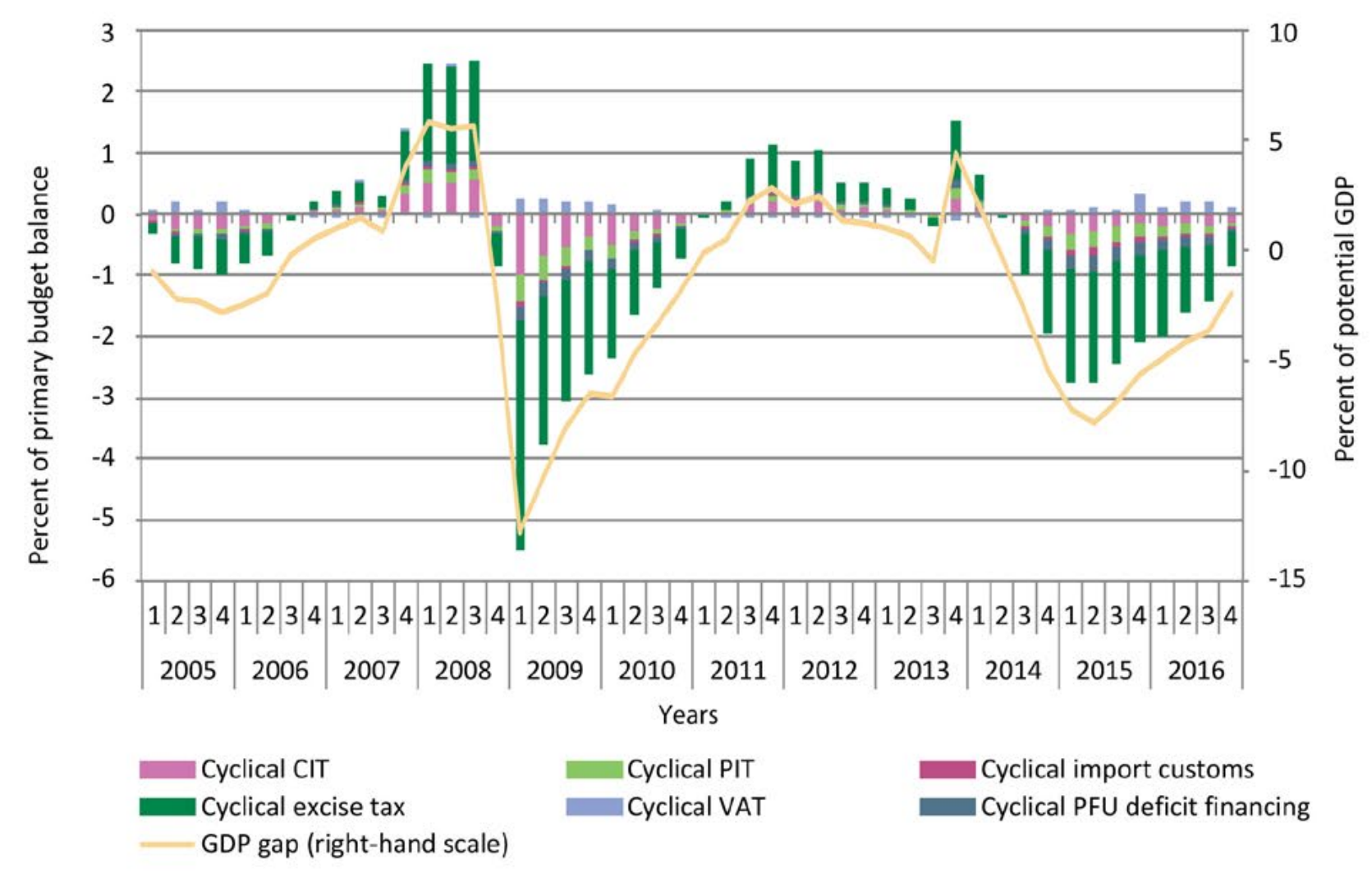

Figure A7. Fiscal Stance and Primary Budget Balance, $\%$ of Seasonally Adjusted Real GDP

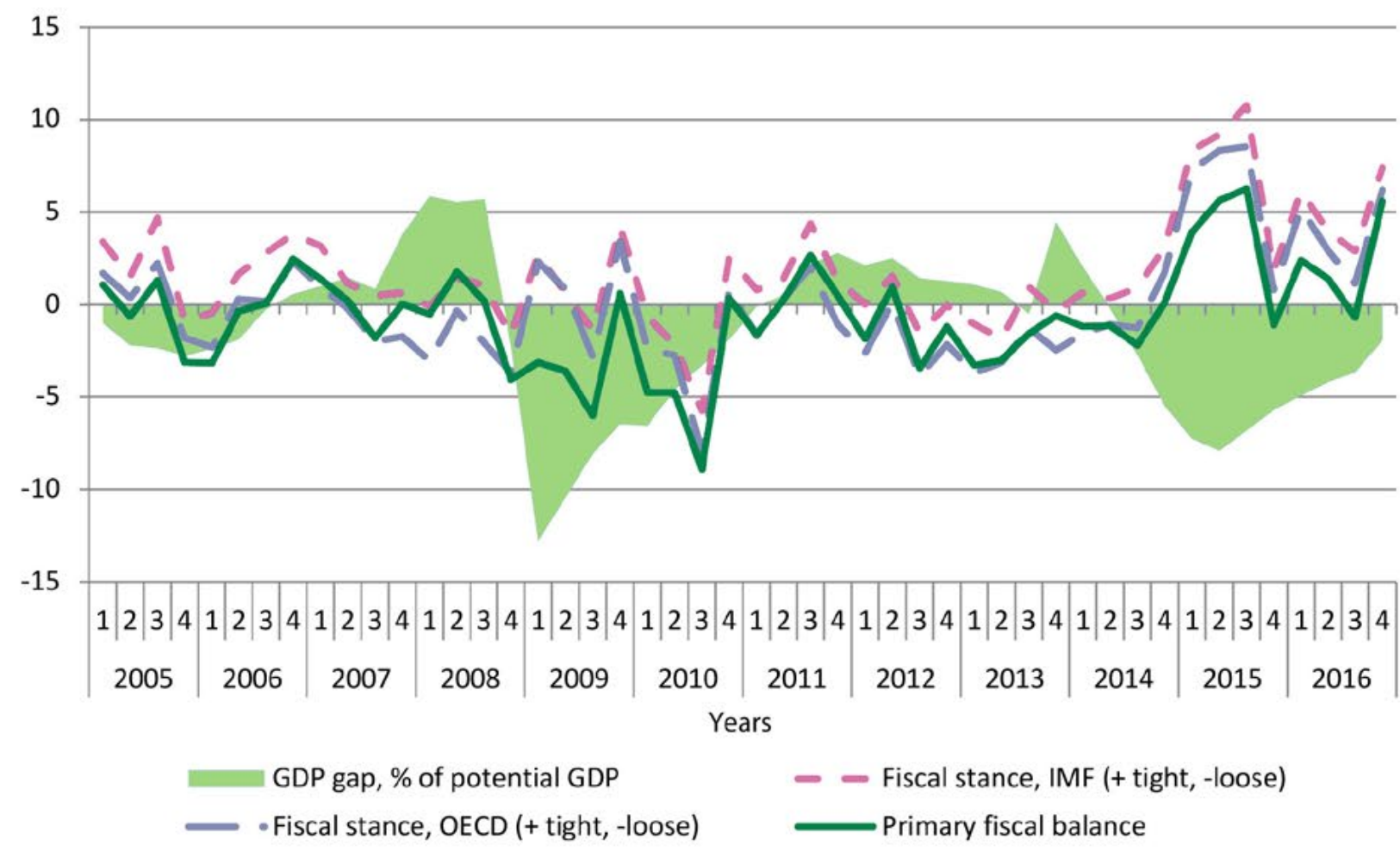


Figure A8. Fiscal Impulse, \% of Seasonally Adjusted Real GDP

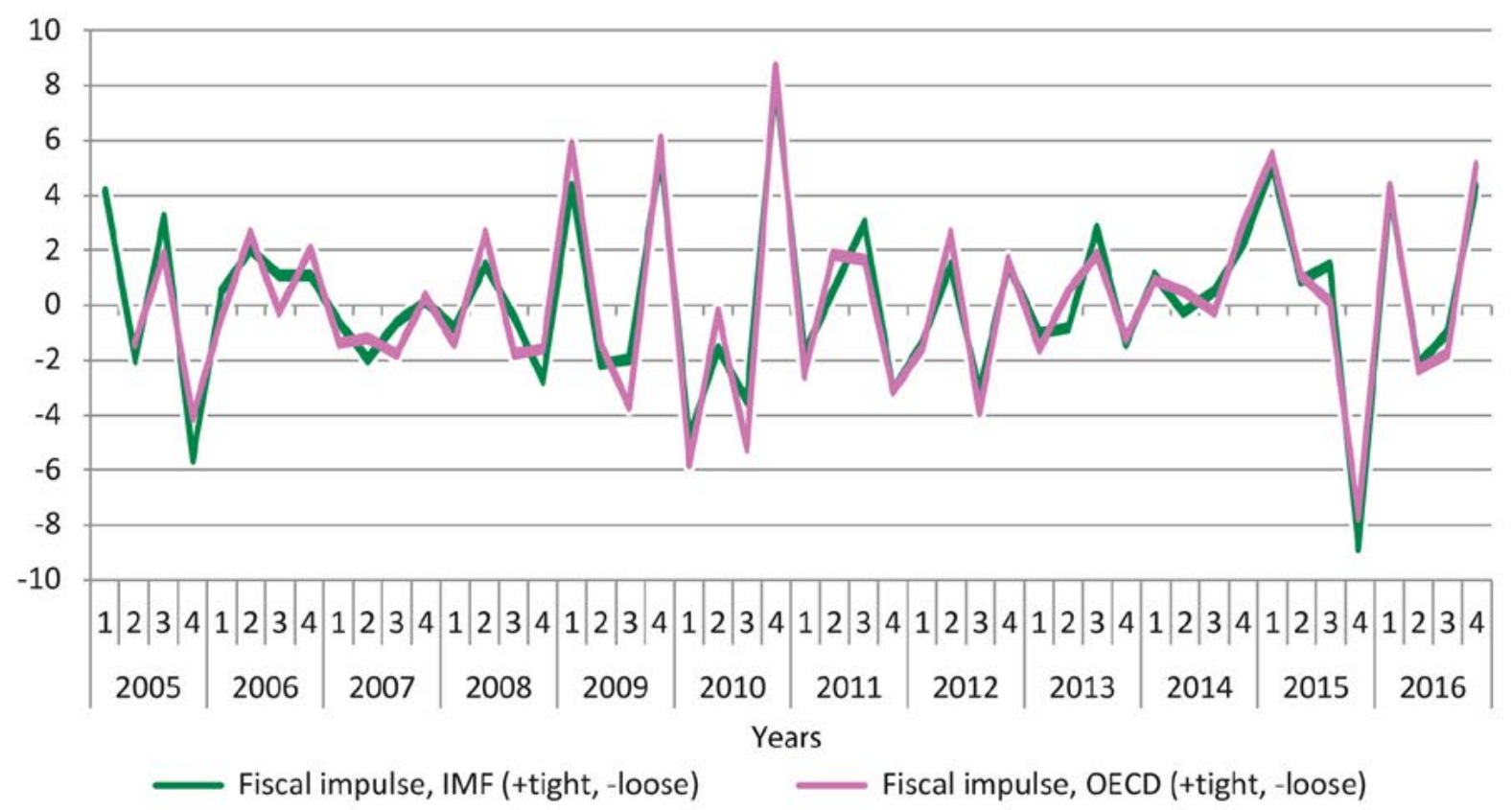

Figure A9. Moving Average of Fiscal Stance, $\%$ of Seasonally Adjusted Real GDP

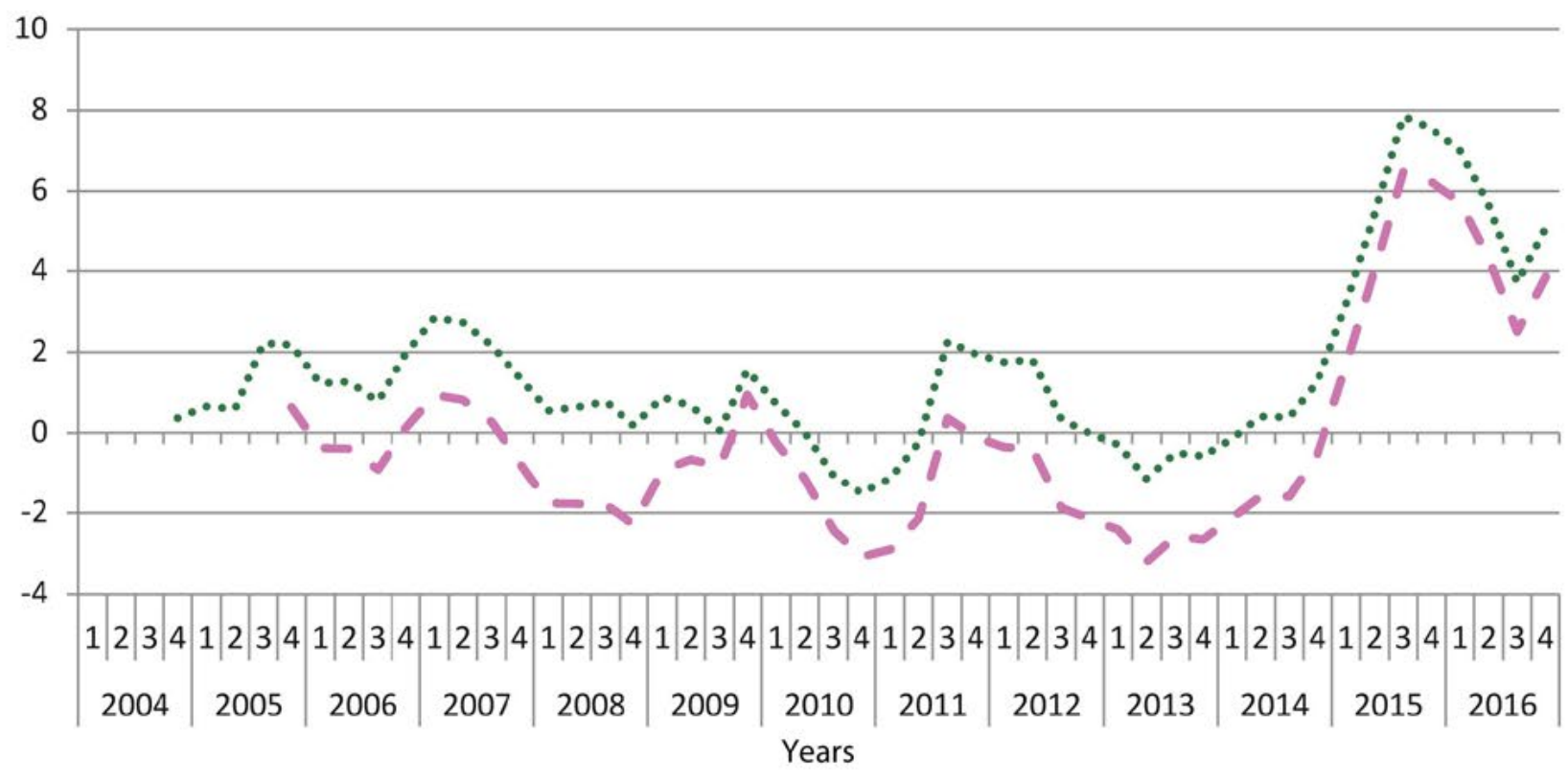

...... Fiscal stance moving average, IMF (+tight, -loose)

- Fiscal stance moving average, OECD (+tight, -loose) 
Figure A10. Fiscal Impulse Dynamics, \% of Seasonally Adjusted Real GDP

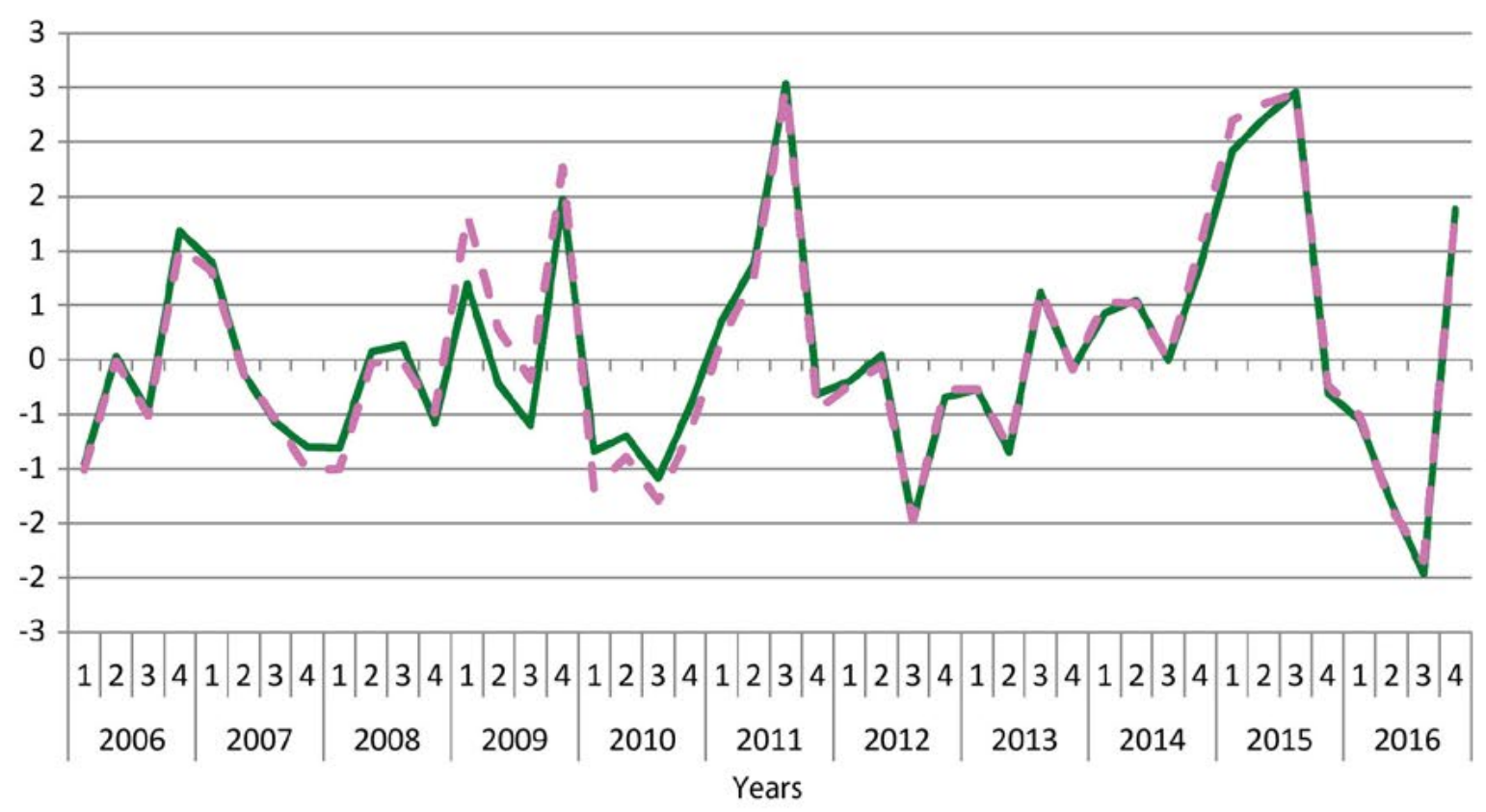

_Fiscal impulse moving average, IMF (+tight, -loose)

- Fiscal impulse moving average, OECD (+tight, -loose)

Figure A11. Annual Fiscal Stance, \% of Real GDP

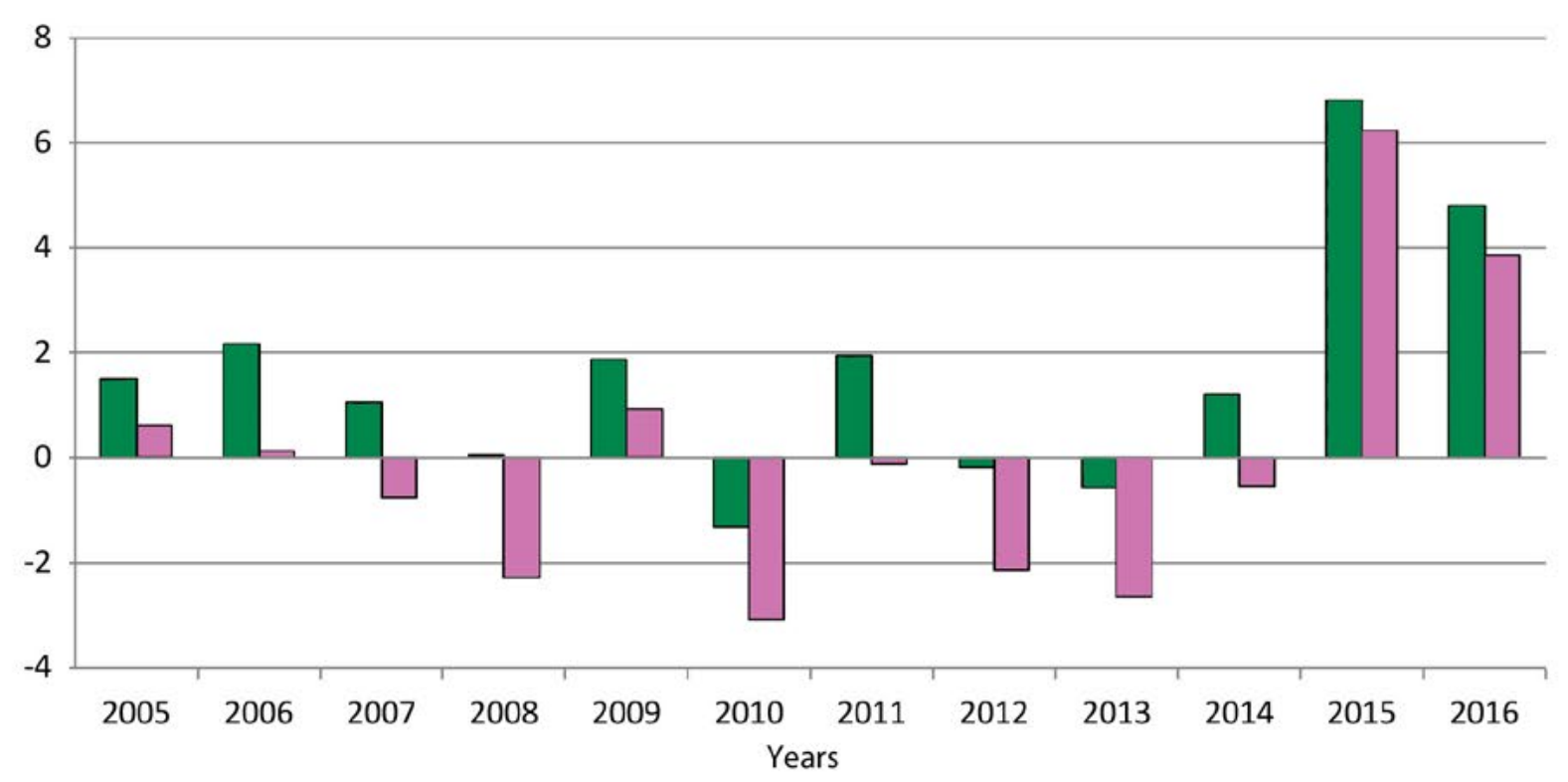

$\square$ Fiscal stance, IMF (+tight, -loose) $\quad \square$ Fiscal stance, OECD (+tight, -loose) 
Figure A12. Annual Fiscal Impulse, \% of Real GDP

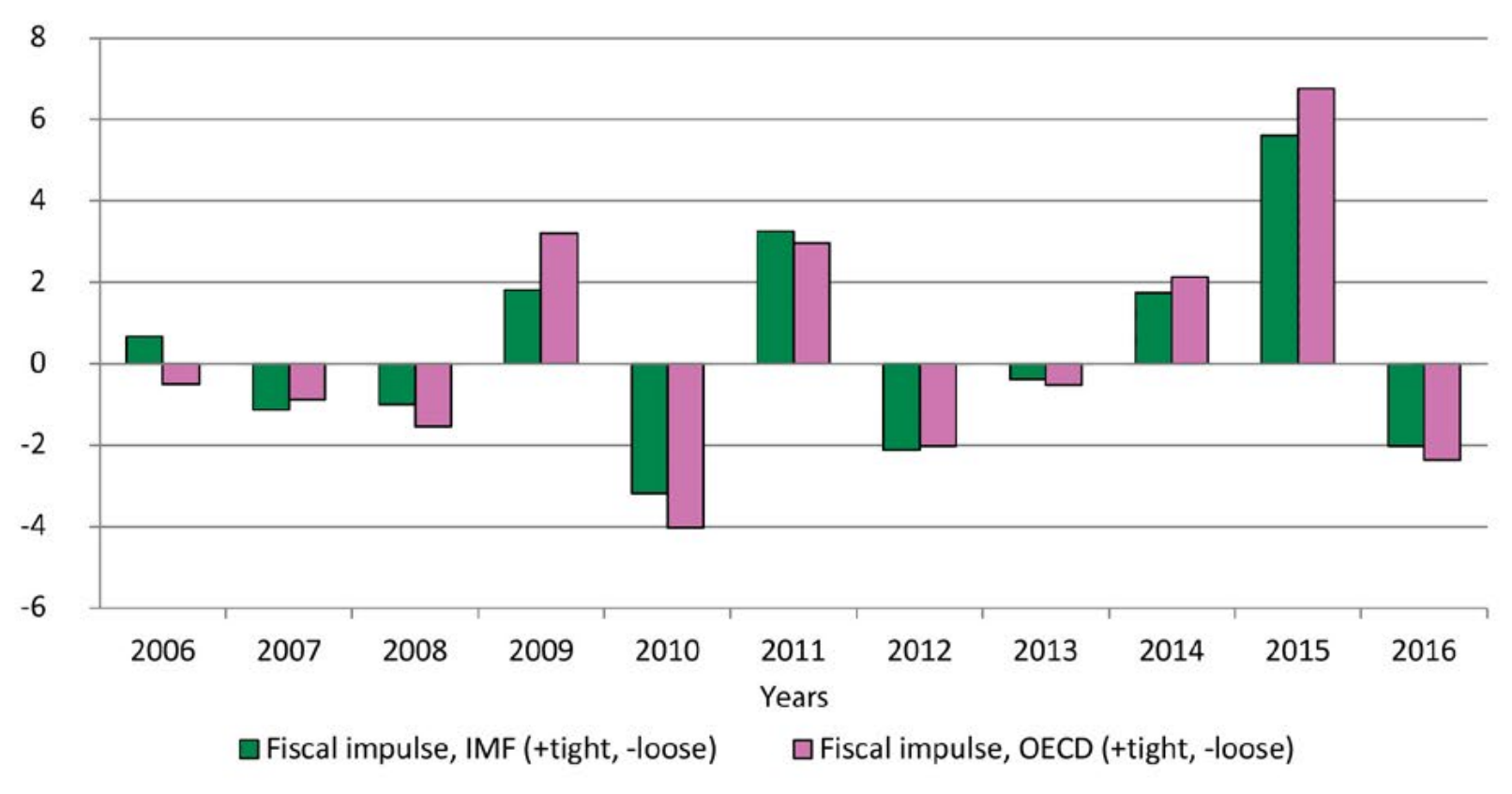


APPENDIX B. TABLES

Table B1. Descriptive Statistics of Variables, Natural Logs

\begin{tabular}{|c|c|c|c|c|c|c|c|c|}
\hline Indicators & PIT & $\mathrm{CIT}$ & $\begin{array}{l}\text { VAT on } \\
\text { imports }\end{array}$ & $\begin{array}{c}\text { Domestic } \\
\text { VAT }\end{array}$ & $\begin{array}{l}\text { Import } \\
\text { tariffs }\end{array}$ & $\begin{array}{c}\text { Excise } \\
\text { tax }\end{array}$ & GDP & $\begin{array}{l}\text { PFU deficit } \\
\text { financing, } \\
\text { UAH } \\
\text { million }\end{array}$ \\
\hline Mean & 9.45 & 9.23 & 9.77 & 9.58 & 7.94 & 8.72 & 12.51 & $3,771.00$ \\
\hline Median & 9.48 & 9.31 & 9.82 & 9.60 & 7.87 & 8.82 & 12.51 & $3,709.91$ \\
\hline Maximum & 9.64 & 9.69 & 10.26 & 9.82 & 8.58 & 9.24 & 12.65 & $15,064.44$ \\
\hline Minimum & 9.13 & 8.26 & 8.97 & 9.23 & 7.40 & 8.26 & 12.38 & 0.00 \\
\hline $\begin{array}{l}\text { Standard } \\
\text { Deviation }\end{array}$ & 0.13 & 0.37 & 0.27 & 0.12 & 0.31 & 0.28 & 0.08 & 3,129.38 \\
\hline Skewness & -0.84 & -1.17 & -1.24 & -0.46 & 0.34 & -0.12 & 0.03 & 1.34 \\
\hline Kurtosis & 3.02 & 3.53 & 5.03 & 2.93 & 2.15 & 1.61 & 1.99 & 5.32 \\
\hline Jarque-Bera & 6.11 & 12.36 & 22.18 & 1.81 & 2.58 & 4.33 & 2.22 & 25.06 \\
\hline Probability & 0.05 & 0.00 & 0.00 & 0.40 & 0.27 & 0.11 & 0.33 & 0.00 \\
\hline Observations & 52 & 52 & 52 & 52 & 52 & 52 & 52 & 48 \\
\hline
\end{tabular}

Table B2. Stationarity Tests of Real GDP and Various Budget Categories in Ukraine

\begin{tabular}{|c|c|c|c|c|c|c|c|c|c|c|}
\hline & $\begin{array}{c}\text { Time series } \\
\text { stationarity test }\end{array}$ & $\begin{array}{l}\text { Real } \\
\text { GDP }\end{array}$ & $\begin{array}{l}\text { Budget } \\
\text { revenues }\end{array}$ & PIT & $\begin{array}{l}\text { VAT on } \\
\text { imports }\end{array}$ & $\begin{array}{l}\text { Domestic } \\
\text { VAT }\end{array}$ & CIT & $\begin{array}{l}\text { Import } \\
\text { tariffs }\end{array}$ & $\begin{array}{c}\text { Excise } \\
\operatorname{tax}\end{array}$ & $\begin{array}{c}\text { PFU } \\
\text { deficit } \\
\text { financing }\end{array}$ \\
\hline \multirow{2}{*}{$\stackrel{\frac{\omega}{0}}{\stackrel{\Xi}{త}}$} & $\begin{array}{l}\text { Dickey-Fuller GLS, } \\
\text { t-statistic }\end{array}$ & -0.95 & -0.90 & -0.40 & -0.76 & -1.40 & -1.60 & -0.92 & 0.27 & -1.78 \\
\hline & $\begin{array}{l}\text { KPSS, } \\
\text { LM-statistics }\end{array}$ & 0.30 & $0.43^{* *}$ & $0.64^{* *}$ & $0.54^{* *}$ & 0.25 & $0.44^{* *}$ & 0.11 & $0.87^{* *}$ & $0.12^{* *}$ \\
\hline \multirow{2}{*}{ 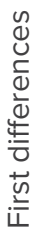 } & $\begin{array}{l}\text { Dickey-Fuller GLS, } \\
\text { t-statistic }\end{array}$ & $-4.05^{* *}$ & $-7.80^{* *}$ & $-7.10^{* *}$ & $-7.07^{* *}$ & $-4.60^{* *}$ & $-3.90^{* *}$ & $-2.37^{* *}$ & -1.75 & $-1.12^{* *}$ \\
\hline & $\begin{array}{l}\text { KPSS, } \\
\text { LM-statistics }\end{array}$ & 0.36 & 0.11 & 0.10 & 0.31 & 0.09 & 0.18 & 0.10 & 0.13 & 0.23 \\
\hline
\end{tabular}

The null hypothesis under Dickey-Fuller GLS is the presence of a unit root; the null hypothesis under KPSS is the absence of a unit root;

${ }^{* *}$ the level of significance of the null hypothesis is $5 \%$. 


\section{Table B3. Elasticities of Individual Consolidated Budget Items with Respect to GDP for Ukraine and OECD Countries}

\begin{tabular}{|c|c|c|c|c|c|}
\hline \multirow[t]{2}{*}{ Variables } & \multicolumn{2}{|c|}{$\begin{array}{l}\text { DOLS estimates } \\
\text { for Ukraine }\end{array}$} & \multicolumn{2}{|c|}{$\begin{array}{l}\text { ARDL estimates } \\
\text { for Ukraine }\end{array}$} & \multirow{2}{*}{$\begin{array}{l}\text { Average estimates } \\
\text { for OECD countries } \\
\text { (Average elasticity) }\end{array}$} \\
\hline & $\left(\beta^{19}\right)$ & $\left(\alpha^{20}\right)$ & $(\beta)$ & $(\alpha)$ & \\
\hline Budget revenues & $1.2^{* * *}$ & $0.7^{* * *}$ & $1.2^{* * *}$ & $0.6^{* * *}$ & \\
\hline PIT & $0.9^{* * *}$ & $0.7^{* * *}$ & & $0.7^{* * * 21}$ & 1.3 \\
\hline VAT on imports & $2.7^{* * *}$ & $1.2^{* * *}$ & $2.5^{* * *}$ & 1.0 & $1.0^{22}$ \\
\hline Domestic VAT & $1.2^{* * *}$ & $1.2^{* * *}$ & $0.7^{* * *}$ & $1.0^{* * *}$ & 1.0 \\
\hline $\mathrm{CIT}$ & $1.7^{* * *}$ & $1.6^{* * *}$ & $1.9^{* * *}$ & $1.5^{* * *}$ & 1.5 \\
\hline Import tariffs & 0.9 & $1.7^{* * *}$ & $0.8^{* * *}$ & $1.7^{* * *}$ & 1.0 \\
\hline Excise tax & 0.6 & $0.7^{*}$ & & $0.7^{*}$ & 1.0 \\
\hline PFU deficit financing & & & & $-1.7^{*}$ & \\
\hline
\end{tabular}

\section{Table B4. DOLS Estimates of the Elasticities of Budget Categories with Respect to Real GDP}

\begin{tabular}{|c|c|c|c|c|c|c|c|}
\hline Variables & $\begin{array}{l}\text { Budget } \\
\text { revenues }\end{array}$ & PIT & $\begin{array}{l}\text { VAT on } \\
\text { imports }\end{array}$ & $\begin{array}{l}\text { Domestic } \\
\text { VAT }\end{array}$ & CIT & $\begin{array}{l}\text { Import } \\
\text { tariff }\end{array}$ & Excise tax \\
\hline$\beta$ & $1.2^{* * *}$ & $0.9^{* * *}$ & $2.7^{* * *}$ & $1.2^{* * *}$ & $1.7^{* * *}$ & 0.9 & 0.6 \\
\hline$\alpha$ & $0.7^{* * *}$ & $0.7^{* * *}$ & $1.2^{* * *}$ & $1.2^{* * *}$ & $1.6^{* * *}$ & $1.7^{* * *}$ & $0.7^{*}$ \\
\hline b & $-0.5^{* * *}$ & -0.03 & $-0.4^{* * *}$ & $-0.3^{* * *}$ & $-0.3^{* * *}$ & $-0.1^{* * *}$ & -0.1 \\
\hline $\begin{array}{l}\text { Engle-Granger test } \\
\text { (Engle-Granger z-statistic) }\end{array}$ & $-26.4^{* * *}$ & -2.2 & -8.1 & -13.6 & $(-8.4)$ & -6.1 & -2.4 \\
\hline Jarque-Bera test, $\left(\chi^{2}\right)$ & 1.6 & 3.4 & 1.1 & 2.5 & 1.6 & 0.3 & 0.9 \\
\hline $\begin{array}{l}\text { Breusch-Godfrey Serial Correlation } \\
\text { LM Test: }\left(4 \text { lags, }\left(\chi^{2}\right)\right)\end{array}$ & 2.6 & 3.2 & 4.6 & 2.4 & 3.3 & 6.3 & 7.5 \\
\hline
\end{tabular}

$\beta$ - long-term elasticity with respect to GDP; $\alpha$ - short-term elasticity with respect to GDP; $b$ - rate of convergence; ***the level of significance of the null hypothesis is $1 \%$; "*t the level of significance of the null hypothesis is $5 \%$; "the level of significance of the null hypothesis is $10 \%$. Engle-Granger test, H0: no time series cointegration. JarqueBera test, HO: the residuals are normally distributed. Breusch-Godfrey Serial Correlation LM Test, HO: no autocorrelation.

\footnotetext{
19 Long-term elasticity.

${ }^{20}$ Short-term elasticity.

${ }^{21}$ For the models in which the long-term relationship hypothesis was rejected, estimates are based on the first differences of the variables.

${ }^{22}$ For VAT on imports, domestic VAT, the import tariffs, and excise taxes, we present the assumed elasticity for indirect taxes.
} 
Table B5. ARDL Estimates of the Elasticities of Budget Categories with Respect to Real GDP

\begin{tabular}{|c|c|c|c|c|c|c|c|c|}
\hline Variables & $\begin{array}{l}\text { Budget } \\
\text { revenues }\end{array}$ & PIT & $\begin{array}{l}\text { VAT on } \\
\text { imports }\end{array}$ & $\begin{array}{c}\text { Domestic } \\
\text { VAT }\end{array}$ & CIT & $\begin{array}{c}\text { Import } \\
\text { tariff }\end{array}$ & Excise tax & $\begin{array}{c}\text { PFU } \\
\text { deficit } \\
\text { financing }\end{array}$ \\
\hline$\beta$ & $1.2^{* * *}$ & & $2.5^{* * *}$ & $0.7^{* * *}$ & $1.9^{* * *}$ & $0.8^{* * *}$ & & \\
\hline$\alpha$ & $0.6^{* * *}$ & $0.7^{* * * 23}$ & 1.0 & $1.0^{* * *}$ & $1.5^{* * *}$ & $1.7^{* * *}$ & $0.7^{*}$ & $-1.7^{*}$ \\
\hline b & $-0.5^{* * *}$ & & $-0.2^{* * *}$ & $-0.4^{* * *}$ & $-0.2^{* * *}$ & $-0.4^{* * *}$ & & \\
\hline Bounds Test, F-statistic & $11.7^{* *}$ & 4.0 & $5.4^{*}$ & $9.1^{* *}$ & $5.1^{*}$ & $26.0^{* *}$ & 1.2 & 3.5 \\
\hline Jarque-Bera test, $\left(\chi^{2}\right)$ & 0.2 & 2.4 & 3.1 & 0.1 & 1.7 & 0.7 & 0.4 & 0.2 \\
\hline $\begin{array}{l}\text { Breusch-Godfrey Serial } \\
\text { Correlation LM Test: } \\
\left(4 \text { lags, }\left(\chi^{2}\right)\right)\end{array}$ & 5.4 & 3.1 & 5.3 & 5.0 & 1.6 & 7.3 & 2.6 & 2.7 \\
\hline
\end{tabular}

$\beta$ - long-term elasticity with respect to GDP; $\alpha$ - short-term elasticity with respect to GDP; $b$ - rate of convergence; ${ }^{* * *}$ the level of significance of the null hypothesis is $1 \%$; "*the level of significance of the null hypothesis is $5 \%$; "the level of significance of the null hypothesis is $10 \%$. Bounds Test, H0: no long-term relationship. Jarque-Bera test, HO: the residuals are normally distributed. For Breusch-Godfrey Serial Correlation LM Test, HO: no autocorrelation.

\footnotetext{
${ }^{23}$ For models in which the long-term relationship hypothesis was rejected, model estimates of first differences of the variables are presented.
} 